\author{
Mon ograph \\ urn:1sid:zoobank.org:pub:F7AB8B53-FEB1-4473-8B22-DFEC9CE98FDD
}

\title{
Species groups in the genus Cubitermes (Isoptera: Termitidae) defined on the basis of enteric valve morphology
}

\author{
Guy Josens ${ }^{1, *} \&$ Jean Deligne ${ }^{2}$ \\ 1,2 Université Libre de Bruxelles, Département de Biologie des Organismes, Écologie végétale et \\ Biogéochimie, Av. Roosevelt 50 - cp 244, 1050 Brussels, Belgium. \\ ${ }^{2}$ Royal Museum for Central Africa, Entomology, Leuvensesteenweg 13, 3080 Tervuren, Belgium. \\ *Corresponding author: gjosens@ulb.ac.be \\ 2Email: jean.deligne@africamuseum.be \\ ${ }^{1}$ urn:1sid:zoobank.org:author:307AD538-214E-4D4B-8BD7-F0EB2B4D363B \\ ${ }^{2}$ urn:1sid:zoobank.org:author:1508E33B-6436-479A-A11B-5458692B151C
}

\section{Table of contents}

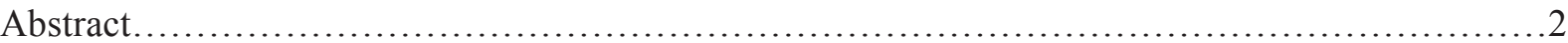

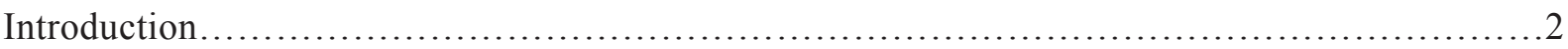

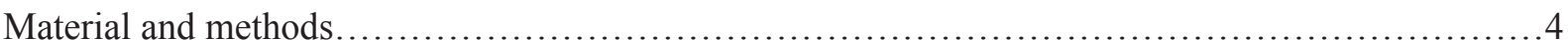

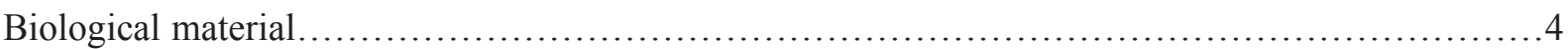

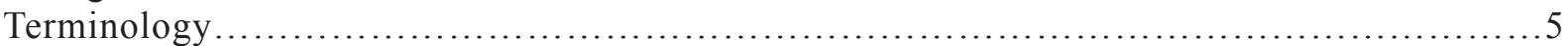

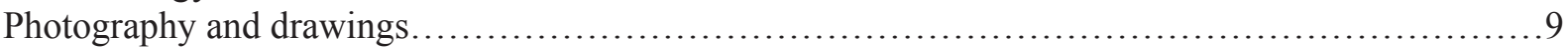

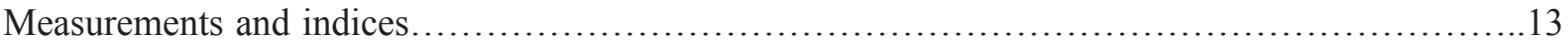

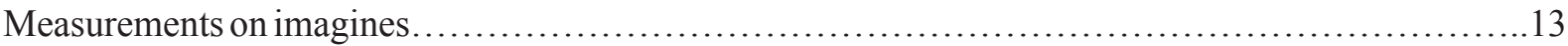

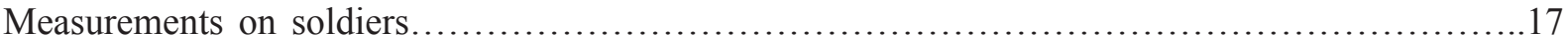

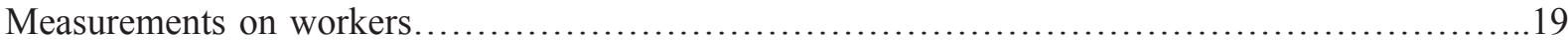

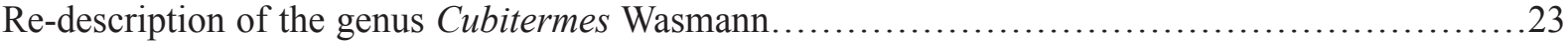

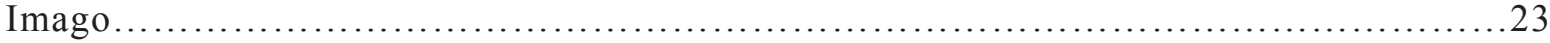

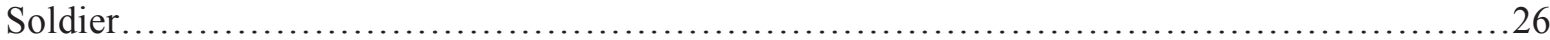

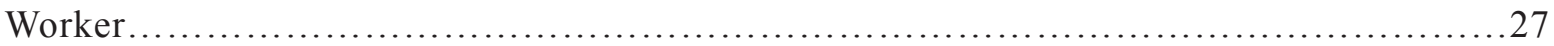

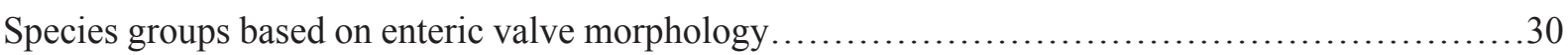

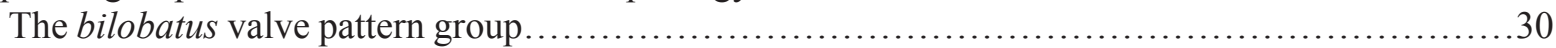

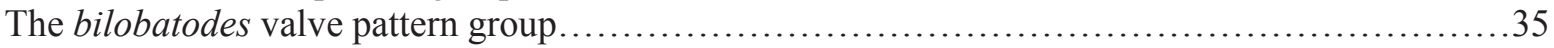

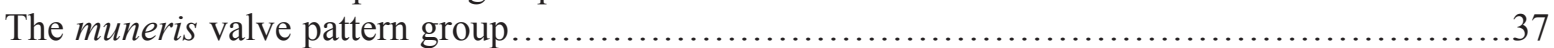

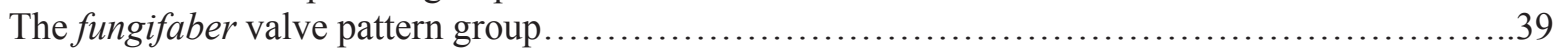

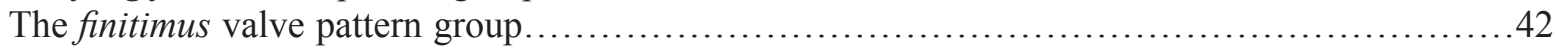

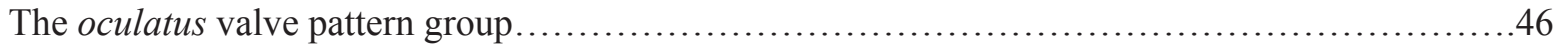

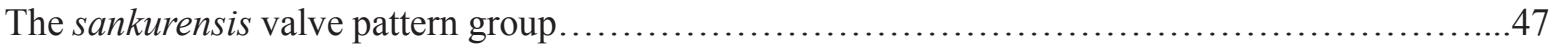

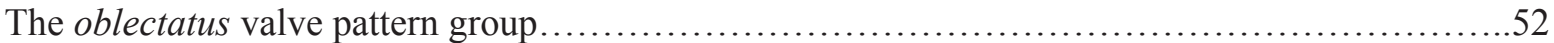

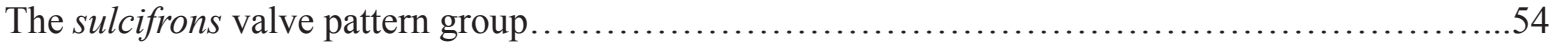

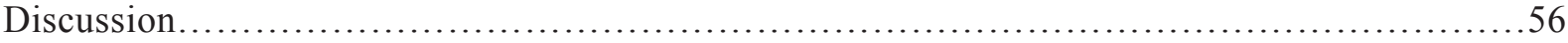

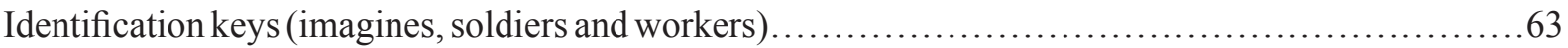

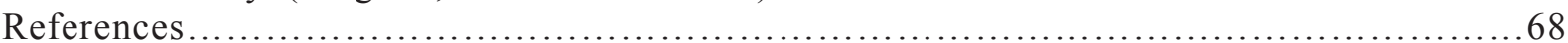


Abstract. Seventy-four species, forms and varieties of Cubitermes Wasmann, 1906 have been studied, including taxa placed in synonymy with other species. Within this group of taxa, the enteric valve, mainly of the workers and soldiers, provided the best and the only clear-cut criteria for distinguishing some major subsets that are proposed here as species groups. The genus Cubitermes is re-described; the morphologies of the enteric valves are described in detail including the number of spatulae at the downstream end of the primary cushions; the possible presence of crests or bulges near the downstream end of the primary cushions; the overall shape of the primary cushions; the number of lateral supporting bristles; the kind of symmetry of the valve; and the structure of the secondary cushions. These characteristics are used to define nine species groups. For now, these groups have no taxonomic ranking but are helpful as regards species recognition. Identification keys for species groups are provided for soldiers and workers together with a partial key for imagines. Geographical ranges of the groups are also provided. On the basis of enteric valve morphology, some synonymies can no longer be validated: (a) C. planifrons Sjöstedt, 1924 is not a synonym of C. fungifaber (Sjöstedt, 1896); (b) C. kemneri Emerson, 1928 is not a synonym of C. zenkeri (Desneux, 1904); and (c) C. fungifaber var. elongata Sjöstedt, 1924 does not belong to the species $C$. fungifaber. Cubitermes planifrons and $C$. kemneri become valid again and $C$. fungifaber var. elongata is an invalid name.

Keywords. Termite, Blattodea, Ethiopian region, revision.

Josens G. \& Deligne J. 2019 Species groups in the genus Cubitermes (Isoptera: Termitidae) defined on the basis of enteric valve morphology. European Journal of Taxonomy 515: 1-72. https://doi.org/10.5852/ejt.2019.515

\section{Introduction}

The soil feeding termites of the genus Cubitermes Wasmann, 1906 have successfully colonised various African ecosystems from evergreen forests to dry savannas (Williams 1966). They play important ecological roles mainly through their action on the soil (Wood et al. 1983; Okwakol 1987; Donovan et al. 2001) and their very high local density (Wango \& Josens 2011). Ecological studies of this genus are, however, hindered by difficulties in identification and the lack of a complete systematic revision. Indeed, the difficulty of identifying species of Cubitermes properly was mentioned by Emerson already in 1928: "The species of this [sub] genus are very difficult to differentiate from each other and it is nearly impossible to determine them with accuracy from the descriptions alone". Echoing the concern of many researchers, Uys (1994) stated: "The species of Cubitermes are very difficult to distinguish and require a revision". In order to carry out this general revision it is possible to rely on a set of morphological, functional, ecological and some scarce genetic data that can be summarised as follows.

The Cubitermes taxa as currently defined have been described since the $18^{\text {th }}$ century but mainly since the early $20^{\text {th }}$ century. Smeathman (1781) provided the first descriptions and figures of Termes atrox and Termes mordax that can be assumed with certainty to belong to the genus Cubitermes; however, his material could not be traced even in the early $20^{\text {th }}$ century (Sjöstedt 1926:218) and is therefore considered lost and unavailable for a systematic revision. The genus Cubitermes was created by Wasmann (1906) in a short footnote description. Another description, hardly more detailed, was provided five years later (Wasmann 1911). Roughly one hundred original descriptions and re-descriptions of species of Cubitermes have been made by (in chronological order) Sjöstedt, 1896; Haviland, 1898; Desneux, 1904; Wasmann, 1911; Sjöstedt, 1911a; Sjöstedt, 1911b; Silvestri, 1912; von Rosen, 1912; Sjöstedt, 1913; Holmgren, 1913; Sjöstedt, 1914; Silvestri, 1914; Schmitz, 1915; Fuller, 1923; Sjöstedt, 1924a; Sjöstedt, 1924b; Sjöstedt, 1925; Fuller, 1925; Sjöstedt, 1927; Sjöstedt, 1926; Emerson, 1928; Ghidini, 1937; Williams, 1954; Emerson, 1960; Harris, 1958; Mathot, 1964; Williams, 1966; Roy-Noël, 1969 and Bouillon \& Vincke, 1971. Many of these descriptions lack detail and ignore the distinctive characteristics of the gut. 
In his revision of African termites, Sjöstedt (1926) considered 51 taxa of Cubitermes (including 48 species, two forms and one variety). About a quarter of a century later, 19 new taxa had been described, so Snyder (1949) could list 70 taxa (64 species, three forms and three varieties); he also proposed one synonymy, thus reducing the number of taxa to 69. Between 1949 and 1966, only three new species were described by Williams (1954), Harris (1958) and Mathot (1964). Williams (1966) revised the species of Cubitermes of East Africa and described five new species; he also proposed four synonymies based on similarity of external morphology. Since 1966, only two new species have been described, by RoyNoël (1969) and Bouillon \& Vincke (1971). Ruelle (1975) proposed five new synonymies and Krishna et al. (2013) two more, but in both cases without any explicit justification. Sands (1998) studied the worker castes of African termite genera and suggested that the genera Megagnathotermes Silvestri, 1914 and Nitiditermes Emerson, 1960 might be merged with the genus Cubitermes. Recently, Krishna et al. (2013) provided a master work that updated and amplified Snyder's catalogue; it supplied a rich set of valuable bibliographic information on systematic works concerning all of the termites and it mentioned the type locality of every species. It also mentioned an unpublished wealth of knowledge that Emerson had gathered throughout his career in his "card-catalog". Concerning Cubitermes, 67 valid taxa are listed. Very little genetic information is available on the genus Cubitermes, but the known facts point to the possible existence of cryptic species (Roy et al. 2006).

During the 1950s, the comparative anatomy of the digestive tract gave new impetus to termite systematics. The gut anatomy of ten or so species had previously been described in more or less detail (Holmgren 1909; Imms 1919; Child 1934), but gut features had never been used as key arguments for defining new taxa. Grassé \& Noirot (1955) provided the first detailed study of the valve located in the middle of the hind-gut of the Termitidae. They described this "valvule entérique" as furnished with a variety of spines or scales of taxonomic interest and noted that its particular significance lies in the fact that it is even more developed in the worker caste, frequently neglected by systematists. They used it to create the subfamily Apicotermitinae and to identify several genera within the subfamily. Noirot \& Kovoor (1958) studied in particular the valves of the Termitinae workers (including the current Cubitermitinae). They described for instance the valve of Thoracotermes brevinotus Silvestri, 1914 as a funnel ending the first paunch of the hind-gut and invaginated into the beginning of the second paunch. The valve, surrounded by annular muscles, has six main folds on its inner side furnished with spines and six secondary, less developed folds bearing shorter spines. In further studies, these folds were called "cushions" or "ridges" by Noirot and other authors. In their study, Noirot \& Kovoor (1958) examined only one species of Cubitermes (namely C. severus Silvestri, 1915) and therefore did not discover the morphological diversity of the enteric valves within the genus Cubitermes.

Bouillon \& Vincke (1971) were the first to mention the diversity of the enteric valves within the genus Cubitermes. They wrote: "it seems that nowadays not any (...) systematic revision can avoid the examination of the structures of the gut" and considered that the genus should be split into at least three genera on the basis of their enteric valves. However, their paper was also devoted to the description of a new species (C. bugeserae Bouillon \& Vincke, 1971) and the information about the various enteric valves seemed to pass unnoticed for over a quarter of a century. Sands (1972) was the first to use the enteric valves thoroughly in his revision of the African soldierless termites and to use them as generic and specific markers. Johnson (1979) recognised the variability of the proctodeal diverticulum in the genus Cubitermes. In his study of the worker castes of the African termite genera, Sands (1998) mentioned and, using figures, illustrated the diversity of enteric valves within the genus Cubitermes without suggesting that this might lead to the subdivision of this genus into several subgroups. Noirot (2001) compared the guts of a large variety of termites. However, he examined only one species of Cubitermes (namely C. fungifaber (Sjöstedt, 1896)) and made no mention of the diversity of valves between species shown by Bouillon \& Vincke (1971) and Sands (1998). 
Study of the enteric valve of course led to questions regarding its functions and ecological significance. In his revision, Williams (1966) provided some notes on interspecific associations and considered that "the more frequently found associations (...) appear not to be fortuitous or temporary but to be normal, suggesting that the two (or more) species are not, or not fully, in competition at such localities." In their 1971 work, Bouillon \& Vincke hypothesised that the morphological diversity of the enteric valves observed among the species of Cubitermes might mirror a diversity of diets. In this respect, it is interesting to note that C. ugandensis Fuller, 1923 and C. testaceus Williams, 1966, two species with different enteric valves, are frequently found together in the vicinity of Kampala, Uganda (Williams 1966). In the same way, Wango \& Josens (2011) pointed to the fact that two species with different enteric valves (C. sankurensis Wasmann, 1911 and C. ugandensis Fuller, 1923) are associated at high densities in the same habitat of Central Africa, suggesting that they occupy different ecological niches. The precise role of the enteric valves is still unsolved but Bignell (2000) and Donovan (2002) provided a functional viewpoint that the valve would act as a filter slowing down and directing the fine fraction of the digestive bolus along the wall of the second paunch, enabling a lengthier digestion of the organic material.

More than a century after its first mention and short description (Wasmann 1906, 1911) and 90 years after Emerson's complaint, the species level taxonomy of the genus Cubitermes still remains unclear, except in East Africa thanks to Williams (1966). On the basis of the information available and new observations, we began a revision of the genus Cubitermes with special focus on the enteric valves, and very soon it appeared that this structure designated supra-specific groups. The objectives of this paper are therefore to redescribe the genus Cubitermes, introduce species groups (corresponding with enteric valve morphologies, here called 'patterns') and provide identification keys and geographical ranges at the level of these patterns. The revision at the specific level is in progress. In parallel and in connection with the present paper, molecular work is being conducted and will tackle the phylogeny of Cubitermes.

\section{Material and methods}

\section{Biological material}

Material was borrowed from several museums:

\section{Institutional abbreviations}

\begin{tabular}{|c|c|}
\hline AMNH & $=$ American Museum of Natural History, New York, the United States \\
\hline IEAP & Instituto di Entomologia Agraria, Portici (Napoli), Italy \\
\hline MCGD & Museo Civico di Storia Naturale "Giacomo Doria”, Genoa, Italy \\
\hline MNHN & Muséum national d’Histoire naturelle, Paris, France \\
\hline MURS & Museo Università di Roma “Sapienza”, Roma, Italy \\
\hline NHMM & Natuurhistorisch Museum of Maastricht, the Netherlands \\
\hline NHMUK & Natural History Museum, London, the United Kingdom \\
\hline PPRI & $\begin{array}{l}=\text { Plant Protection Research Institute, Biosystematics Division, Queenswood, Pretoria, } \\
\text { South Africa }\end{array}$ \\
\hline RMCA & Royal Museum for Central Africa, Tervuren, Belgium \\
\hline ULB & $=$ Université Libre de Bruxelles, Belgium (temporary depository of some samples) \\
\hline
\end{tabular}

\section{Country abbreviations}

DRC $=$ the Democratic Republic of the Congo (Kinshasa)

$\mathrm{RCA}=$ the Republic of Central Africa 


\section{Additional new material was collected by the following researchers (in alphabetic order) in 10 countries.}

Dr Pierre Akama (Université de Yaoundé 1) in Cameroon

Dr Tenon Coulibaly (Université Peleforo Gon, Korhogo) in Côte d'Ivoire and Burkina Faso

Dr Kanvaly Dosso (Université Nangui Abrogoua, Abidjan) in Côte d'Ivoire

Benoît Host in Burundi

Patrick Kasangij (Université de Lubumbashi) in DRC, Haut-Katanga province

Dr Carmel Kifukieto (Université de Kinshasa) in DRC, Kinshasa province

Dr Laura Estelle Loko (Université Polytechnique d'Abomey) in Benin

Prof. Pierre Meerts (Université Libre de Bruxelles) in DRC, Haut-Katanga province

Prof. Basile Mujinya Bazirake (Université de Lubumbashi) in DRC, Haut-Katanga province

Dr Abdoulaye Baila Ndiaye (Université de Dakar) in Senegal, Gambia and Burkina Faso

Prof. Yves Roisin (Université Libre de Bruxelles) in Cameroon, Côte d'Ivoire, DRC, Tshopo province, and Burundi

Dr Jan Šobotnik (Czech University of Life Sciences) in Cameroon and Kenya

Dr Saran Traoré (Université Polytechnique de Bobo) in Burkina Faso

Geo Trembleau in Gabon

Specimens were also collected by the first author in Côte d'Ivoire, RCA and DRC, Kinshasa and HautKatanga provinces, and by the second author in Gabon.

Seventy-four known species, subspecies, forms and varieties of Cubitermes from museum collections have been studied. They include several species that have already been published as synonyms of other species by Williams (1966) and Ruelle (1975) or recorded as such in Emerson's "card-catalog" and quoted in Krishna et al. (2013). These species will be re-examined because their synonymy was generally proposed without any arguments and their enteric valves have never been taken into consideration previously.

Other new material includes several new species that will not be described here.

\section{Colour terminology}

Colour names are rather subjective and vary between authors. In order to objectivise the colour codes, two palettes of eight colour levels have been established with their RGB values (Fig. 1). Almost all of the colours encountered in this study are included in these palettes or are situated between them. The
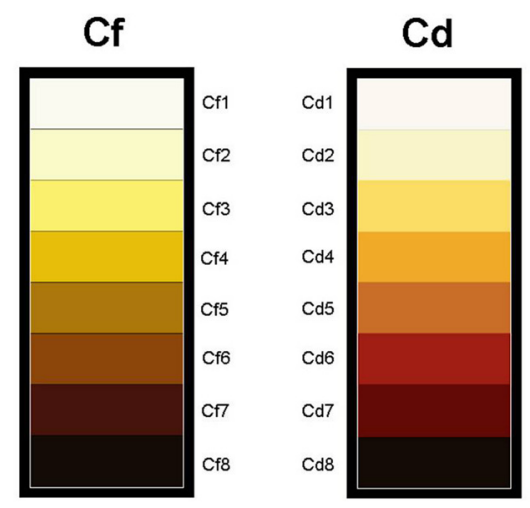

\begin{tabular}{cccccccc}
\hline Cf & R & G & B & Cd & R & G & B \\
\hline Cf1 & 250 & 250 & 240 & Cd1 & 250 & 248 & 240 \\
Cf2 & 250 & 250 & 200 & Cd2 & 250 & 245 & 200 \\
Cf3 & 250 & 240 & 110 & Cd3 & 250 & 220 & 100 \\
Cf4 & 230 & 190 & 10 & Cd4 & 240 & 170 & 40 \\
Cf5 & 170 & 120 & 10 & Cd5 & 200 & 110 & 40 \\
Cf6 & 140 & 70 & 10 & Cd6 & 160 & 30 & 20 \\
Cf7 & 70 & 20 & 10 & Cd7 & 100 & 10 & 5 \\
Cf8 & 20 & 10 & 5 & Cd8 & 20 & 10 & 5 \\
\hline
\end{tabular}

Fig. 1. Colour palettes used in this study. Cf: "faded" palette; Cd: "deep" palette, each with eight levels and their RGB values. 
colour codes contain two letters and a number. The two letters are always ' $\mathrm{C}$ ' (for 'colour') followed by either ' $\mathrm{f}$ ' (for the 'faded' colours) or ' $\mathrm{d}$ ' (for the 'deep' colours); the number indicates the darkness of the colour, from level 1 for almost white to level 8 for almost black. The letters ' $\mathrm{f}$ ' or ' $\mathrm{d}$ ' may be omitted if unnecessary, limiting the code to ' $\mathrm{C}$ ' and a number. The 'faded palette' was established first and fits most of the long-preserved museum specimens rather well (because the muscles turn grey after many years of preservation and alter the original colours). However, some old specimens and most of the recent ones have brighter colours tending towards the 'deep palette'. This terminology enables semi-quantitative colour comparisons: for example, if one appendage is paler than another, it will be said that it is one, two or three levels paler.

\section{Setation terminology}

Four types of articulated processes of the tegument are considered: claws, spurs, spines and setae. Spurs and claws are defined as robust articulate outgrowths of the cuticle situated at the apex (or near the apex) of the tibia and at the end of the pretarsus respectively. The term 'spine' is taken here in the general sense of "thick, heavily sclerotised, socketed seta" (Krishna et al. 2013) corresponding to Sands' (1998) "spine-like seta". The presence and number of such spines, especially those furnishing fore coxae and fore trochanters, have proven to be a useful discriminatory characteristic for some species. However, the distinction between fine setae, strong setae, fine spines and strong spines remains subjective. To help distinguish between them, it should be borne in mind that the setae are thinner and give the impression that they can bend easily, whereas the more massive and darker spines give the impression that they are rigid and cannot bend. For setation of the enteric valves, see 'enteric valve terminology'.

\section{Antennal terminology}

For numbering the antennal articles, the third article is not counted as a full article unless it bears at least one prominent distal seta; if it is partially present but does not bear any long seta, it is considered as one-half of an article (Fig. 2).

\section{Imago and worker mandible terminology}

In this work we draw on the terminology proposed by Emerson (1933) who distinguished an apical tooth, marginal teeth and a molar plate along the mesial edge of mandibles, but we replace the term

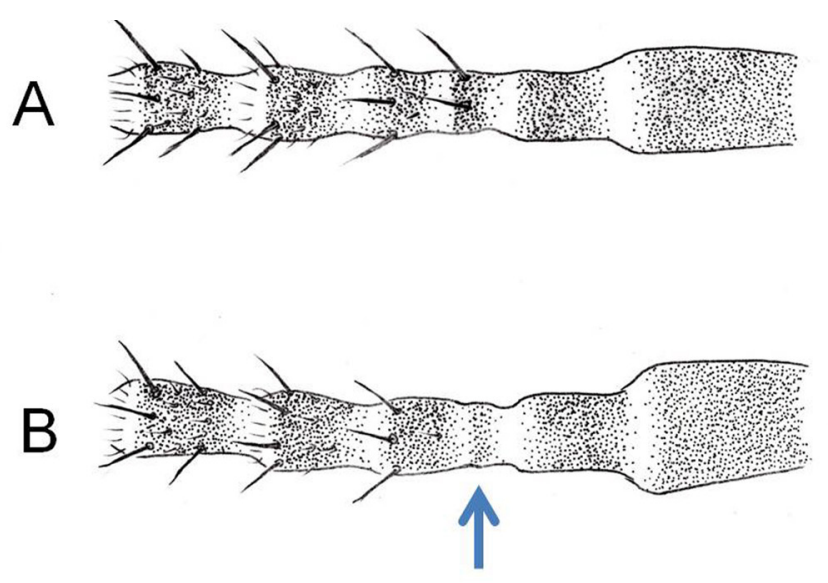

Fig. 2. Counting of the antennal articles. A. Six proximal articles of a C. speciosus Sjöstedt, 1924 soldier. B. Proximal articles of another C. speciosus soldier (same colony); the "third", unfinished article does not bear any prominent setae (arrow) and is counted as one half; there are thus 5.5 articles shown in this figure. 
"molar plate" by 'molar tooth', because in humivorous termites this structure is not a plate as found in ancestral xylophagous species. In Cubitermes and allied genera, the molar tooth instead has a concave mesial face. Furthermore, in the left mandible, this face is overhung in dorsal view by a rounded flange here called a 'molar prominence' ("cuilleron" in Deligne 1966). The right mandible shows a similar structure at its ventral side. To that must be added a "premolar tooth" (Deligne and Pasteels 1969, Deligne 1999) situated between the third marginal tooth and molar tooth, only on the left mandible. This tooth is also called the "subsidiary marginal tooth" (Sands 1972; Uys 1994) or " $4^{\text {th }}$ marginal tooth" (Sands 1992) (Fig. 3).

\section{Enteric valve terminology}

An enteric valve, in the Cubitermitinae, is basically a funnel (Fig. 4A) bearing six primary elongated prominent cushions alternating with non-prominent, secondary cushions (Noirot 2001). The primary and secondary cushions are referred to here using the abbreviations 'PCs' and 'SCs'. The enteric valve is surrounded by a layer of annular muscles (Fig. 4B). The upstream and downstream ends (anterior and posterior ends in Uys 2002) refer to the flow of the alimentary bolus. Sands $(1972,1998)$ numbered the PCs in a bilateral way with the cushion $n^{\circ} 1$ being innermost to the coiling of the gut and $n^{\circ} 4$ opposite $n^{\circ} 1$, while the same number $\left(n^{\circ} 2\right)$ was given to the two cushions located on both sides of $n^{\circ} 1$ and the same number $\left(\mathrm{n}^{\circ} 3\right)$ to the two cushions on both sides of $\mathrm{n}^{\circ} 4$ (Fig. 4B). This numbering is convenient for enteric valves with hexaradial, triradial or bilateral symmetries. However, in several species of Cubitermes, there is no symmetry (Bouillon \& Vincke 1971). Therefore, here we use asymmetric numbering: the primary cushions are designated as PC1 to PC6, cushion PC1 ( ${ }^{\circ} 1$ in Sands' nomenclature) is defined as the most internal; subsequent numbering is continuous and clockwise while looking through the valve from upstream; the secondary cushions are numbered SC12 (between PC1 and PC2) to SC61 (between PC6 and PC1, Fig. 4B). Noirot (2001) noted that PC1 is frequently longer than the five other primary cushions. We have confirmed in quite a few samples of various species of Cubitermes that PC1 is indeed the longest primary cushion except in some species with hexaradial symmetry or furnished
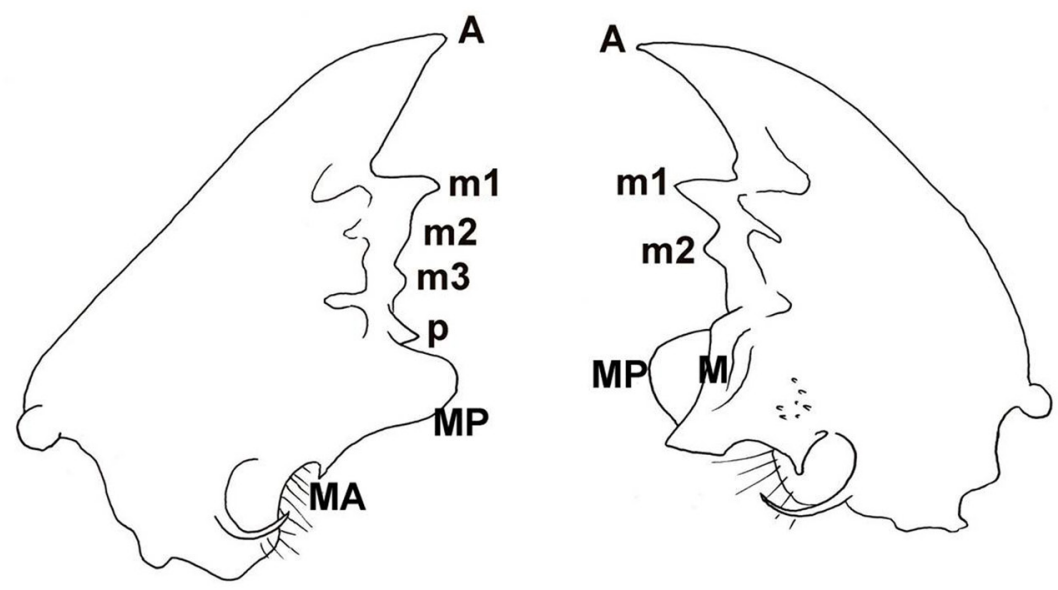

Fig. 3. Imago and worker mandible terminology. Left mandible on the left side, $A=$ apical tooth, $m 1=$ first marginal, $\mathrm{m} 2=$ second marginal (reduced to a wave), $\mathrm{m} 3=$ third marginal, $\mathrm{p}=$ premolar tooth, $\mathrm{MP}=$ molar prominence (the molar tooth is hidden behind the molar prominence), $\mathrm{MA}=$ molar posterior acute apophysis. Right mandible on the right, $\mathrm{A}=$ apical tooth, $\mathrm{m} 1=$ first marginal, $\mathrm{m} 2$ = second marginal, $\mathrm{M}=$ molar tooth, $\mathrm{MP}=$ molar prominence. 

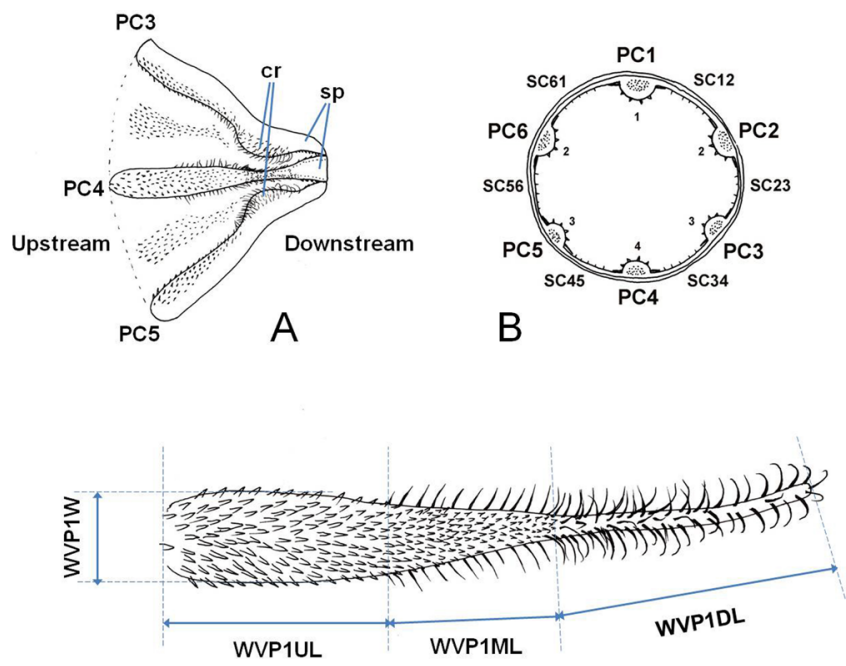

C

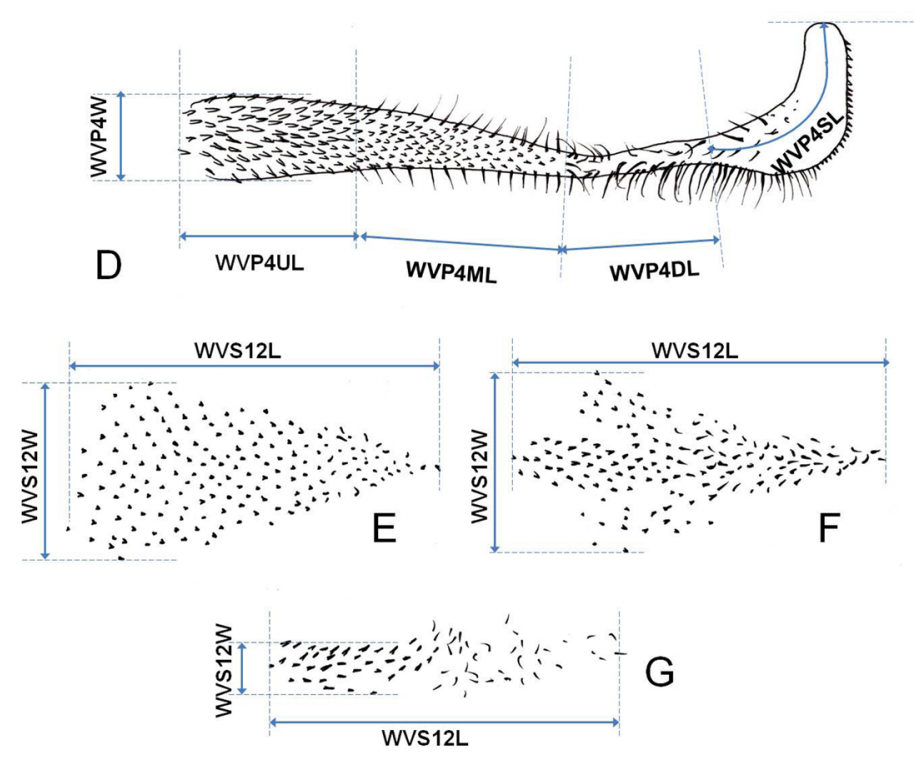

Fig. 4. A. Enteric valve (of C. oblectatus Harris, 1958), seen in profile with simplified pilosity. In this species, the primary cushions PC3 and PC5 bear not only spatulae (sp) but also crests (cr) near the downstream end. B. Section through an enteric valve, seen from upstream. Sands' numbering of the cushions is inside; present numbering of the primary (PC1 to PC6) and secondary (SC12 to SC61) cushions outside. C. Measurements on PC1: WVP1UL = length of the upstream spiny part (it starts at the first spine and ends at the first lateral supporting bristle); WVP1ML = length of the middle spiny part (it starts at the first lateral supporting bristle and ends at the last lateral supporting bristle); WVP1DL = length of the downstream bristly part (it starts at the last lateral supporting bristle); WVP1W = maximal width. D. Measurements on PC4 (one of the PCs with spatula in the sankurensis valve pattern): WVP4SL $=$ length of the downstream spatula part (this is also the part that sticks out of the valve when in function). Other symbols as in figure C. E. Measurements on SC12 in the case of a wide and homogeneous cushion (in the muneris valve pattern). F. Measurements on SC12 in the case of a heterogeneous spearheadshaped cushion (in the bilobatodes valve pattern). G. Measurements on SC12 in the case of a narrow cushion that becomes wider and fuzzy in its downstream part (in the oculatus valve pattern); in E, F and G, WVS12L = length of the secondary cushion (between the most extreme spines or bristles), WVS12W $=$ width of the secondary cushion (between the most extreme spines or bristles in its upstream third). 
with spatulae. As it is frequently difficult to position the enteric valve (especially in poorly preserved samples), we considered the longest primary cushion without a spatula as being PC1.

The cushions are armed with cuticular outgrowths of different sizes and shapes. We call some of them 'spines' without assuming any precise homology with the tegument spines. They are triangular, pale yellow, lying nearly flat against the cushion, with their tips pointing downstream. On the contrary, the 'bristles' have a more cylindrical basal shaft erected on the cushion; they are either pale yellow or darker, straight or often bent or even hooked with their tip pointing upstream. Particular pale-yellow spindle-like bristles inserted on the lateral margins of the cushions and leaning on the funnel membrane are referred to as 'supporting bristles' (Fig. 4C-D). The workers, which feed on crude soil, show fully developed enteric valves; they are the leading individuals in the descriptions of the valve patterns. The soldiers, which are fed with soil, also have an enteric valve but with the primary cushions generally less developed than in workers. The imagines, which are mainly or totally fed by salivary nutrients, have small, poorly developed, enteric valves; these valves are not considered in this work, except in a few cases.

\section{Photo capture}

Samples were observed with a Zeiss Discovery V12 stereoscopic microscope (magnification 8-100×) and photographed with an ICc3 camera (3 million pixels resolution). The photographs were taken in extended focus driven by the AxioVision ${ }^{\circledR} 4.8$ (Zeiss) software. In most cases, the samples were oriented according to a standardised procedure: the head or the body was slightly sunk into a bed of fine glass beads (Glaskügelchen by Kremer Pigmente $\mathrm{GmbH}, 150-210 \mu \mathrm{m}$ ) and orientated so that two or more points were simultaneously in focus in order to make subsequent measurements comparable.

\section{Photo standardisation on imagines}

The photo capture and associated operations followed this sequence.

Two to four general photos were first taken:

- entire individual with wings (if present) in dorsal view (code: 'photo ITotDV1')

- entire individual after wing removal in dorsal, ventral and lateral (left side) views (codes: "photo ITotDV2', 'photo ITotVV' and 'photo ITotLV'), or, in case of a physogastric queen, one to three photographs according to the possibilities (code: 'photo ITotxx'), without standardised orientation.

The antennae were then removed for further treatment, and the head was cut off the body before taking the six following standardised photos:

- head capsule in dorsal view (code: 'photo IHCDV', Fig. 5A): simultaneous focus on the outlines of both compound eyes and the outline of the posterior head rim

- fontanelle at high magnification (code: 'photo IFontan'): simultaneous focus on the outlines of both ocelli

- head capsule in lateral view (code: 'photo IHCLV', Fig. 5B): simultaneous focus on the outlines of the posterior head rim and of the clypeus along with a tangential view to the top of the postclypeus

- head capsule in oblique view at high magnification (code: 'photo IHCObV', Fig. 5D): simultaneous focus on the rims of the left ocellus and compound eye

- pronotum in dorsal view (code: 'photo IPronot', Fig. 5C): simultaneous focus (a) on the outlines of both sides of the pronotum and (b) on the outlines of the anterior and posterior pronotum margins

- hind tibia (code: 'photo ITibia', cf. Fig. 5J): simultaneous focus on both ends of the left hind tibia

The mandibles were then cut off the head and mounted, dorsal side upwards, with the antennae and with the anterior left wing in Euparal ${ }^{\circledR}$ (Roth) on a microscope slide. Sands (1998) recommended not separating the mandibles from the head because they have a tetrahedral shape that may entail improper 

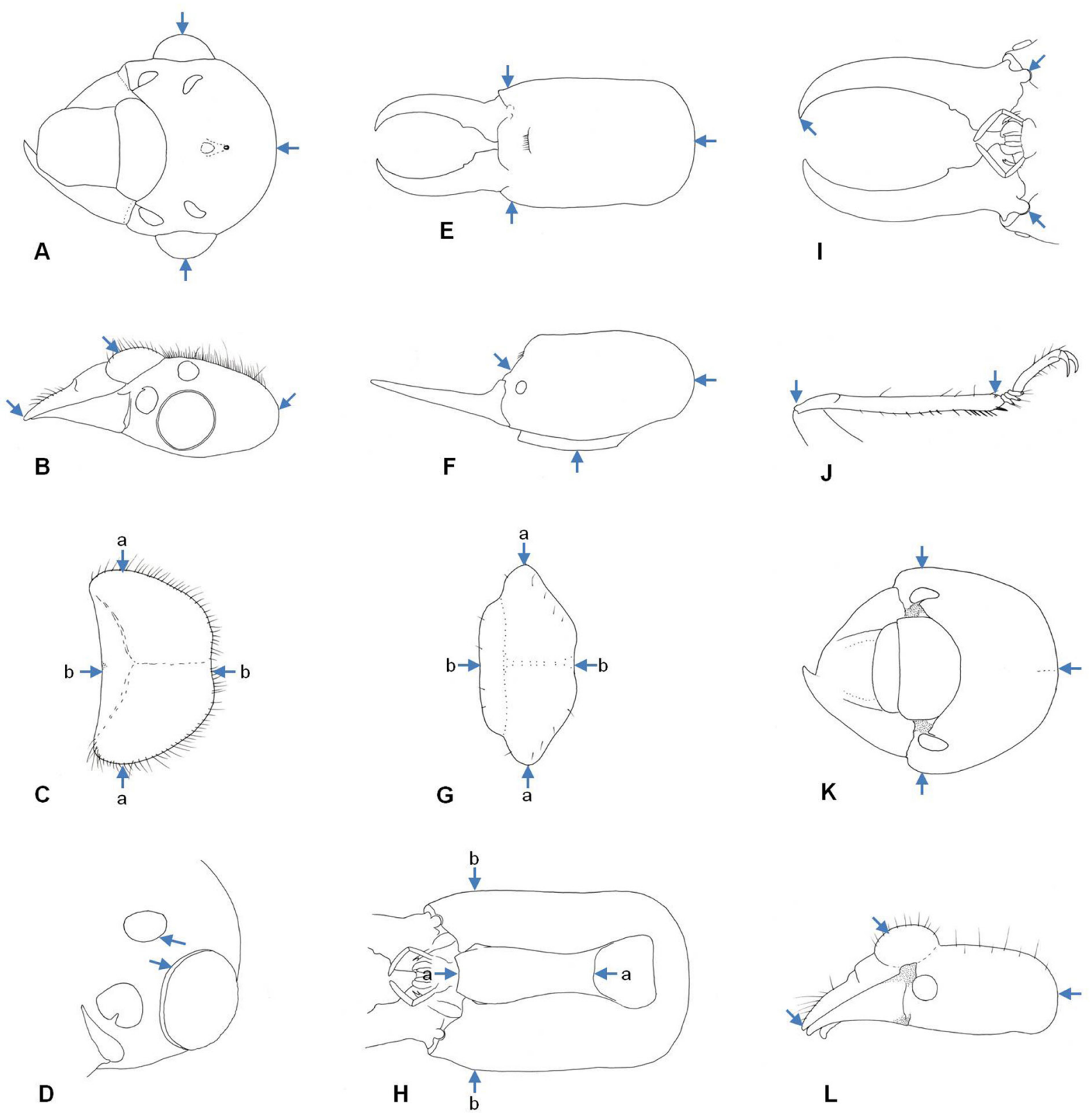

Fig. 5. Photo standardisation, the arrows point to the spots which have to be in focus simultaneously. A. Dorsal view of the head capsule of an imago ('photo IHCDV'). B. Lateral view of the head capsule of an imago ('photo IHCLV'). C. Dorsal view of the pronotum of an imago ('photo IPronot'). D. Oblique view of the head capsule of an imago ('photo IHCObV'). E. Dorsal view of the head capsule of a soldier ('photo SHCDV'). F. Lateral view of the head capsule of a soldier ('photo SHCLV'). G. Dorsal view of the pronotum of a soldier ('photo SPronot'). H. Ventral view of the head capsule of a soldier ('photo SHCVV'). I. Ventral view of the mandibles of a soldier ('photo SMandVV'). J. Hind tibia and tarsus of a soldier ('photo STibia'). K. Dorsal view of the head capsule of a worker ('photo WHCDV'). L. Lateral view of the head capsule of a worker ('photo WHCLV'). All the drawings are issued from C. fungifaber (Sjöstedt, 1896) type material (not to the same scale). 
orientation on a microscope slide. This is indeed true for xylophagous termites; however, in Cubitermes (like in other humivorous genera) the molar tooth is quite poorly and equally developed in the different species; so the mandibles turn between the microscope slide and cover glass in a reproducible way. Four or five photos were finally taken:

- one of an antenna (code: 'photo IAnten')

- left mandible in dorsal view (code: 'photo IMandL')

- right mandible in dorsal view (code: 'photo IMandR')

- left fore wing in dorsal view, if available (code: 'photo IWing')

- enteric valve open, only in very few cases (code: 'photo IValve')

In the photo codes, the letter 'I' may be replaced with 'F' (winged female), 'M' (winged male), 'Q' (queen), or ' $\mathrm{K}$ ' (king), depending on the kind of imago.

\section{Photo standardisation on soldiers}

The photo capture and associated operations followed this sequence.

Three general and two standardised photos were first taken:

- entire individual, in dorsal, ventral and lateral (left side) views (codes: 'photo STotDV', 'photo STotVV' and 'photo STotLV')

- pronotum in dorsal view (code: 'photo SPronot', Fig. 5G): simultaneous focus on (a) the outlines of both sides of the pronotum and (b) the outlines of the anterior and posterior margins

- hind tibia (code: 'photo STibia', Fig. 5J): simultaneous focus on both ends of the left hind tibia

The antennae and labrum were then removed from the head for further treatment and the head was cut off the body; if the mandibles were crossed, they were uncrossed as far as possible in order to have their tips close to each other before taking the following standardised photos:

- head capsule in dorsal view (code: 'photo SHCDV', Fig. 5E): simultaneous focus on the outlines of both sides (near the antennal sockets) and the outline of the posterior head rim

- head capsule in lateral view (code: 'photo SHCLV', Fig. 5F): simultaneous focus on the outlines of the posterior and inferior head rims along with a tangential view to the frons

- head capsule in ventral view (code: 'photo SHCVV', Fig. 5H): simultaneous focus (a) on both ends of the gulamentum and (b) on the outlines of both head sides (near antennal sockets)

- mandibles in dorsal view, not detached from head (code: 'photo SMandDV'): simultaneous focus on the visible bases of both mandibles and the tip of at least the left mandible

- mandibles in ventral view, not detached from head (code: 'photo SMandVV', Fig. 5I): simultaneous focus on the condyles of both mandibles and the tip of at least the left mandible.

The abdomen was then peeled and the soft tissues encompassing the gut removed with fine tweezers, enabling the following photo to be taken:

- caecum or diverticulum of paunch (code: 'photo SCaecum'): the gut was oriented so that the diverticulum became clearly visible

The upstream part of the hindgut (P1 + P2 in Holmgren 1909; Noirot 2001) was then cut off the digestive tract with a fine scalpel and photographed:

- enteric valve in situ, before opening (Code: 'photo SValIS'); in several old samples, however, the gut was more or less decayed and this photo could not be taken

The valve (P2) was then cut off the ileum (P1) and squeezed gently in order to soften it and to partly remove the soil it contained. It was then put in alcohol in a small Petri dish which was put at the surface of an ultrasonic bath (VWR Ultrasonic Cleaner, $45 \mathrm{kHz}, 30 \mathrm{~W}$ ); two to five seconds were generally 
enough to remove the soil particles and to unfasten most of the muscle layers from the chitinous wall; the remaining muscle fibres were removed as far as possible with fine tweezers. The chitinous valve was then cut open with fine scissors or with a fine needle. Both antennae, the labrum (upside upwards) and the enteric valve (inner side upwards) were then mounted on a microscope slide in Euparal ${ }^{\circledR}$ (Roth) and photos were taken:

- one of an antenna (code: 'photo SAnten')

- labrum (code: 'photo SLabrum')

- enteric valve open (code: 'photo SValve')

\section{Photo standardisation on workers}

The photo capture and associated operations followed this sequence.

Three general and two standardised photos were first taken:

- entire individual, in dorsal, ventral and lateral (left side) views (codes: 'photo WTotDV', 'photo WTotVV' and 'photo WTotLV')

- pronotum in dorsal view (code: 'photo WPronot' cf. Fig. 5G): simultaneous focus on (a) the outlines of both sides of the pronotum and (b) the outlines of the anterior and posterior pronotum margins; however, the pronotum, especially in old, long preserved samples, was sometimes distorted and this photo could not always be taken

- hind tibia (code: 'photo WTibia', cf. Fig. 5J): simultaneous focus on both ends of the left hind tibia

The antennae were then removed for further treatment, the head and fore legs were cut off the body before taking the following two photos:

- head capsule in dorsal view (code: 'photo WHCDV', Fig. 5K): simultaneous focus on the outlines of both sides and the posterior head rim

- head capsule in lateral view (code: 'photo WHCLV', Fig. 5L): simultaneous focus on the outlines of the posterior head rim and of the clypeus along with a tangential view to the top of the postclypeus

The mandibles were then cut off the head for further treatment; the abdomen was peeled and the soft tissues encompassing the gut removed with fine tweezers, allowing the following photo to be taken:

- diverticulum or caecum of the second paunch (P3 in Holmgren 1909) (code: 'photo WCaecum'): the gut was oriented so that the diverticulum became clearly visible

The upstream part of the hindgut (P1 + P2 in Homlgren 1909; Noirot 2001) was then cut off the digestive tract with a fine scalpel and photographed:

- enteric valve in situ, before opening (Code: 'photo WValIS'); in several old samples, however, the gut was more or less decayed and this photo could not be taken

The valve (P2) was then cut off the ileum (P1) and squeezed gently in order to soften it and to remove most of the soil it contained. It was then put in alcohol in a small Petri dish which was put at the surface of an ultrasonic bath (VWR Ultrasonic Cleaner, $45 \mathrm{kHz}, 30 \mathrm{~W}$ ); two to five seconds were generally enough to remove the soil particles and to unfasten most of the muscle layers from the chitinous wall; the remaining muscle fibres were removed as far as possible with fine tweezers. The chitinous valve was then cut open with fine scissors or with a fine needle. Both fore legs, both antennae, both mandibles (dorsal side upwards) and the enteric valve (inner side upwards) were then mounted on a microscope slide in Euparal ${ }^{\circledR}$ (Roth) and photos of these five organs were taken:

- one of a fore leg (code: 'photo WFLeg')

- one of an antenna (code: 'photo WAnten')

- left mandible in dorsal view (code: 'photo MandL')

- right mandible in dorsal view (code: 'photo WMandR')

- enteric valve (code: 'photo WValve') 


\section{Figure drawings}

To produce the figures, the photographs were traced on tracing paper applied to the screen of a computer.

\section{Measurements and observational errors}

Measurements were taken on the photographs with the AxioVision ${ }^{\circledR}$ (release 4.8) software (Zeiss) and automatically stored in an Excel file.

The possible random error of this kind of measurements is, in most cases, two pixels: one pixel on each side of the object that is measured. These possible random errors have been taken into consideration in Tables 1-3 and 5 providing the ranges of measurements and indices as well as in the identification keys: the highest values have been increased by $0.75-3 \%$ and the lowest values have been decreased by $0.75-3 \%$ depending on the magnification used and the type of value (raw data or indices).

\section{Variable Codification}

Since a large number of variables have been used, their code names have necessitated a codification following some simple rules.

The first letter of a code always shows the caste: $\mathrm{I}=$ imago, $\mathrm{S}=$ soldier and $\mathrm{W}=$ worker.

The last letter of a code always indicates the type of measurement: $\mathrm{A}=$ angle, $\mathrm{C}=$ concavity (of a soldier's head) or large curvature (of a soldier's mandible), $c=$ lesser curvature (of a soldier's mandible), $\mathrm{D}=$ distance (between two structures), $D$ (in italics) = large diameter (of an eye or ocellus) $d$ (in italics) $=$ lesser diameter (of an eye or ocellus), $\mathrm{H}=$ total height, $\mathrm{h}=$ lesser height, $\mathrm{L}=$ length, $\mathrm{N}=$ number, $\mathrm{R}=$ radius of curvature and $\mathrm{W}=$ width.

The letters between the first and last ones abbreviate the organ or appendage concerned: $\mathrm{A}=$ apical tooth, $\mathrm{Cx} 1 \mathrm{C}=$ the carina of the first coxa, $\mathrm{Cx} 1 \mathrm{~S}=$ the fore side of the first coxa, $\mathrm{d}=$ distal, Ey $=$ eye, $\mathrm{F}=$ the labrum fork, $\mathrm{Fr}=$ frons, $\mathrm{Gu}=$ gulamentum, $\mathrm{Hd}=$ head, $\mathrm{La}=$ labrum, $\mathrm{m}=$ marginal teeth, $\mathrm{M}=$ molar tooth, $\mathrm{Ml}=$ left mandible, $\mathrm{Mr}=$ right mandible, $\mathrm{Oc}=$ ocellus, $\mathrm{p}=$ proximal, $\mathrm{Pc}=$ postclypeus, $\mathrm{Pn}=$ pronotum, $\mathrm{T} 1=$ fore tibia, $\mathrm{T} 3=$ hind tibia, $\mathrm{VP} 1=$ valve, first primary cushion, $\mathrm{VP} 1 \mathrm{D}=$ the downstream, bristly part, of PC1, VP1DB = the bristles on the downstream, bristly part of PC1, VP1M = the middle, spiny part of PC1, VP1SB = the supporting bristles on one side of the middle, spiny part of PC1, VP1U = the upstream, spiny part of PC1, VP4S = the downstream, spatula part of PC4, VS12 = the valve, secondary cushion 12 , and $\mathrm{Wg}=$ Wing.

The codes containing the signs '/' or '-' are ratios or indices.

\section{Measurements on imagines (in alphabetical order)}

Initially 38 measurements were taken of every imago and 17 indices calculated on those measurements. Several regression analyses, principal component analyses and stepwise variable selections (in factorial discriminative analyses) led us to select and retain the following 29 variables and eight indices.

ICx1CN $=$ imago, number of spines on the carina of a fore coxa by direct observation

ICX1SN = imago, number of spines on the fore side of a fore coxa by direct observation

$\mathrm{IEy} D=$ imago, left compound eye large diameter, measured on 'photo IHCLV' (Fig. 6B)

IEyd = imago, left compound eye small diameter, measured on 'photo IHCVL' (Fig. 6B)

IEyHdD = imago, left compound eye distance from inferior head margin, measured on "photo IHCLV' (Fig. 6B)

IEyOcD = imago, left compound eye to ocellus minimal distance, measured on 'photo IHCObV' (Fig. 6D) 

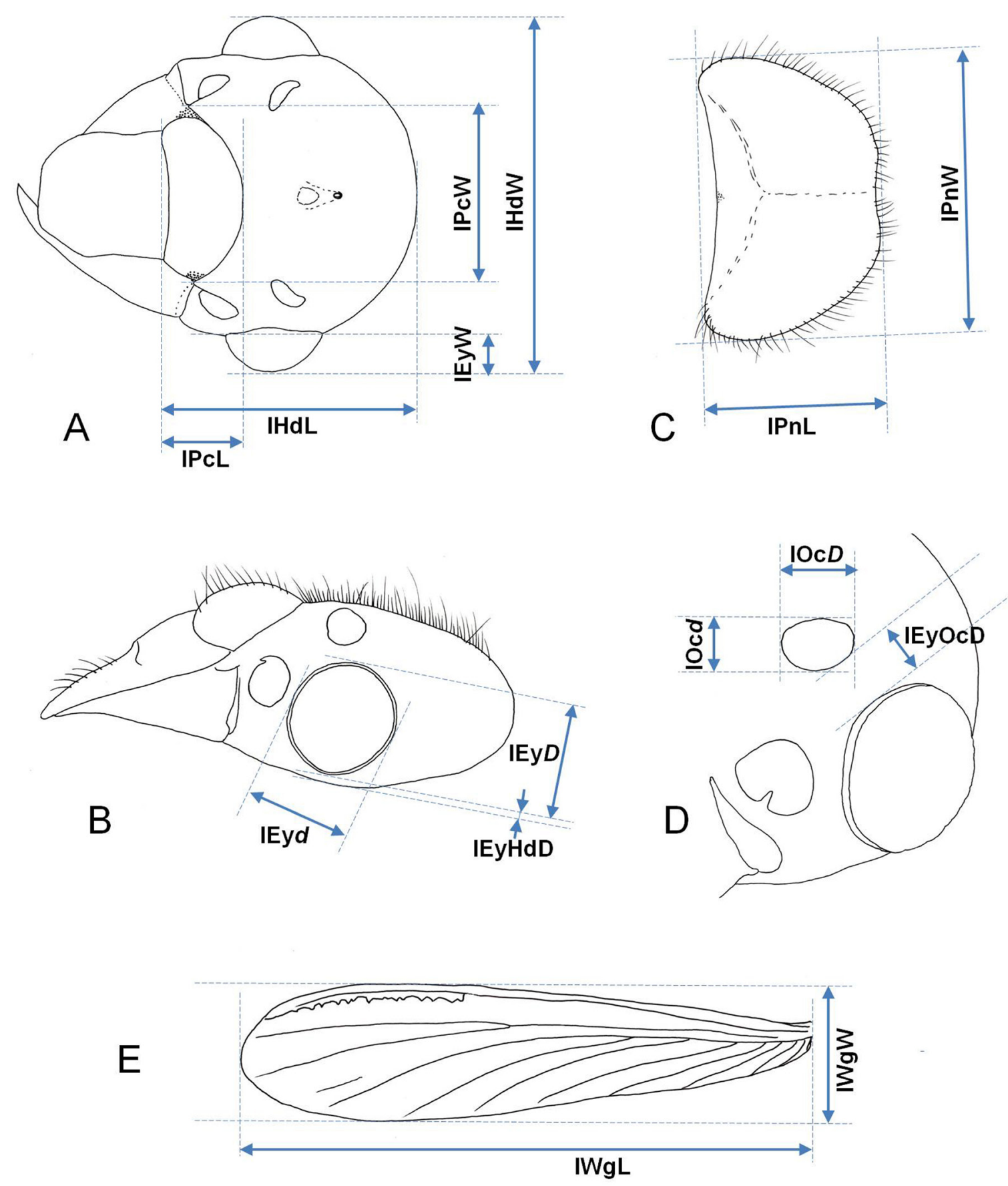

Fig. 6. Measurements on imagines. A. On the head in dorsal view ("photo IHCDV"), IEyW = eye width, $\mathrm{IHdL}=$ head length, $\mathrm{IHdW}=$ head width, $\mathrm{IPcL}=$ posclypeus length, $\mathrm{IPcW}=$ posclypeus width. $\mathbf{B}$. On the head in lateral view ("photo IHCLV"), IEy $D=$ eye great diameter, IEyd = eye small diameter, IEyHdD $=$ minimal distance between the left eye and head inferior edge. $\mathbf{C}$. On the pronotum in dorsal view ("photo IPronot"), IPnL = pronotum length, IPnW = pronotum width. $\mathbf{D}$. On the head in oblique view ("photo IHCObV"), IOc $D=$ ocellus great diameter, IOc $d=$ ocellus small diameter, IEyOcD = minimal distance between the left eye and ocellus. E. On the left fore wing ("photo IWing"), IWgL = length to the suture, $\mathrm{IWgW}=$ maximal width. 


$$
\begin{aligned}
& \text { IEyW = imago, left compound eye width (bulging), as in Fig. 6A, measured on 'photo IHCDV' } \\
& \text { IHdL = imago, head length to fore margin of postclypeus, measured on 'photo IHCDV' (Fig. 6A) } \\
& \text { IHdW = imago, head width across compound eyes, measured on 'photo IHCDV' (Fig. 6A) } \\
& \text { IMlAL = imago, length of left mandible apical tooth, measured on 'photo IMandL' (as WMIAL } \\
& \text { in Fig. 8C) } \\
& \mathrm{IM} 1 \mathrm{AmD}=\text { imago, left mandible, apical to first marginal distance (between tips), measured on 'photo } \\
& \text { IMandL' (as WMlAmD in Fig. 8B) } \\
& \text { IMlAW = imago, maximal width of left mandible apical tooth, measured on 'photo IMandL' (as } \\
& \text { WM1AW in Fig. 8C) } \\
& \text { IMIL = imago, left mandible functional length, measured on 'photo IMandL' (as WMIL in } \\
& \text { Fig. 8C) } \\
& \text { IMIML = imago, left mandible, length of molar tooth from the point where the molar prominence } \\
& \text { stands out against the background to posterior molar acute apophysis, measured on } \\
& \text { 'photo IMandL' (as WMIML in Fig. 8B) } \\
& \text { IMlmMD = imago, left mandible, distance between third marginal tip and the distal point where the } \\
& \text { molar prominence stands out against the background, measured on 'photo IMandL' (as } \\
& \text { WMlmMD in Fig. 8B) } \\
& \text { IMlmmD = imago, left mandible, first to third marginal distance (between tips), measured on "photo } \\
& \text { IMandL' (as WMlmmD in Fig. 8B) } \\
& \text { IMlmW = imago, left mandible, width of first marginal tooth, measured on 'photo IMandL' (as } \\
& \text { WMlmW in Fig. 8C) } \\
& \text { IMlW = imago, left mandible width from summit of molar prominence, measured on "photo } \\
& \text { IMandL' (as WMIW in Fig. 8C) } \\
& \mathrm{IMrAmD}=\text { imago, right mandible apical to first marginal distance (between tips), measured on photo } \\
& \text { 'IMandR' (as WMrAmD in Fig. 8D) }
\end{aligned}
$$

It can be noted that most measurements taken of the right mandible were discarded because of high redundancy with those from the left mandible.

\section{Indices (in alphabetical order)}

$\mathrm{IEy} D / \mathrm{IEy} d=$ compound eye elongation index (= eye index in Williams 1966), equals 1 if the eye is circular and increases when it becomes more oval

$\mathrm{IEy} D / \mathrm{IHdW}=$ eye size index; it increases when the compound eye becomes larger with respect to head width 

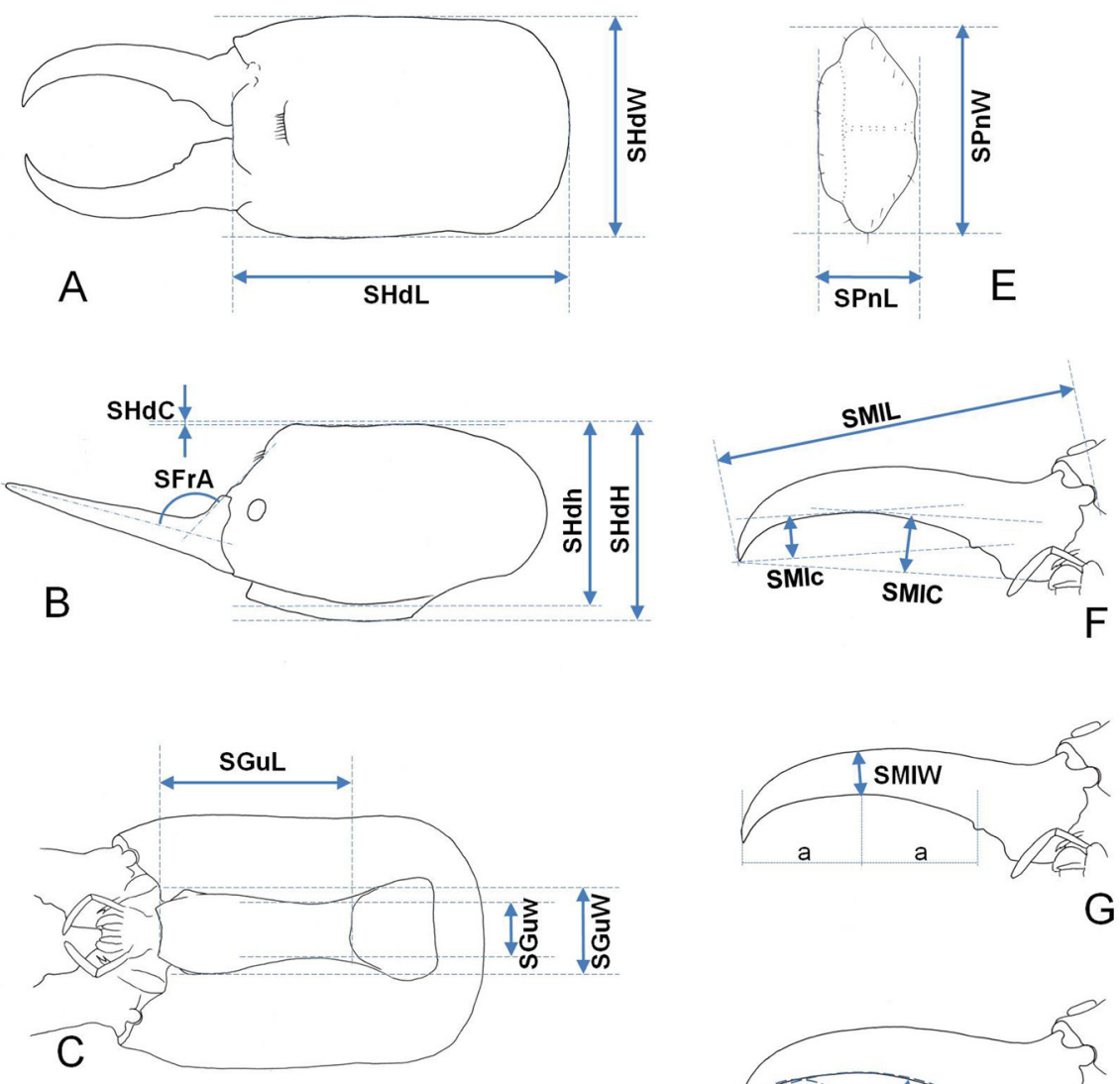

$\mathrm{G}$
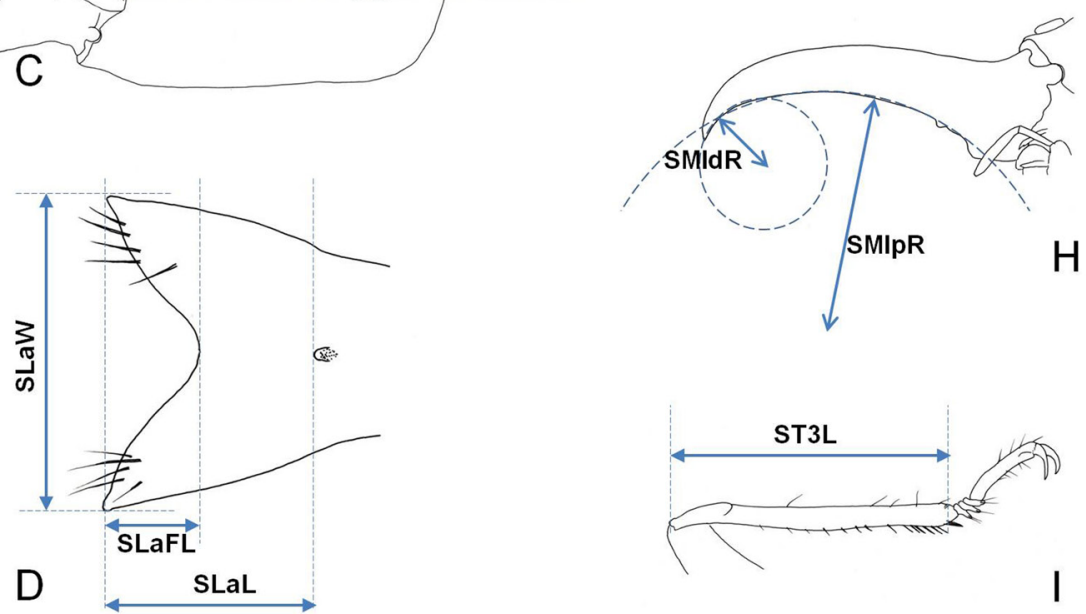

$\mathrm{H}$

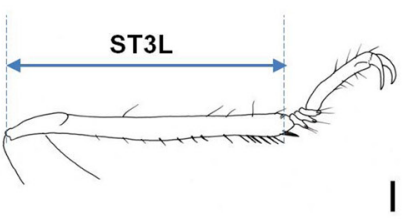

Fig. 7. Measurements on soldiers. A. On the head in dorsal view ("photo SHCDV"), SHdL = head length, SHdW = head width. B. On the head in lateral view ("photo SHCLV"), SFrA = frontal angle, $\mathrm{SHdC}=$ sagitta of the head upper concavity, $\mathrm{SHdH}=$ head total thickness, $\mathrm{SHdh}=$ head lesser thickness. C. On the head in ventral view ("photo SHCVV"), SGuL = gulamentum length, SGuW = gulamentum maximal width, SGuw = gulamentum minimal width. D. On the labrum ("photo SLabrum"), SLaFL = labrum, length of the fork, $\mathrm{SLaL}=$ labrum length to the apophysis, SLaW = labrum maximal width. E. On the pronotum dorsal view ("photo SPronot"), SPnL = pronotum length, SPnW = pronotum width. F. On the left mandible in ventral view ("photo SMandVV"), SMlc = lesser mandible curvature (or sagitta of the apico-marginal arc), SMlC = larger mandible curvature (or sagitta of the apico-molar arc), SMlL = length from tip to apophysis. G. On the left mandible in ventral view ("photo SMandVV"), SMIW = width of the mandible precisely at mid-distance between the marginal and the apical tips. H. On the left mandible in ventral view ("photo SMandVV"), SMldR = radius of the circle of the distal mandible quarter, SMlpR = radius of the circle of the proximal mandible half. I. On the left hind tibia ("photo STibia"), ST3L = length of the hind tibia. 


\begin{tabular}{|c|c|}
\hline IEyHdD/IEy $D$ & $\begin{aligned}= & \text { left eye elevation index (from inferior head margin) with respect to eye large } \\
& \text { diameter }\end{aligned}$ \\
\hline $\mathrm{IEyOcD} / \mathrm{IOc} D$ & $=$ eye to ocellus minimal distance index with respect to ocellus large diameter \\
\hline IEyW/IHdW & $=$ compound eye prominence index with respect to head width \\
\hline IMlAmD/IMlmmD & $\begin{array}{l}=\text { left apico-marginal index }(=\mathrm{La} / \mathrm{L} 1 \text { in Sands } 1972) \text {; it increases when the } \\
\text { apical tooth of the left mandible becomes longer with respect to the distance } \\
\text { between the first and third marginal teeth }\end{array}$ \\
\hline IMrAmD/IMrmmD & $\begin{array}{l}=\text { right apico-marginal index }(=\mathrm{Ra} / \mathrm{R} 1 \text { in Sands } 1972) \text {; it increases when the } \\
\text { apical tooth of the right mandible becomes longer with respect to the distance } \\
\text { between the first and second marginal teeth }\end{array}$ \\
\hline $\mathrm{IOc} D / \mathrm{IHdW}$ & $\begin{array}{l}=\text { ocellus size index; it increases when the ocellus becomes larger with respect to } \\
\text { head width }\end{array}$ \\
\hline
\end{tabular}

\section{Measurements on soldiers (in alphabetical order)}

Initially 48 measurements were taken of every soldier and 22 indices calculated from those measurements. Several regression analyses, principal component analyses and stepwise variable selections (in factorial discriminative analyses) led us to select and retain the following 36 variables and 16 indices.

\begin{tabular}{|c|c|}
\hline $\mathrm{SCx} 1 \mathrm{CN}$ & $=$ soldier, number of spines on the carina of fore coxa by direct observation \\
\hline SCx1SN & soldier, number of spines on the fore side of fore coxa by direct observation \\
\hline SFrA & $\begin{aligned}= & \text { soldier, angle between extended left mandible and postclypeus plus frons under } \\
& \text { fontanelle (in profile) (Fig. 7B) }\end{aligned}$ \\
\hline $\mathrm{SGuH}$ & soldier, gulamentum height (= SHdH-SHdh), measured on 'photo SHCVV' \\
\hline SGuL & soldier, gulamentum median length, measured on 'photo SHCVV' (Fig. 7C) \\
\hline SGuW & soldier, gulamentum maximal width, measured on 'photo SHCVV' (Fig. 7C) \\
\hline SGuw & soldier, gulamentum minimal width, measured on 'photo SHCVV' (Fig. 7C) \\
\hline SHdC & $\begin{aligned}= & \text { soldier, sagitta of head upper concavity, measured on 'photo SHCLV' (Fig. 7B) } \\
& \text { (equals zero if the upper profile is either straight or slightly convex) }\end{aligned}$ \\
\hline SHdh & $\begin{aligned}= & \text { soldier, lesser height of head capsule (gulamentum excluded), measured on } \\
& \text { 'photo SHCLV' (Fig. 7B) }\end{aligned}$ \\
\hline SHdH & $\begin{array}{l}=\text { soldier, maximal height of head capsule (gulamentum included), measured on } \\
\text { 'photo SHCLV' (Fig. 7B) }\end{array}$ \\
\hline SHdL & $\begin{aligned}= & \text { soldier, head median length to the fore margin of the clypeus, measured on 'photo } \\
& \text { SHCDV' (Fig. 7A) }\end{aligned}$ \\
\hline SHdW & soldier, head maximal width, measured on 'photo SHCDV' (Fig. 7A) \\
\hline SLaFL & $\begin{array}{l}\text { soldier, labrum fork length, from the tips of the lobes to the deepest point of the } \\
\text { fork, measured on 'photo SLabrum' (Fig. 7D) }\end{array}$ \\
\hline SLaL & $\begin{array}{l}=\text { soldier, labrum length or distance from the tips of the lobes to labrum apophysis, } \\
\text { measured on 'photo SLabrum' (Fig. 7D) }\end{array}$ \\
\hline SLaW & soldier, labrum maximal width, measured on 'photo SLabrum' (Fig. 7D) \\
\hline SMlC & $\begin{array}{l}=\text { soldier, left mandible larger curvature (or sagitta of apico-molar arc), greatest } \\
\text { distance between the inner edge of the blade and a line tangent to the tip of } \\
\text { apical tooth and to the margin of the molar tooth, measured on 'photo } \\
\text { SMandVV' (Fig. 7F); this is the same measurement as in Williams (1966); it } \\
\text { is sometimes difficult to measure if the mandible is not detached from the head }\end{array}$ \\
\hline SMlc & $\begin{array}{l}=\text { soldier, left mandible lesser curvature (or sagitta of apico-marginal arc) between } \\
\text { the marginal tooth and the apical tip, measured on 'photo SMandVV' (Fig. 7F); } \\
\text { often easier to measure than SMlC }\end{array}$ \\
\hline
\end{tabular}


SMldR

SMIL

SMlpR

SMIW

SPnL

SPnW

ST3L

SVP1L to SVP6L = soldier, enteric valve, lengths of the primary cushions 1 to 6 , measured on 'photo SValve' (as WVPnL in Fig. 4C)

SVP1W to SVP6W = soldier, enteric valve, maximal widths of the primary cushions 1 to 6 , measured on 'photo SValve' (as WVPnW in Fig. 4C)

\section{Indices and averages (in alphabetical order)}

$100 * \mathrm{SHdC} / \mathrm{SHdL}=$ percentage of upper head concavity relative to head length: it equals zero if the head upper profile is not concave, and it increases when the upper hump grows

$\ln ($ SMlpR $)-\ln ($ SMldR $)=$ acceleration of the mandible curvature between proximal and distal parts: it increases if the mandible becomes more curved distally with respect to the proximal curvature and it would equal zero if the mandible blade was a section of a circle (same proximal and distal radii)

$\mathrm{SGuH} / \mathrm{SHdH}$

$=$ gulamentum height index, ratio between the gulamentum height and the head total height

$\mathrm{SGuW/SGuw}$

$=$ gulamentum constriction index, ratio between maximum and minimum widths of gulamentum: it would equal one if the gulamentum lateral sides were parallel and it increases when the gulamentum becomes more constricted

SHdL/SHdW

$=$ head elongation index: it increases when the cephalic capsule becomes longer with respect to its width

$\mathrm{SLaFL} / \mathrm{SLaL}=$ labrum fork index: it increases when the fork deepens with respect to the labrum length

SLaW/SLaL $\quad=$ labrum widening index: it increases when the labrum becomes wider with respect to its length

$\mathrm{SMlC} / \mathrm{SMlc}=$ left mandible bi-curvature index: it increases mainly when the molar tooth becomes more prominent

SMlc/SMIL $\quad=$ left mandible apical curvature index, sagitta of the apico-marginal arc relative to the mandible length: it increases when the mandible becomes more curved; this is not the same curvature index as in Williams (1966), who used the apico-molar arc

SMIL/SHdL $\quad=$ gnatho-cephalic index: it increases when the mandible becomes longer with respect to head length 


$\begin{array}{ll}\text { SMIW/SMIL }= & \begin{array}{l}\text { left mandible robustness index; it increases when the mandible becomes } \\ \text { sturdier with respect to its length } \\ \text { Soldier's valve PC1-bilaterality index: it is calculated as the ratio of } \\ \text { SVP1-Bil } \\ \text { SVP1L over the average length of the two other odd cushions (SVP3L, } \\ \text { SVP5L); it provides a measure of transition from triradial to bilateral } \\ \text { symmetry }\end{array}=\begin{array}{l}\text { soldier's valve PC1-pre-eminence index: it is calculated as the ratio of } \\ \text { SVP1L over the average length of the five other primary cushions; it } \\ \text { measures the relative importance of PC1 } \\ \text { SVldier's valve alternation index: it is calculated as the ratio of the average } \\ \text { length of odd primary cushions (SVP1L, SVP3L and SVP5L) over the } \\ \text { average length of even primary cushions (SVP2L, SVP4L and SVP6L). It } \\ \text { provides a measure of transition from hexaradial to triradial symmetry }\end{array} \\ \text { SVP-Alt }= & \begin{array}{l}\text { soldier, enteric valve, average length of primary cushions 1 to 6 } \\ \text { soldier's valve odd PCs elongation index: it is calculated as the average } \\ \text { length of the odd primary cushions (SVP1L, SVP3L, SVP5L) on the } \\ \text { average width of the same odd cushions (SVP1W, SVP3W and SVP5W); } \\ \text { it measures the narrowness of the odd PCs }\end{array}\end{array}$

It can be noted that the measurements taken of the right mandibles have been discarded, because of high redundancy with those from the left mandible.

\section{Measurements on workers (in alphabetical order)}

Initially 57 measurements were taken of every worker and 30 indices calculated on those measurements. Several regression analyses, principal component analyses and stepwise variable selections (in factorial discriminative analyses) led us to select and retain the following 50 variables and 14 indices.

$\mathrm{WCx} 1 \mathrm{CN}$

WCx1SN

WHdL

WHdW

WMIAL

WMlAmD

WMIAW

WMIL

WMIML

WMlmMD
$=$ worker, number of spines on the carina of the fore coxa by direct observation and on 'photo WFLeg'

$=$ worker, number of spines on the fore side of the fore coxa by direct observation and on 'photo WFLeg'

$=$ worker, head length to fore margin of postclypeus, measured on 'photo WHCDV' (Fig. 8A)

$=$ worker, head maximal width, measured on 'photo WHCDV' (Fig. 8A)

$=$ worker, left mandible length of the inner side of the apical tooth, measured on 'photo WMandL' (Fig. 8C)

$=$ worker, left mandible apical to first marginal distance (between tips), measured on 'photo WMandL' (Fig. 8B)

$=$ worker, left mandible apical tooth width at its base, measured on 'photo WMandL' (Fig. 8C)

$=$ worker, left mandible functional length, from the tip of the apical tooth to the posterior apophysis of the molar tooth, measured on 'photo WMandL' (Fig. 8C)

$=$ worker, left mandible, length of the molar tooth, from the distal point where the molar prominence stands out against the background to its posterior apophysis, measured on 'photo WMandL' (Fig. 8B)

$=$ worker, left mandible distance between the third marginal tip and the distal point where the molar prominence stands out against the background, measured on 'photo WMandL' (Fig. 8B) 

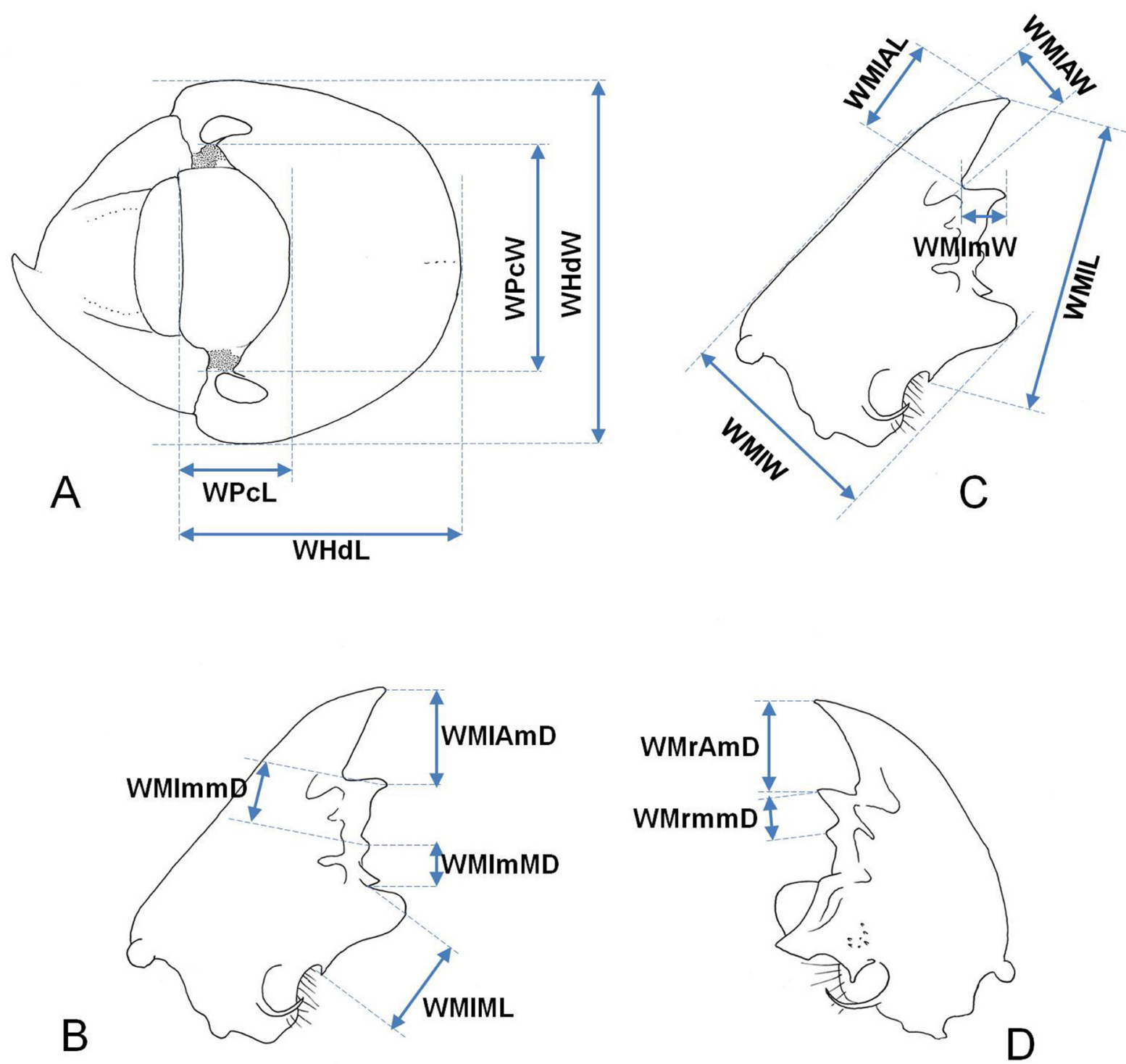

Fig. 8. Measurements on workers. A. On the head in dorsal view ("photo WHCDV"), WHdL = head length, WHdW = head width, $\mathrm{WPcL}=$ postclypeus length, $\mathrm{WPcW}=$ postclypeus width. $\mathbf{B}$. On the left mandible in dorsal view ("photo WMandL"), WMlAmD = distance between the apical and the first marginal tips, WMlmmD = distance between the first and third marginal tips, WMlmMD $=$ distance between the third marginal tip and the distal point where the molar prominence stands out against the background, WMlML = length of the molar tooth or distance between the distal point where the molar prominence stands out against the background and the posterior apophysis. C. On the left mandible in dorsal view ("photo WMandL"), WM1AL = length of apical tooth, WM1AW = maximal width of apical tooth, WMIL = functional length, WMlmW = width of the first marginal tooth, WMIW = width from mesial molar prominence. D. On the right mandible in dorsal view ("photo WMandR"), WMrAmD $=$ distance between the apical and the first marginal tips, $\mathrm{WMrmmD}=$ distance between the first and second marginal tips. 
WMlmmD

WMlmW

WMIW

WMrAmD

WMrmmD

WPcL

WPcW

WT1L

WT1W

WT3L

WVP1DBN

WVP1DL

WVP1L to WVP6L

WVP1ML

WVP1SBN

WVP1UL

WVP1W to WVP6W

WVP4SL

WVS12L to WVS61L =

$\mathrm{WVS} 12 \mathrm{~W}$ to WVS61W = worker, enteric valve, maximal widths of the secondary cushions 12 to 61 , measured in their upstream third on 'photo WValve' (Fig. 4E-4G)

\section{Indices and averages (in alphabetical order)}

WMlAmD/WMlmmD = left apico-marginal index (= La/L1 in Sands 1972): it increases when the apical tooth of the left mandible becomes longer with respect to the distance between first and third marginal teeth 
$\begin{aligned} \mathrm{WMlmmD} / \mathrm{WMrmmD}= & \text { intermandibular intermarginal index; it increases when the distance } \\ & \text { between marginal } 1 \text { and } 3 \text { tips (on the left mandible) becomes longer with } \\ & \text { respect to the distance between marginal } 1 \text { and } 2 \text { tips (on the right mandible) }\end{aligned}$

$\mathrm{WMrAmD} / \mathrm{WMrmmD}=$ right apico-marginal index (= Ra/R1 in Sands 1972); it increases when the apical tooth of the right mandible becomes longer with respect to the distance between the first and second marginal teeth

WT1W/WT1L = fore tibia width index: it increases when the tibia becomes wider with respect to its length

WT3L/WHdW = hind tibia-cephalic index; it increases when the tibia becomes longer with respect to the head width

WVP1-Bil = worker's valve PC1-bilaterality index; it is calculated as the ratio of WVP1L over the average length of the two other odd cushions (WVP3L and WVP5L); it provides a measure of transition from triradial to bilateral symmetry

WVP1-Pre = worker's valve PC1-pre-eminence index; it is calculated as the ratio of WVP1L over the average length of the other five primary cushions; it measures the relative importance of $\mathrm{PC} 1$

WVP-Alt = worker's valve alternation index; it is calculated as the ratio of the average length of the odd primary cushions (WVP1L, WVP3L and WVP5L) over the average length of the even primary cushions (WVP2L, WVP4L and WVP6L); it provides a measure of transition from hexaradial to triradial symmetry

WVP-AvL = worker, enteric valve, average length of the primary cushions 1 to 6

WVPOdd-Elg = worker's valve odd PCs elongation index; it is calculated as the average length of the odd cushions (WVP1L, WVP3L and WVP5L) on the average width of the same odd cushions (WVP1W, WVP3W and WVP5W); it measures the narrowness of the odd PCs

WVS-AvL = worker, enteric valve, average length of the secondary cushions 12 to 61

WVS-AvW = worker, enteric valve, average width of the secondary cushions 12 to 61

WVS-Elg = worker's valve SCs elongation index; it is calculated as the average length of the secondary cushions (WVS12L to WVS61) on the average width of the secondary cushions (WVS12W to WVS61W)

WVS/WVP = worker's valve secondary to primary width index; it is calculated as the average width of the secondary cushions (WVS12W to WVS61W) on the average width of the primary cushions (WVP1W to WVP6W)

\section{Statistical analyses}

The data were analysed by principal component analyses, linear regressions and factorial discriminative analyses with the software R, packages ade4 (Chessel et al. 2004), FactoMineR and klaR; the maps were produced with the package Maptools. 


\title{
Results
}

\section{Re-description of the genus Cubitermes Wasmann, 1906}

\author{
Phylum Arthropoda Latreille, 1829 \\ Class Insecta Linnaeus, 1758 \\ Infraorder Isoptera Brullé, 1932 \\ Family Termitidae Latreille, 1802 \\ Subfamily Cubitermitinae Weidner, 1956 \\ Genus Cubitermes Wasmann, 1906
}

Cubitermes Wasmann, 1906: 573.

Cubitermes - Wasmann 1911: 149 (original description).- Holmgren 1910: 286 and Holmgren 1912: 107 (as a subgenus of Mirotermes). — Emerson 1928: 506 (as a subgenus of Mirotermes). — Snyder 1949: 155 (as a genus).- Krishna et al. 2013: 1911 (as a genus).

The genus Cubitermes is currently included in the Cubitermitinae. This subfamily, first proposed as the tribe Cubitermitini by Weidner (1956), then synonymised with the Termitinae (Engel \& Krishna 2004), was eventually restored by Engel et al. (2009) as one of the eight subfamilies in Termitidae. The Cubitermitinae are characterised notably by the presence of a mixed segment and a blind diverticulum, or caecum, on the second paunch of the hindgut (P3) in workers, soldiers and imagines. They comprise 26 genera, among which Cubitermes is by far the richest in species. We consider here as belonging to Cubitermes all the species recorded as such in the recent Treatise of Krishna et al. (2013).

In this article the results are divided into two parts: the detailed re-description of the genus Cubitermes and the descriptions of nine groups of species based on their valve morphology.

\section{Type species}

Cubitermes bilobatus Haviland, 1898, by original designation (type deposited in the NHMM). The original descriptions of Wasmann $(1906 ; 1911)$ are very scant and have not been completed since, except for the worker caste (Sands 1998). A more detailed description is therefore proposed here, based on both published and new data, for imagines (255 individuals), soldiers (427 individuals) and workers (421 individuals).

\section{Imago}

Colour.

Head capsule: Well sclerotised and generally dark, C6-C8 (however, long preserved imagines can become as clear as C4, as already mentioned by Williams 1966); fontanelle concolorous with or paler than head capsule (one to five palette levels paler); postclypeus $\mathrm{C} 4-\mathrm{C} 7$ frequently paler (one to two levels) than head capsule, sometimes concolorous; three muscle insertions on head capsule visible as paler areas, one on each side between ocellus and postclypeus, and a smaller one immediately in front of fontanelle, but these insertions are sometimes indistinct due to dark colour of head of imagines; antennae $\mathrm{C} 4-\mathrm{C} 7$ without any difference between proximal and distal articles.

Thorax: Pronotum C4-C7 more or less as postclypeus, frequently one to two levels paler than head capsule, with some still paler areas, that is a T-shaped marking centrally, one oval spot near each antero-lateral corner and two oval spots in middle near posterior margin; meso- and metanotum $\mathrm{C} 4-\mathrm{C} 7$, 
frequently somewhat paler than pronotum; legs generally C3-C5, tibiae usually slightly (one level) darker than femora; wings hyaline with brown to grey tinge (Cf2-Cf4), anterior veins darker.

Abdomen: Tergites $\mathrm{C} 5-\mathrm{C} 7$; sternites appreciably paler in middle $(\mathrm{C} 3-\mathrm{C} 4)$ with both sides darker $(\mathrm{C} 4-$ $\mathrm{C} 6)$; posterior sternites darker (C4-C6) than anterior.

\section{SETATION}

Head capsule: Labrum and postclypeus with a variable density of prominent setae set amongst a very variable density of shorter, finer setae of variable length: sometimes these small setae are almost lacking, sometimes they form a dense mat; antennae with some prominent setae, some more numerous smaller setae and, mainly distally on most articles, a bunch of very fine bent setae (visible only at high magnification, $50 \times$ or more).

Thorax: Pronotum with prominent setae mainly on margins and shorter ones in middle; mesonotum and metanotum glabrous or with some fine setae, sometimes so small and thin that they cannot be seen even at a magnification of $100 \times$, remaining, however, detectable through their setal sockets, visible as pale round spots.

Legs: Generally very pilose, often furnished with spines in various densities on fore coxae and trochanters; fore, mid and hind tibiae bearing 3, 2, 2 apical spurs and 0, 2, 0 subapical spurs respectively (subapical spurs sometimes weakly developed).

Abdominal tergites: With many large and small setae; abdominal sternites with long setae, vertical or directed slightly forward, and many long and smaller setae directed backwards.

\section{Structure (measurements in Table 1)}

Head capsule: Compound eyes nearly round to shortly oval; ocelli nearly round to oval, removed from eyes by a variable distance relative to their own greatest diameter. Fontanelle varies from a tiny round or elongate marking to a round, obvious, margined depression larger than one-tenth of head width.

Antennae: Generally 16 articles on alate individuals, rarely 15 (in 7\% of individuals), or very rarely 17 (in $1 \%$ of individuals), almost always shortened by amputation by at least one article in queens and kings (one exception, not shortened, on 116 individuals examined).

Labrum: Cupola-shaped, generally wider than long.

Left mandible (Fig. 3): With apical tooth of variable length but always longer and more prominent than first marginal; marginal teeth three in number but second one only suggested by an undulation of edge between first and third marginal teeth; only apical tooth is acute in unworn specimens; premolar tooth with proximal end obscured or partly obscured by molar prominence in dorsal view; molar tooth bearing a rounded molar prominence dorsally and ending posteriorly in a tiny acute apophysis.

Right mandible (Fig. 3): With apical tooth of variable length but always longer and more prominent than first marginal; marginal teeth two in number; first marginal tooth well developed with a sharp tip when fresh; second marginal tooth smaller and with a blunt tip even when fresh; molar tooth bearing a ventral rounded flange and ending posteriorly in a kind of heel.

Thorax: Pronotum appreciably wider than long and narrower than head width (including eyes), straight to very weakly sellate, with anterior lobe short and very slightly elevated. 
Table 1. Ranges of measurements taken of 257 Cubitermes Wasmann, 1906 imagines (only 103 individuals for the wings) in 56 taxa, including some possible synonyms and some possible new species (in alphabetical order of the "Code" column).

\begin{tabular}{|c|c|c|}
\hline Imagines (counts) & Code & Range (nb) \\
\hline Fore coxae: number of spines on carina & $\mathrm{ICx} 1 \mathrm{CN}$ & $0-25$ \\
\hline Fore coxae: number of spines on fore side & ICx1SN & $0-8$ \\
\hline Imagines (raw data) & Code & Range (mm) \\
\hline Eye: large diameter & IEy $D$ & $0.23-0.57$ \\
\hline Eye: small diameter & IEyd & $0.21-0.50$ \\
\hline Eye distance from inferior head edge & IEyHdD & $0.01-0.14$ \\
\hline Eye to ocellus minimal distance & IEyOcD & $0.05-0.25$ \\
\hline Eye width (bulging) & IEyW & $0.08-0.23$ \\
\hline Head: length to fore edge of postclypeus & IHdL & $0.82-1.58$ \\
\hline Head: width across the eyes & IHdW & $1.10-1.91$ \\
\hline Mandible (left): length of apical tooth & IMlAL & $0.10-0.39$ \\
\hline Mandible (left): apical to first marginal & IMlAmD & $0.10-0.33$ \\
\hline Mandible (left): width of apical tooth & IMlAW & $0.09-0.22$ \\
\hline Mandible (left): functional length & IMlL & $0.43-0.84$ \\
\hline Mandible (left): length of molar tooth & IMlML & $0.14-0.28$ \\
\hline Mandible (left): first to third marginal & IMlmmD & $0.10-0.19$ \\
\hline Mandible (left): third marginal to molar & IMlmMD & $0.06-0.13$ \\
\hline Mandible (left): width of the first marginal & IMlmW & $0.03-0.16$ \\
\hline Mandible (left): width from molar prominence & IMlW & $0.29-0.58$ \\
\hline Mandible (right): apical to first marginal & IMrAmD & $0.12-0.31$ \\
\hline Mandible (right): first to second marginal & IMrmmD & $0.07-0.13$ \\
\hline Ocellus: large diameter & $\mathrm{IOc} D$ & $0.11-0.27$ \\
\hline Ocellus: small diameter & IOcd & $0.07-0.18$ \\
\hline Postclypeus: maximal length & IPcL & $0.26-0.53$ \\
\hline Postclypeus: width & IPcW & $0.52-0.98$ \\
\hline Pronotum: maximal length & IPnL & $0.58-1.21$ \\
\hline Pronotum: maximal width & IPnW & $0.88-1.77$ \\
\hline Tibia (hind): length & IT3L & $1.06-2.31$ \\
\hline Wing: length & $\mathrm{IWgL}$ & $8.44-21.8$ \\
\hline Wing: maximal width & IWgW & $2.01-5.31$ \\
\hline Imagines (indices) & Code & Range (ratio) \\
\hline Eye elongation index & IEy $D /$ IEyd & $0.98-1.26$ \\
\hline Eye size index & IEyD/IHdW & $0.20-0.34$ \\
\hline Eye elevation index & IEyHdD/IEy $D$ & $0.03-0.41$ \\
\hline Eye-ocellus index & IEyOcD/IOc $D$ & $0.21-1.45$ \\
\hline Eye prominence index & IEyW/IHdW & $0.06-0.13$ \\
\hline Mandible left apico-marginal index & IMlAmD/IMlmmD & $0.83-1.94$ \\
\hline Mandible right apico-marginal index & IMrAmD/IMrmmD & $1.34-3.28$ \\
\hline Ocellus size index & $\mathrm{IOc} D / \mathrm{IHdW}$ & $0.07-0.18$ \\
\hline
\end{tabular}


Wings: R1 fused entirely with costal margin, sclerotised; Rs simple, sclerotised; M not sclerotised with 2-7 branches near wingtip; $\mathrm{Cu}$ with 7-14 branches to posterior margin of wing.

Gut (only studied in some cases): enteric valve is weakly developed and hardly comparable with workers' and soldiers' valves; diverticulum (or caecum) is present as a small amorphous button.

\section{Soldier}

COLOUR

Head: Capsule generally tending towards deep palette $(\mathrm{Cd} 3-\mathrm{Cd} 6)$ with a generally smooth but sometimes a more abrupt gradient from a dark frons to a paler back (e.g., Cd6-Cd4); antennae and labrum frequently paler than head capsule.

Mandibles: Dark (C6-C8) with an abrupt clearing on their bases (two palette levels) which are generally of same colour as frons.

Thorax and legs: Paler than head capsule (C3-C4).

Abdomen: Grey to red-brown owing to digestive bolus, sometimes with a yellow to reddish-brown tinge on tergites.

\section{SETATION}

Head capsule: With few scattered setae; on frons a dense bunch of hair-like setae surrounds and overhangs fontanelle; antennae with some more numerous smaller setae and at distal extremity of distal articles, a bunch of very fine bent setae (visible only at high magnification, $50 \times$ or more); labrum always with some large setae on lobes (generally $<20$, exceptionally up to 24 ). Thorax: pronotum and mesonotum with a small number $(<20)$ of setae mainly located on rims.

Legs: Furnished with a row of spines along shaft of every tibia; fore coxae bear at least one fine seta and may or may not be furnished with some spines on carina and front surface; trochanters generally with some long, lined-up setae, sometimes with six or seven spines; fore, mid and hind tibiae bearing 3, 2, 2 apical spurs and 0,2,0 subapical spurs, respectively (latter sometimes weakly developed).

Abdominal tergites: With some large setae, mainly or only on their posterior rim; abdominal sternites with long setae, vertical or slightly directed forward, often coloured, and smaller setae directed backwards.

\section{STRUCTURE (measurements in Table 2)}

Head capsule: Always clearly sclerotised. Proportions: head length varies from being almost as wide as long to appreciably longer. Dorsal view: lateral sides mostly subparallel (frequently with a small narrowing near posterior third or fourth) or slightly convex, converging slightly towards anterior until antennal sockets or, rarely, towards posterior; from antennal sockets sides converge more or less clearly towards bases of mandibles; posterior side variable. In profile: upper profile straight to clearly concave; angle between extended mandibles and frons varies from almost right to obtuse; frons with or without an anterior frontal hump; profile of gulamentum variable. In ventral view: gulamentum variable, from almost rectangular to more or less constricted in its posterior half, with sides of anterior part either roundly convex or forming an acute widening or even a kind of ear on each side.

Antennae: Mostly of $14.5-15$ articles, or rarely 14 (in $12 \%$ of specimens examined).

Labrum: Always more or less deeply bifurcate, varying from as long as wide to much wider, with sides varying from straight to slightly concave or lyre-shaped, rarely convex (Fig. 9); tips of lobes rounded 
or angular or with fine whitish or translucent tips; anterior margin concave, ranging from round to more or less V-shaped.

Mandibles: Sabre-like with variable curvatures; inner edges generally smooth (rarely finely serrated) with one distinct marginal tooth, sometimes very small, near molar tooth on each mandible; mandibles generally shorter or a little longer (rarely much longer) than head; entire surface of both mandibles generally smooth and glossy but sometimes matt due to very fine stripes mainly near tips.

Thorax: Pronotum sellate, as wide as $45-90 \%$ of head width, with an anterior margin varying from entire to distinctly notched in its middle.

Gut: Configuration as shown in Fig. 10. Enteric valve placed on left side, more visible in ventral view, situated in second half of abdomen. Diverticulum of gut (or caecum) always rather small, more visible in ventral view, near centre of abdomen, amorphous or lobed, sometimes with a lobe expanded forward or backwards. Arrangement of enteric valve cushions variable, showing hexaradial, trilateral or bilateral symmetry or no symmetry at all.

\section{Worker}

\section{COLOUR}

Head capsule: Pale (C1-C3).

Antennae: Proximal articles pale (C2-C3), distal articles appreciably darker (C4-C5).

Thorax and legs: pale (C1-C3).

Abdomen: Grey to red-brown owing to digestive bolus.
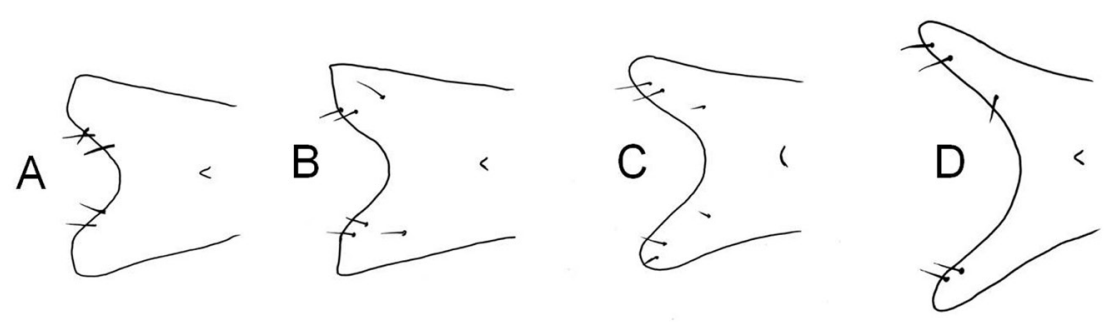

$1 \mathrm{~mm}$
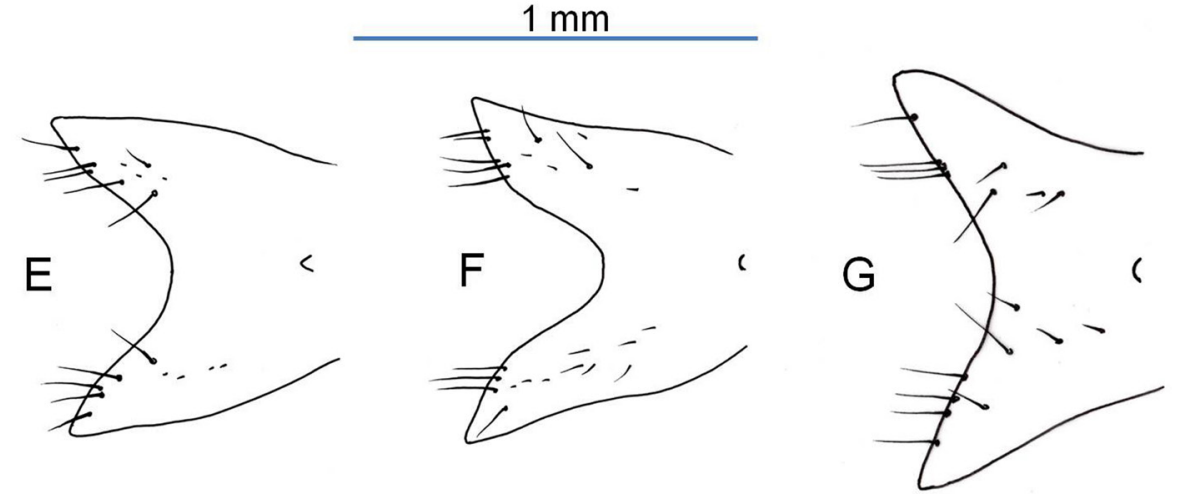

Fig. 9. Basic shapes of the labrum in soldiers. The lobes are A. Truncated without sharp angles; B. Truncated with sharp angles; C. Short finger-like; D. Elongated finger-like; E. Convex almost lyreshaped; F. Lyre-shaped; G. Triangular. All drawings to the same scale. 
Table 2. Ranges of measurements taken of 427 soldiers in 73 taxa Cubitermes Wasmann? 1906, including some possible synonyms and some possible new species (in alphabetical order of the "Code" column).

\begin{tabular}{|c|c|c|}
\hline Soldiers (counts) & Code & Range (Nb) \\
\hline Fore coxae: number of spines on carina & $\mathrm{SCx} 1 \mathrm{CN}$ & $0-16$ \\
\hline Fore coxae: number of spines on fore side & SCx1SN & $0-2$ \\
\hline $\begin{array}{l}\text { Soldiers (raw data) } \\
\end{array}$ & Code & Range $\left({ }^{\circ}\right)$ \\
\hline Angle between mandible and frons (in profile) & SFrA & $81-147$ \\
\hline $\begin{array}{l}\text { Soldiers (raw data) } \\
\end{array}$ & Code & Range (mm) \\
\hline Gulamentum: thickness & $\mathrm{SGuH}$ & $0.06-0.25$ \\
\hline Gulamentum: median length & $\mathrm{SGuL}$ & $0.72-2.09$ \\
\hline Gulamentum: maximal width & SGuW & $0.37-0.88$ \\
\hline Gulamentum: minimal width & SGuw & $0.22-0.58$ \\
\hline Head: sagitta of upper concavity & SHdC & $0.00-0.11$ \\
\hline Head maximal thickness & $\mathrm{SHdH}$ & $0.98-2.31$ \\
\hline Head lesser thickness & SHdh & $0.87-2.17$ \\
\hline Head: median length & SHdL & $1.40-3.83$ \\
\hline Head: maximal width & SHdW & $1.15-2.63$ \\
\hline Labrum: length of fork & SLaFL & $0.07-0.40$ \\
\hline Labrum: maximal length to apophyse & SLaL & $0.24-0.74$ \\
\hline Labrum: maximal width & SLaW & $0.41-1.41$ \\
\hline Mandible (left): larger mandible curvature & SMlC & $0.11-0.51$ \\
\hline Mandible (left): lesser mandible curvature & SMlc & $0.07-0.38$ \\
\hline Mandible (left): distal radius & SMldR & $0.26-0.99$ \\
\hline Mandible (left): length in ventral view & SMlL & $1.41-3.37$ \\
\hline Mandible (left): proximal radius & SMlpR & $0.59-8.62$ \\
\hline Mandible (left): width (see definition) & SMlW & $0.12-0.38$ \\
\hline Pronotum: length & SPnL & $0.30-0.72$ \\
\hline Pronotum: maximal width & SPnW & $0.62-1.55$ \\
\hline Tibia (hind): length & ST3L & $0.96-2.11$ \\
\hline Soldiers (indices) & Code & Range (ratio) \\
\hline Head upper concavity percentage & $100 * \mathrm{SHdC} / \mathrm{SHdL}$ & $0.00-3.38$ \\
\hline Mandible (left) curvature acceleration index & $\ln (\mathrm{SMlpR})-\ln (\mathrm{SMldR})$ & $0.09-3.01$ \\
\hline Gulamentum thickness index & $\mathrm{SGuH} / \mathrm{SHdH}$ & $0.04-0.17$ \\
\hline Gulamentum constriction index & SGuW/SGuw & $1.12-2.20$ \\
\hline Head elongation index & SHdL/SHdW & $1.04-1.68$ \\
\hline Labrum fork index & SLaFL/SLaL & $0.20-0.73$ \\
\hline Labrum widening index & SLaW/SLaL & $0.98-3.85$ \\
\hline Mandible bi-curvature index & SMlC/SMlc & $1.12-2.45$ \\
\hline Mandible (left) apico-marginal lesser curvature index & SMlc/SMlL & $0.03-0.21$ \\
\hline Gnatho-cephalic index & SMlL/SHdL & $0.54-1.43$ \\
\hline Mandible (left) robustness index & SMlW/SMlL & $0.07-0.20$ \\
\hline Valve: bilateral symmetry index & SVP1-Bil & $0.80-1.88$ \\
\hline Valve: $\mathrm{PC} 1$ pre-eminence index & SVP1-Pre & $0.81-1.95$ \\
\hline Valve: alternation index & SVP-Alt & $0.82-1.75$ \\
\hline Valve: average cushion length & SVP-AvL & $0.31-0.82$ \\
\hline Valve: odd PC elongation index & SVPOdd-Elg & $4.97-15.8$ \\
\hline
\end{tabular}


SETATION

Head capsule: Postclypeus and labrum with few scattered setae.

Antennae: With some prominent setae, some more numerous smaller setae and at distal extremity of distal articles, a bunch of very fine bent setae (visible only at high magnification, $50 \times$ or more).

Thorax: With some scattered setae; legs furnished with a row of spines along shaft of each tibia; fore coxae bearing at least one fine seta and furnished or not with a small number of setae or spines on carina and anterior surface; trochanters with or without spines; fore, mid and hind tibiae bearing 3, 2, 2 apical spurs and 0, 2, 0 subapical spurs, respectively (latter sometimes weakly developed).

Abdominal tergites: With some scattered setae; abdominal sternites with long setae, vertical or slightly directed forward, often coloured and smaller setae directed backwards.

STRUCTURE (measurements in Table 3)

Head capsule: Weakly sclerotised (except mandibles).

Antennae: Of 14-14.5 articles, rarely 15 (in $4 \%$ of specimens examined).

Labrum: Cupola-shaped, generally wider than long.
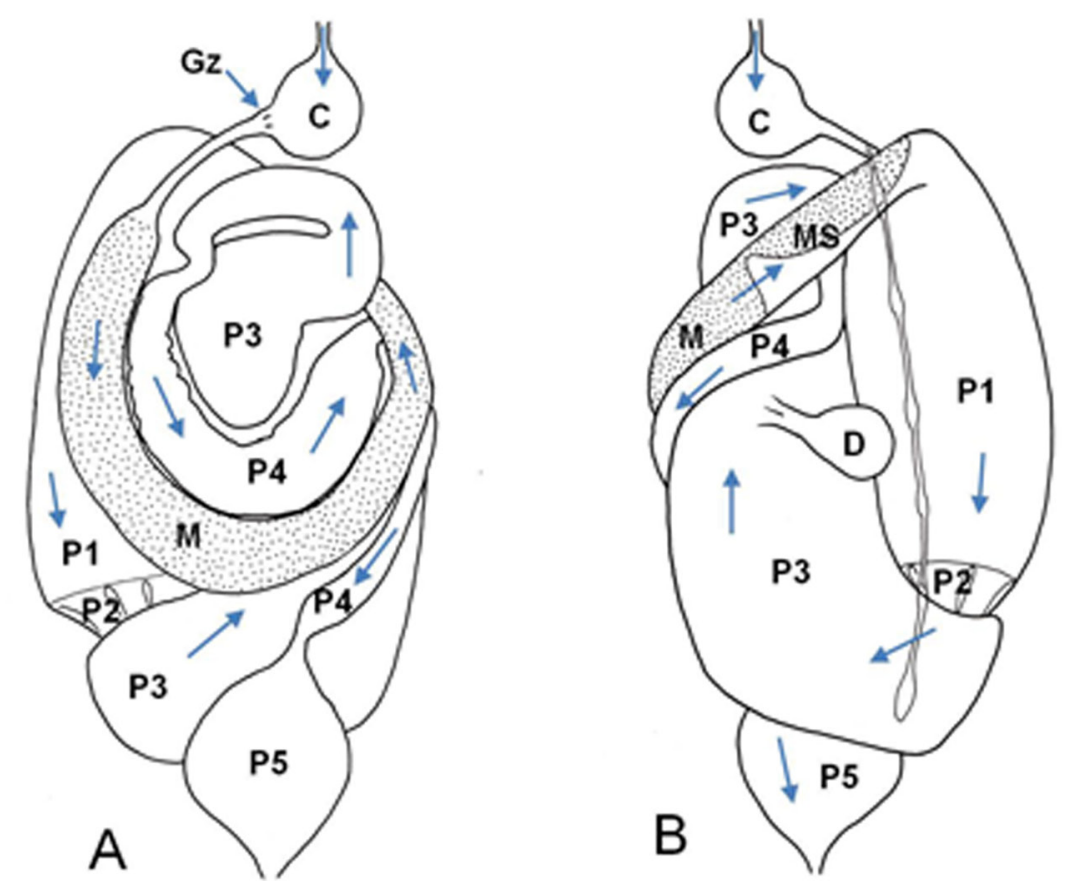

Fig. 10. Gut coiling in soldiers and workers. A. Dorsal view; B. Ventral view. $C=$ crop; $D=$ diverticulum or caecum of the second paunch; $\mathrm{Gz}=$ Gizzard; $\mathrm{M}=$ mesenteron (dotted segment); $\mathrm{MS}=$ mixed segment; P1 to P5: first to fifth hind-gut segments (Holmgren 1909; Noirot 2001): P1 = ileum, P2 = enteric valve, $\mathrm{P} 3=$ paunch, $\mathrm{P} 4=$ colon, $\mathrm{P} 5=$ rectum. The gut is quite convoluted and some masked parts need to be described. In dorsal view, the distal end of the mesenteron (M) passes behind the upper loop of P3 to join P1 which is connected to P3 via P2; P3 turns forward, passes under the loops of M and P4 and finally turns left to join $\mathrm{P} 4$; $\mathrm{P} 4$ loops rightwards along $\mathrm{M}$, then turns right and backwards behind $\mathrm{M}$ to join $\mathrm{P} 5$. 
Left mandible (Fig. 3): Apical tooth well developed with a sharp tip when fresh; marginal teeth three in number, first marginal tooth well developed but with a blunt tip even when fresh, second marginal tooth faint (visible as an undulated edge and disappearing in worn mandibles), third marginal tooth with a blunt tip; premolar tooth with its proximal end generally hidden under molar prominence; molar tooth bearing a rounded molar prominence dorsally and ending posteriorly in a tiny acute apophysis; apicomarginal index variable.

Right mandible (Fig. 3): Apical tooth well developed with a sharp tip when fresh; marginal teeth two in number; first marginal tooth well developed with a sharp tip when fresh; second marginal tooth smaller and with a blunt tip even when fresh; molar tooth bearing a ventral rounded flange and ending posteriorly in a kind of heel. Apico-marginal index variable.

Thorax: Pronotum sellate, as wide as 50 to $80 \%$ of head width.

Gut: Configuration of gut as shown in Fig. 10. Enteric valve placed on left side, more visible in ventral view, situated in second half of abdomen. Diverticulum of gut (or caecum) always rather small, visible in ventral view, near centre of abdomen, amorphous or lobed, sometimes with a lobe expanded forward or backwards. Arrangement of enteric valve cushions variable, showing hexaradial, trilateral or bilateral symmetry or no symmetry at all.

\section{Species groups based on enteric valve morphology}

Following the suggestion made by Bouillon \& Vincke (1971), the enteric valves in the worker and soldier castes were systematically examined with a possible outcome of creating new genera or subgenera. Obviously, the genus Cubitermes might have been divided into four clear taxa: one with "basic valves" (without any spatulae) and three taxa with "spatulated enteric valves" showing respectively two, three and six primary cushions ending in a flat structure looking like a spatula which sticks out of the valve. However, an ongoing molecular study suggests that some of these taxa would not be monophyletic. Therefore, in the prospect of a revision of the genus Cubitermes the first step proposed in this article is to introduce nine rather clear-cut species groups based on the morphology (Fig 11, Tables 3 and 4) and biometry (Table 5) of their enteric valves. These groups, referred to here as 'valve pattern groups', or 'valve patterns' for short, have for now no taxonomic ranking, but their definition will enable a better recognition of species of Cubitermes: some species with different valve patterns indeed cannot be distinguished based on their external morphology alone.

\section{The bilobatus valve pattern group}

The workers within this pattern have basic enteric valves: all six primary cushions (PCs) are similar in their arrangement (Fig. 12A). In the upstream and middle spiny parts, they are armed with relatively strong spines, becoming gradually thinner downstream; moreover, the middle part bears some lateral supporting spindle-like bristles leaning on the funnel membrane. In the downstream bristly part, the spines are rather abruptly replaced with longer and bristle-like setae, first straight, then curved and eventually hooked. The PCs are roughly triangular: their largest width is generally located near their upstream end and their lateral margins converge gradually downstream until the bristly part where they remain parallel (Fig. 11A). The enteric valve shows hexaradial to triradial symmetry, the odd PCs often being somewhat longer than the even PCs. In some cases, PC1 is still longer than PC3 and PC5, tending towards bilateral symmetry. 

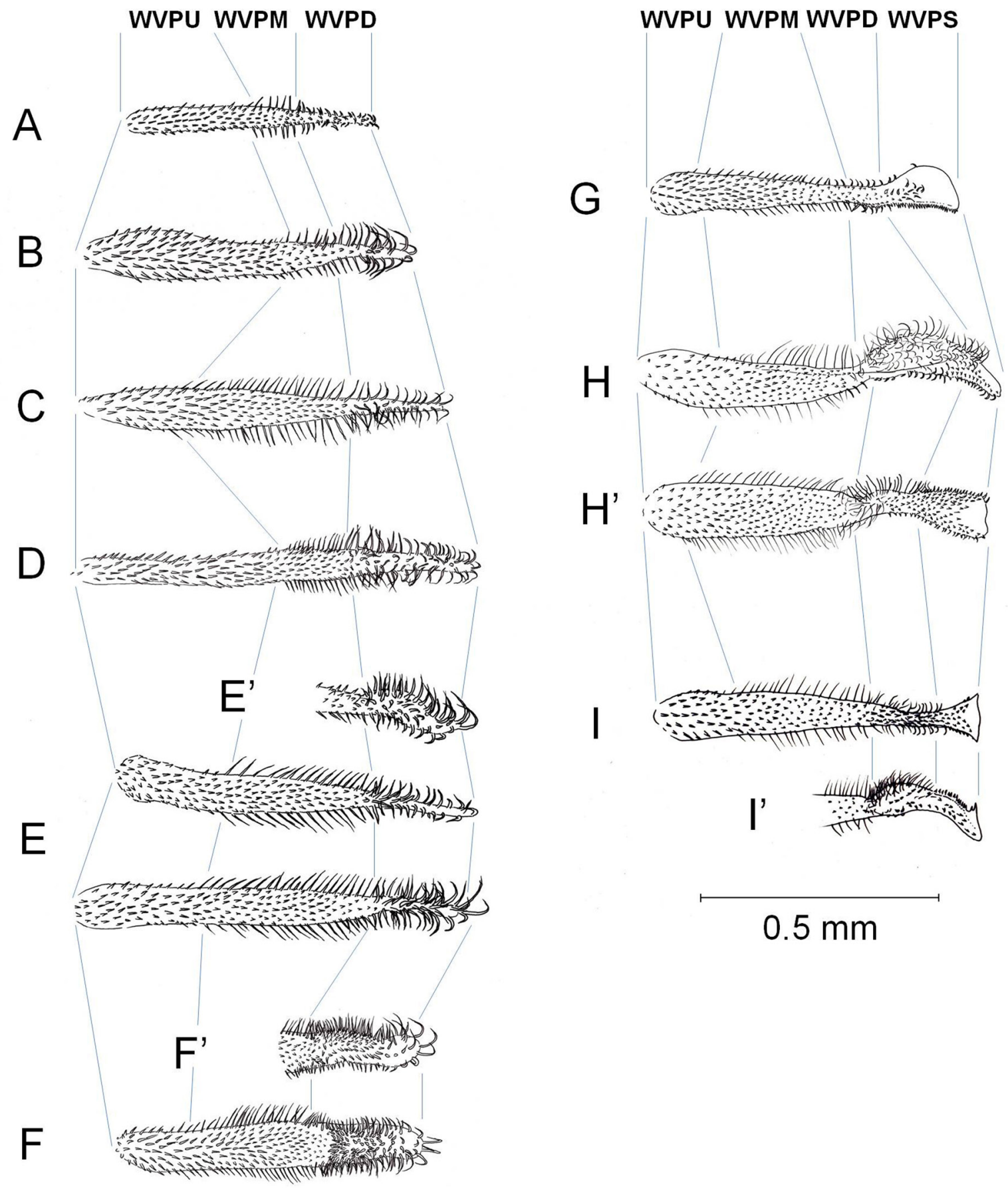

Fig. 11. Representative primary cushions of the various patterns encountered in the workers of the genus Cubitermes; WVPD = downstream bristly part; WVPM = middle spiny part; WVPS = spatula; WVPU = upstream spiny part. A. PC1 of the bilobatus valve pattern. B. PC1 of the oculatus valve pattern. C. any odd PC of the bilobatodes valve pattern. D. PC1 of the muneris valve pattern. E. PC6 and PC1 of the fungifaber valve pattern. E'. PC3 of the fungifaber valve pattern, twisted and partly seen in profile. F. PC1 of the finitimus valve pattern. F'. PC3 of the finitimus valve pattern, twisted and seen in profile. G. PC3 of the sankurensis valve pattern. H and $\mathbf{H}^{\prime}$. PC3 and PC4 of the oblectatus valve pattern. I. Any PC of the sulcifrons valve pattern. I'. Any PC of the sulcifrons valve pattern, twisted and seen in profile. All drawings to the same scale. 
Table 3. Ranges of measurements taken of 421 workers in 73 taxa of Cubitermes Wasmann 1906, including some possible synonyms and some possible new species (in alphabetical order of the "Code" column).

\begin{tabular}{|c|c|c|}
\hline Workers (counts) & Code & Range (Nb) \\
\hline Fore coxa: number of spines on carina & WCx1CN & $0-20$ \\
\hline Fore coxa: number of spines on fore side & WCx1SN & $0-4$ \\
\hline Valve: number of bristles on $\mathrm{PC} 1$ downstream part & WVP1DBN & $15-160$ \\
\hline Valve: number of lateral supporting bristles on PC1 (one side) & WVP1SBN & $3-37$ \\
\hline Workers (raw data) & Code & Range (mm) \\
\hline Head: length to fore edge of postclypeus & WHdL & $0.67-1.37$ \\
\hline Head: width & WHdW & $0.84-1.55$ \\
\hline Mandible (left): length of apical tooth inner side & WMIAL & $0.08-0.28$ \\
\hline Mandible (left): apical to first marginal & WMlAmD & $0.09-0.27$ \\
\hline Mandible (left): apical tooth width at its base & WMIAW & $0.07-0.20$ \\
\hline Mandible (left): functional length & WMIL & $0.35-0.75$ \\
\hline Mandible (left): length of the molar tooth & WMIML & $0.13-0.25$ \\
\hline Mandible (left): first to third marginal & WMlmmD & $0.08-0.17$ \\
\hline Mandible (left): third marginal to molar & WMlmMD & $0.05-0.12$ \\
\hline Mandible (left): width of the first marginal tooth & WMlmW & $0.03-0.13$ \\
\hline Mandible (left): width & WMlW & $0.26-0.56$ \\
\hline Mandible (right): apical to first marginal distance & WMrAmD & $0.09-0.26$ \\
\hline Mandible (right): first to second marginal distance & WMrmmD & $0.05-0.12$ \\
\hline Valve: length of downstream bristly part of $\mathrm{PC}^{1}{ }^{1}$ & WVP1DL & $0.09-0.39$ \\
\hline Valve: length of $\mathrm{PC}^{1}$ & WVP1L & $0.45-1.04$ \\
\hline Valve: length of middle spiny part of $\mathrm{PC} 1^{1}$ & WVP1ML & $0.04-0.53$ \\
\hline Valve: length of upstream spiny part of $\mathrm{PC}^{1}$ & WVP1UL & $0.07-0.57$ \\
\hline Valve: width of $\mathrm{PC}^{2}$ & WVP1W & $0.04-0.15$ \\
\hline Valve: average length of $\mathrm{PCs}^{2}$ & WVP-AvL & $0.43-0.85$ \\
\hline Valve: average width of $\mathrm{PCs}^{2}$ & WVP-AvW & $0.04-0.12$ \\
\hline Postclypeus: length & WPcL & $0.24-0.47$ \\
\hline Postclypeus: width & WPcW & $0.52-0.96$ \\
\hline Tibia (fore): length & WT1L & $0.60-1.18$ \\
\hline Tibia (fore): maximal width & WT1W & $0.11-0.25$ \\
\hline Tibia (hind): length & WT3L & $0.84-1.66$ \\
\hline Workers (indices) & Code & Range (ratio) \\
\hline Mandible left apico-marginal index & WMlAmD/WMlmmD & $0.84-2.12$ \\
\hline Intermandibular intermarginal index & WMlmmD/WMrmmD & $1.10-1.98$ \\
\hline Mandible right apico-marginal index & WMrAmD/WMrmmD & $1.27-3.47$ \\
\hline Fore tibia width index & WT1W/WT1L & $0.15-0.30$ \\
\hline Hind tibia-cephalic index & WT3L/WHdW & $0.82-1.29$ \\
\hline Valve: bilateral symmetry index & WVP1-Bil & $0.94-1.74$ \\
\hline Valve: $\mathrm{PC} 1$ pre-eminence index & WVP1-Pre & $0.94-1.74$ \\
\hline Valve: alternation index & WVP-Alt & $0.83-1.63$ \\
\hline Valve: odd PC elongation index & WVPOdd-Elg & $5.07-16.4$ \\
\hline Valve: average length of $\mathrm{SCs}^{2}$ & WVS-AvL & $0.17-0.74$ \\
\hline Valve: average width of $\mathrm{SCs}^{2}$ & WVS-AvW & $0.03-0.50$ \\
\hline Valve: SC elongation index & WVS-Elg & $1.22-11.1$ \\
\hline Valve: $\mathrm{SC}$ to $\mathrm{PC}$ width index & WVS/WVP & $0.33-6.20$ \\
\hline
\end{tabular}

${ }^{1}$ Excluding the members of the sulcifrons pattern which bear a spatula on PC1

${ }^{2}$ Including all PCs of all species (with and without spatulas) 
An odd primary cushion (Fig. 11A) is made of (a) a long, upstream, spiny part (38-58\% of total length) with relatively strong spines, (b) a short, middle, spiny part ( $8-15 \%$ of total length) with somewhat weaker spines and with few lateral supporting bristles (3-6 on each side), and (c) a long, downstream, bristly part (27-49\% of total length) with $15-50$ straight or curved short bristles and possibly a few hooked ones (Fig. 11A).

The secondary cushions (SCs) are also armed upstream with spines (less robust than on the primary cushions) and downstream with short bristles; the SCs are wide at the upstream end, narrowing noticeably downstream, in most species with a heterogeneous scattering of the spines (the spines are lacking in some irregular spots) (Fig. 12A), more rarely with a homogeneous scattering of the spines.

In the soldier's enteric valve, the primary cushions are barely or not at all outlined (Fig. 12B); the lateral supporting bristles are very short or absent and there are few bristles on the downstream end. The secondary cushions are like those of workers but bear less developed spines.

This basic valve pattern is therefore characterised by scarcely developed valves, with very few $(\leq 6)$ supporting bristles on each side of the PCs and generally heterogeneous spines scattering on the SCs; all of the species are small.

\section{Material examined}

Ten taxa have such enteric valves:

Cubitermes bilobatus (Haviland, 1898)

REPUBLIC OF SOUTH AFRICA • 1 ô (king), 1 + (queen), 1 soldier, 1 worker, syntypes; KwazuluNatal; 1897; NHMM • 1 soldier, 1 worker; Natal; 1905; AMNH • 1 soldier, 1 worker; Transvaal, Woodbush Village; 20 Aug. 1918; AMNH.

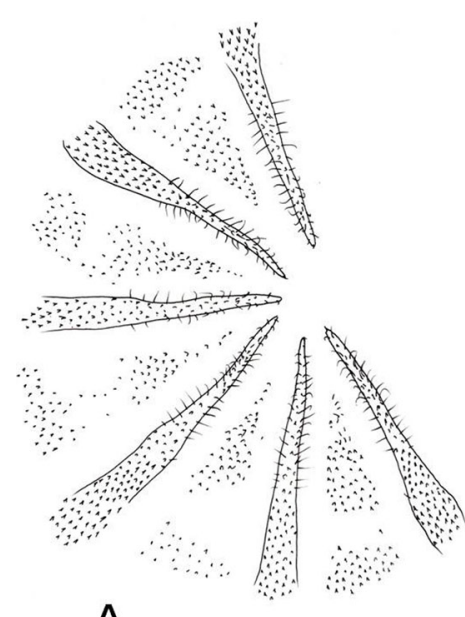

A

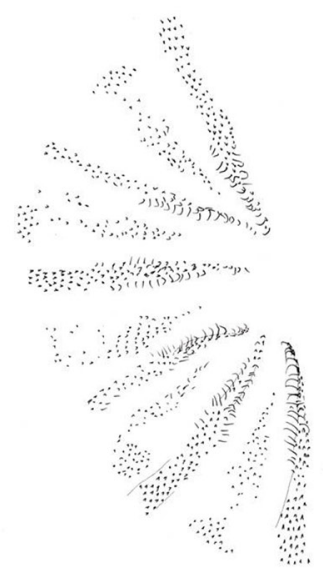

B

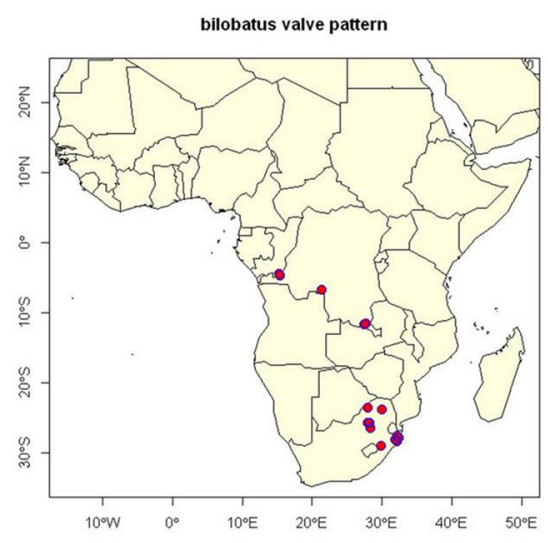

C

$1 \mathrm{~mm}$

Fig. 12. A. Enteric valve of the "bilobatus valve pattern", from a worker of Cubitermes bilobatus (Haviland, 1898): note the irregular scattering of the spines of the secondary cushions; B. Idem from a soldier of C. bilobatus; C. Geographical distribution of the species with the bilobatus valve pattern. 
Table 4. Summary of the qualitative characteristics of the workers' enteric valve patterns.

\begin{tabular}{|c|c|c|c|c|c|c|c|c|c|}
\hline Pattern & bilobatus & bilobatodes & muneris & fungifaber & finitimus & oculatus & sankurensis & oblectatus & sulcifrons \\
\hline Spatulas & none & none & none & none & none & none & $\begin{array}{l}2 \text { (on PC3 } \\
\text { and PC4) }\end{array}$ & $\begin{array}{c}3 \text { (on PC3, } \\
\text { PC4 and } \\
\text { PC5) }\end{array}$ & $\begin{array}{c}6 \text { (on all } \\
\text { PCs) }\end{array}$ \\
\hline $\begin{array}{l}\text { shape of } \\
\text { primary } \\
\text { cushions }\end{array}$ & $\begin{array}{l}\text { nearly } \\
\text { triangular }\end{array}$ & fusiform & $\begin{array}{l}\text { roughly } \\
\text { rectangular }\end{array}$ & $\begin{array}{l}\text { triangular } \\
\text { or fusiform }\end{array}$ & $\begin{array}{l}\text { roughly } \\
\text { rectangular }\end{array}$ & $\begin{array}{l}\text { nearly } \\
\text { triangular }\end{array}$ & $\begin{array}{l}\text { roughly } \\
\text { triangular }\end{array}$ & $\begin{array}{c}\text { roughly } \\
\text { rectangular } \\
\text { to fusiform }\end{array}$ & $\begin{array}{c}\text { more or less } \\
\text { fusiform }\end{array}$ \\
\hline crests & none & none & none & $\begin{array}{l}\text { high, on } \\
\text { PC1, PC3 } \\
\text { and PC5 }\end{array}$ & $\begin{array}{c}\text { wide, on } \\
\text { PC1, PC3 } \\
\text { and PC5 }\end{array}$ & none & none & $\begin{array}{l}\text { high, on } \\
\text { PC1, PC3 } \\
\text { and PC5 }\end{array}$ & $\begin{array}{l}\text { high, on all } \\
\text { PCs }\end{array}$ \\
\hline symmetry & $\begin{array}{l}\text { triradial to } \\
\text { bilateral }\end{array}$ & triradial & triradial & triradial & triradial & bilateral & none & bilateral & hexaradial \\
\hline $\begin{array}{l}\text { secondary } \\
\text { cushions }\end{array}$ & $\begin{array}{l}\text { wider than } \\
\text { PC; hetero- } \\
\text { geneous }\end{array}$ & $\begin{array}{c}\text { wider } \\
\text { than PC to } \\
\text { spearhead- } \\
\text { shaped }\end{array}$ & $\begin{array}{l}\text { wider than } \\
\text { PC, homo- } \\
\text { genous }\end{array}$ & $\begin{array}{l}\text { wider than } \\
\text { PC, homo- } \\
\text { genous }\end{array}$ & $\begin{array}{l}\text { wider than } \\
\text { PC, homo- } \\
\text { genous }\end{array}$ & $\begin{array}{l}\text { not wider } \\
\text { than PC; } \\
\text { SC12 and } \\
\text { SC61 faint }\end{array}$ & $\begin{array}{c}\text { not wider } \\
\text { than } 120 \% \\
\text { of PC }\end{array}$ & $\begin{array}{c}2-3 \text { times } \\
\text { wider than } \\
\text { PC, homo- } \\
\text { genous }\end{array}$ & $\begin{array}{l}\text { somewhat } \\
\text { wider than } \\
\text { PC or } \\
\text { spearhead- } \\
\text { shaped }\end{array}$ \\
\hline
\end{tabular}

Cubitermes conjenii (Fuller, 1925)

REPUBLIC OF SOUTH AFRICA • 1 đ (alate), lectotype (designated by Ruelle 1971); KwazuluNatal, near Conjeni; 12 Sep. 1922; PPRI, registration number: TYPH 02120 • 1 (alate), 1 worker, paralectotypes; same data as preceding; PPRI.

Cubitermes exiguus Mathot, 1964

DEMOCRATIC REPUBLIC OF THE CONGO • 1 + (alate), 1 worker; Kinshasa, University campus; 20 Aug. 1963; PPRI 1 \ (king), 1 + (queen), 1 soldier, 1 worker; same data as preceding; 6 Jun. 1964; RMCA 1 soldier, 1 worker; Kinshasa, Njili-Sanda road; 19 May 1964; RMCA • 1 q (queen), 1 soldier, 1 worker; Kinshasa, Kimwenza; 11 Mar. 1965; RMCA 1 1 (queen), 1 soldier, 1 worker; Kinshasa, Funa valley; 18 Oct. 2014; ULB • 1 soldier, 1 worker; Kinshasa, Funa valley; 24 Apr. 2017; ULB • 1 (queen), 1 soldier, 1 worker; Kinshasa, university campus; 24 Apr. 2017; ULB.

Cubitermes pretorianus Silvestri, 1914

REPUBLIC OF SOUTH AFRICA • 1 soldier, 1 worker, syntypes; Transvaal, Pretoria; 14 Mar. 1913; IEAP.

Cubitermes pretorianus var. heidelbergi Fuller, 1925

REPUBLIC OF SOUTH AFRICA • 1 soldier, lectotype (designated by Ruelle 1971); Gauteng; 1917; PPRI, registration number: TYPH 02122.

Cubitermes pseudoduplex (Fuller, 1925)

REPUBLIC OF SOUTH AFRICA • 1 soldier, lectotype (designated by Ruelle 1971); Kwazulu-Natal, Somkele; 29 Sep. 1922; PPRI, registration number: TYPH 02129 • 1 क (alate), $1 \precsim$ (alate), paralectotypes; same data as preceding; PPRI $\bullet 1$ (alate), 1 soldier, 1 worker, paralectotypes; same data as preceding; AMNH.

Cubitermes sanctaeluciae (Fuller, 1925)

REPUBLIC OF SOUTH AFRICA • 1 soldier, lectotype (designated by Ruelle 1971); Kwazulu-Natal, Nibele; 19 Sep. 1923; PPRI, registration number: TYPH02123 • 1 q (alate), 1 đ (alate), 1 soldier, 1 worker, paralectotypes; same data as preceding; PPRI. 
Cubitermes tenuiceps (Sjöstedt, 1913)

DEMOCRATIC REPUBLIC OF THE CONGO • 1 soldier, 1 worker, syntypes; Katanga, Lubumbashi; 20 Mar. 1912; RMCA - 2 soldiers, 2 workers (two samples); Katanga, Lubemba; Jul. 2014; ULB • 2 soldiers, 2 workers (two samples); Katanga, Mikembo; Jun. 2016; ULB.

Cubitermes transvaalensis (Fuller, 1925)

REPUBLIC OF SOUTH AFRICA • 1 soldier, lectotype (designated by Ruelle 1971); Gauteng, De Wildt; 12 oct. 1920; PPRI, registration number: 02124 • 1 (alate), 1 ô (alate), 1 soldier, 1 worker, paralectotypes, same data as preceding; PPRI $\bullet 1$ (alate), 1 soldier, 1 worker, paralectotypes; same data as preceding; AMNH.

Cubitermes zulucola Sjöstedt, 1924

REPUBLIC OF SOUTH AFRICA • 1 soldier, lectotype (designated by Ruelle 1971); Kwazulu-Natal, Hlabisa; 29 Sep. 1922; PPRI, registration number: 02129 • 1 \& (alate), 1 soldier, paralectotypes; same data as preceding; PPRI • 1 soldier, 1 worker; Kwazulu-Natal, Hlabisa; 2 Aug. 1921; AMNH 1 soldier, 1 worker; Kwazulu-Natal, Somkele; 25 Apr. 1935; AMNH.

The above were collected in Central and Southern Africa (Fig. 12C).

\section{The bilobatodes valve pattern group}

The workers within this pattern have basic enteric valves: all six primary cushions are similar in their arrangement (Fig. 13A). In the upstream and middle spiny parts, they are armed with relatively strong spines becoming gradually thinner downstream; the middle part also bears some lateral supporting spindle-like bristles leaning on the funnel membrane. In the downstream bristly part, the spines are rather abruptly replaced with longer and bristle-like setae, first straight, then curved and eventually hooked. The primary cushions are mainly fusiform: their largest width is located between the first upstream third and the middle, and their lateral margins converge gradually upstream and downstream (Fig. 11C). The odd PCs are longer than the even PCs, giving triradial symmetry to the valve (Fig. 13A).

An odd PC is made of (a) an upstream spiny part (27-51\% of total length) with relatively strong spines, (b) a middle spiny part (24-47\% of total length) with somewhat weaker spines and with 13-30 lateral supporting bristles on each side, and (c) a bristly part: (22-37\% of total length) with 35-75 straight, curved and eventually hooked bristles (Fig. 11C).

The secondary cushions are either broad at the upstream end, narrowing noticeably downstream, with a homogeneous scattering of spines (as in Fig. 4E for the species from East and Southern Africa), or somewhat stalked, widening near the first third with a heterogeneous scattering of spines tending towards the shape of a spearhead (Figs 4F, 13A for the species from West and Central Africa).

In the soldier's enteric valve, the primary cushions are similar to those of the worker with triradial symmetry, the odd PCs being longer than the even PCs; the secondary cushions are broad and either homogeneous or with a tendency towards the shape of spearheads (Fig. 13B).

This basic valve pattern is therefore characterised by high alternation indices in both workers and soldiers and by fusiform odd PCs; most species are small- to medium-sized. 


\section{Material examined}

Five species have such enteric valves:

Cubitermes bilobatodes Silvestri 1912

GUINEA BISSAU • 1 q (queen), 1 soldier, 1 worker, syntypes; Bolama; 6 Dec. 1899, MCGD • 1 soldier, syntype; Bolama; 6 Dec. 1899; AMNH; only the so-called miles major (major soldier) of a mixed syntype series has this form of enteric valve 1 soldier; Cacine; Sep. 1996; RMCA.

Cubitermes duplex (Holmgren, 1913)

REPUBLIC OF SOUTH AFRICA • 1 soldier, 1 worker, syntypes; Kwazulu-Natal, near Mfolosi?; 1905; PPRI • 1 soldier; Transvaal, Woodbush Village; 20 Aug. 1918; AMNH.

SWAZILAND • 1 q (queen), 2 soldiers, 3 workers (three samples); Mbabane-Bremersdorp road; 21 Apr. 1935; AMNH.

Cubitermes microduplex (Fuller, 1925)

REPUBLIC OF SOUTH AFRICA 1 soldier, lectotype (designated by Ruelle 1971); Eastern Cape, Pondweni; 17 Sep. 1923; PPRI, registration number: TYPH 02121 • 1 q (alate), 1 đ (alate), 1 soldier, 1 worker, paralectotypes; same data as preceding $\bullet 1 \hat{\jmath}$ (alate), 1 soldier, 1 worker; Kwazulu-Natal, west of lake Sibaya; 26 Oct. 1924; AMNH.

Cubitermes subcrenulatus Silvestri, 1914

CÔTE D'IVOIRE • 1 soldier, 1 worker; Man-Biankouma road; 11 Apr. 1968; RMCA • five samples: 2 우 (alates), 2 के $\partial^{\lambda}$ (alates), 5 soldiers, 5 workers; region of Korhogo; 2012-2013; ULB • 1 q (queen),

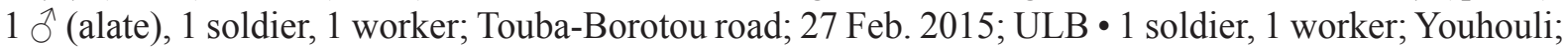
18 Feb. 2015; ULB.

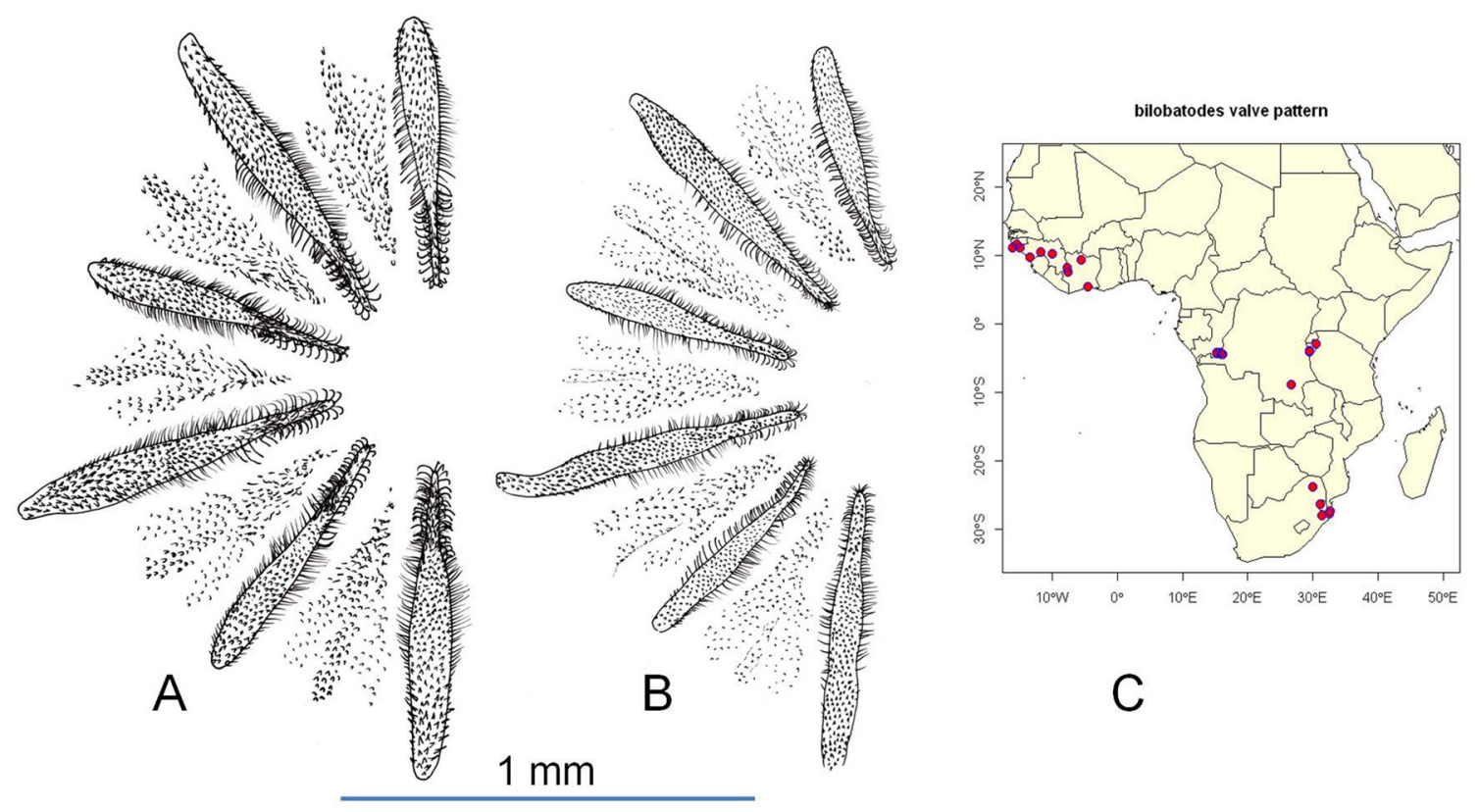

Fig. 13. A. Enteric valve of the "bilobatodes valve pattern", from a worker of Cubitermes bilobatodes Silvestri 1912: note the spearhead-shape of the secondary cushions; B. Idem from a soldier of C. bilobatodes; C. Geographical distribution of the species with the bilobatodes valve pattern. 
GUINEA • 1 q (queen), 1 soldier, 1 worker, syntypes; Kakoulima; 4 Aug. 1912; IEAP • 1 q (queen), 1 soldier, 1 worker; Mamou; 26 Aug. 1912; IEAP • 1 soldier, 1 worker; Haut-Niger National Park; May 1996; RMCA.

Cubitermes weissi Silvestri, 1912

CONGO $\bullet 1$ क (alate), 1 soldier, 1 worker, syntypes; Brazzaville; 1907?; IEAP • 1 soldier, 1 worker; Brazzaville; 8 Jun. 1946; RMCA.

DEMOCRATIC REPUBLIC OF THE CONGO $\bullet 2$ 우 (queens), 2 soldiers, 2 workers (two samples); Kinshasa, Bateke Plateau near Menkao; 29 Jan. 1972; RMCA • 1 soldier, 1 worker; Kinshasa, Bateke Plateau, Bombo-Lumene reserve; 15 Dec. 2012; ULB.

The above were collected in West, Central and Southern Africa (Fig. 13C).

\section{The muneris valve pattern group}

The workers within this pattern have basic enteric valves: all six primary cushions are similar in their arrangement but not in their sizes (Fig. 14A). In the upstream and middle spiny parts, they are armed with relatively strong spines becoming gradually thinner downstream; moreover, the middle part bears some lateral supporting spindle-like bristles leaning on the funnel membrane. In the downstream bristly part, the spines are rather abruptly replaced with longer and bristle-like setae, first straight, then curved and eventually hooked. The odd primary cushions are elongate and roughly rectangular: their lateral margins are almost parallel until the bristly part, where they are narrowed (Fig. 11D). The odd PCs are clearly longer than the even PCs, giving triradial symmetry to the valve (Fig. 14A).
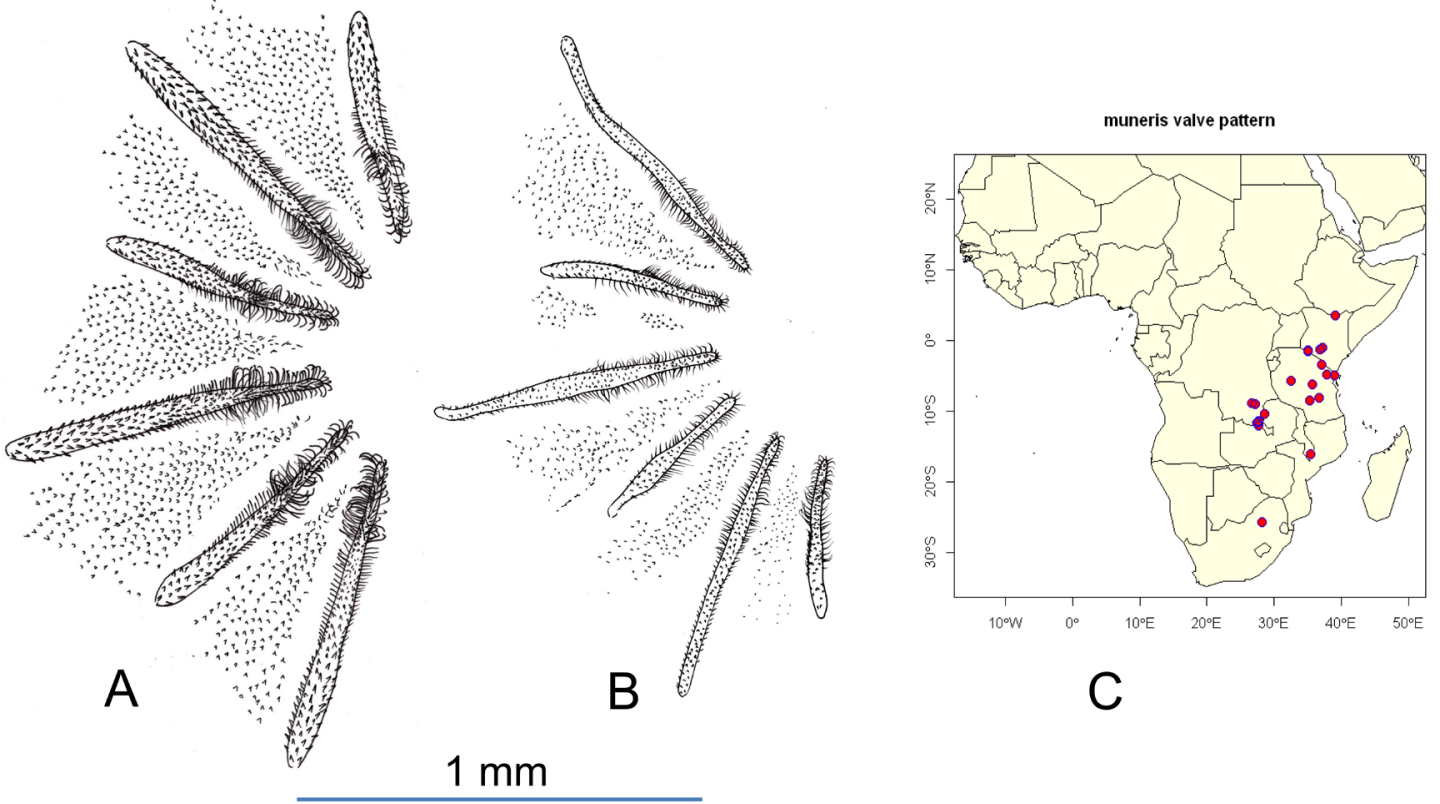

Fig. 14. A. Enteric valve of the "muneris valve pattern", from a worker of Cubitermes pallidiceps (Sjöstedt, 1913): note the elongation of the primary cushions; B. Idem from a soldier of C. muneris (Sjöstedt, 1913); C. Geographical distribution of the species with the muneris valve pattern. 
An odd PC is made of (a) a long upstream spiny part (42-56\% of total length) with relatively strong spines, (b) a short middle, spiny part (17-31\% of total length) with clearly weaker spines and with 11-18 lateral supporting bristles on each side, and (c) a bristly part (22-30\% of total length) with 50-65 straight, curved and eventually hooked bristles (Fig. 11D).

The secondary cushions are wide at the upstream end, almost filling the space between the PCs, narrowing noticeably downstream with a homogeneous spine scattering (Fig. 14A).

In the soldier's enteric valve, the PCs are even more slender than in the worker with triradial symmetry, the odd PCs being clearly longer than the even PCs (Fig. 14B). The secondary cushions are like those of workers but bear less developed spines.

This basic valve pattern is therefore characterised by high alternation indices in both workers and soldiers and by roughly rectangular odd PCs; most species are small- to medium-sized.

\section{Material examined}

Nine species have such enteric valves:

Cubitermes bisulcatus (Sjöstedt, 1914)

MALAWI • 1 soldier, 1 worker, syntypes; Mlanje; Aug. 1913; AMNH.

Cubitermes breviceps (Sjöstedt, 1913)

TANZANIA - 1 soldier; Dodoma; 8 Jan. 1935; note that the inclusion of C. breviceps in this species group is based on a single non-type soldier; AMNH.

Cubitermes falcifer Williams, 1966

TANZANIA • 1 \& (alate), 1 soldier, 1 worker, paratypes; Sao Hill; 6 Oct. 1953; NHMUK • 1 q (queen), 1 soldier, 1 worker, paratypes; Sao Hill; 6 Oct. 1953; PPRI.

Cubitermes glebae (Sjöstedt, 1913)

KENYA • 1 q (queen), 1 § (king), 1 soldier, 1 worker; near Nairobi; 20 Nov. 1934; AMNH.

TANZANIA • 1 q (alate), 1 soldier, 1 worker; Kilimanjaro, Kibongoto; 2 Mar. 1954; NHMUK.

Cubitermes latens Williams, 1966

TANZANIA • 1 soldier, 1 worker, paratypes; Shinyanga; 6 Mar. 1949; NHMUK • 1 ô (king), 1 soldier; Kakoma; May 1948; AMNH.

Cubitermes muneris (Sjöstedt, 1913)

DEMOCRATIC REPUBLIC OF THE CONGO • 1 soldier, syntype; Katanga, Lumata; 6 Jun. 1912; RMCA $\bullet 6$ 우 (queens), 3 $\widehat{\partial}$ (kings), 3 soldiers, 3 workers (six samples); Katanga, Upemba National Park; 28 Mar.-29 Nov. 1947; RMCA.

KENYA • 2 soldiers, 2 workers (two samples); 6-7 Aug. 2015; ULB.

Cubitermes pallidiceps (Sjöstedt, 1913)

DEMOCRATIC REPUBLIC OF THE CONGO • 1 soldier, 1 worker, syntypes; Katanga, Lubumbashi; 19 Mar. 1912; RMCA -2 q $q$ (queens), 1 § (king), 5 soldiers, 5 workers (five samples); Katanga, Lubumbashi; 20 Feb.-19 Apr. 1912; RMCA • 1 q (queen), 1 đ (king), 1 soldier, 1 worker; Katanga, Kasenga; 2 Feb. 1912; RMCA • 1 soldier, 1 worker; Katanga, Lubumbashi-Kasenga road; Jul. 2014; ULB $\bullet 3$ soldiers, 3 workers (three samples); Katanga, Mikembo; Jun. 2016; ULB. 
Cubitermes undulatus (Fuller, 1925)

REPUBLIC OF SOUTH AFRICA 1 soldier, lectotype (designated by Ruelle 1971); Gauteng, Pretoria; 1980; PPRI, registration number: TYPH 02128 • 1 soldier, 1 worker, paralectotypes; Gauteng, Pretoria; 1980; PPRI.

Cubitermes zavattarii Ghidini, 1937

ETHIOPIA • 1 worker, paratype; Moiale; 18 May 1937; MCGD • 1 worker; Moiale; 13 Apr. 1937; MCGD.

KENYA • 1 soldier, 1 worker; 14-falls; 15 May 1952; AMNH.

The above were collected in East and Southern Africa (Fig. 14C).

\section{Intermediate valve pattern group}

Some samples show an intermediate pattern between the muneris and the bilobatodes valve patterns.

\section{The fungifaber valve pattern group}

In the worker's enteric valve, the primary cushions are of two types: the even PCs are similar to the PCs of the basic enteric valves but the odd PCs, in their downstream part, are crested and protrude within the lumen of the valve (as in Fig. 4A). The primary cushions are either fusiform (their largest width is located near the middle and their lateral margins converge gradually towards both ends) or triangular (their largest width is located near their upstream end and their lateral margins converge gradually downstream). The odd PCs bear crests that are as high as or higher than they are wide, with longer and stronger bristles (Fig. 11E). On a microscope slide, it is quite frequent that at least one of these PCs is twisted, showing the crest in profile (Fig. 11E'). The enteric valve thus shows triradial symmetry. In some samples, however, the crests are weakly developed; their valves are then sometimes difficult to distinguish from the basic enteric valves of the bilobatodes or the muneris patterns.

An odd PC is made of (a) an upstream spiny part (18-42\% of total length) with relatively strong spines, (b) a middle spiny part (34-55\% of total length) with somewhat weaker spines and with 13-30 lateral supporting bristles on each side, and (c) a bristly part (21-36\% of total length) with 35-85 long, straight or curved bristles on a crest generally higher than wide; behind the crest, the bristly part bears some curved or hooked bristles (Fig. 15A).

The secondary cushions are wide at the upstream end, narrowing noticeably downstream with a homogeneous spine scattering (Fig. 15A).

In the soldier's enteric valve (Fig. 15B), the crests (on the odd PCs) are generally absent or weakly developed, and often their valves can hardly be distinguished from the basic enteric valves of the bilobatodes or muneris patterns. The secondary cushions are like those of workers but bear less developed spines.

The imago's enteric valve is much smaller than those of the soldiers and workers; the primary cushions are simple, without any crest, the secondary cushions are wide and homogeneous (Fig. 15C).

This basic valve pattern is therefore characterised by high and narrow hairy crests on the downstream end of the odd PCs; most species are large. 


\section{Material examined}

Eleven species have such enteric valves:

Cubitermes antennalis Sjöstedt, 1924

DEMOCRATIC REPUBLIC OF THE CONGO $\bullet 1$ (queen), 1 (alate), 1 (alate), 1 soldier, 1 worker, syntypes; Haut-Uele, Moto; 1923; RMCA.

Cubitermes banksi (Emerson, 1928)

CAMEROON $\bullet 1$ soldier, 1 worker, paratypes; Bipindi; 1920 ; AMNH $\bullet 1$ soldier, 1 worker, paratypes; Bipindi; 1920; RMCA 1 \& (alate), 1 soldier, 1 worker; Ebodjie; Nov. 1991; RMCA.

Cubitermes comstocki (Emerson, 1928)

CAMEROON • 1 + (queen), 1 worker, paratypes; Bipindi; 1920; AMNH • 1 soldier, 1 worker, paratypes; Bipindi; 1920; RMCA.

Cubitermes fungifaber (Sjöstedt, 1896)

CAMEROON • 1 q (queen), 1 soldier, 1 worker, syntypes; Mbonge; Oct. 1891; NHMM • 1 q (queen), 1 soldier, 1 worker, syntypes; Mbonge; Oct. 1891; AMNH) • 1 क (alate), 1 soldier, 1 worker; Mungo; 1903; AMNH • 1 § (alate), 3 soldiers, 3 workers (three samples); Bipindi; 23 Nov. 2016; ULB 11 \% (alate), $2 \widehat{\partial}$ (alates), 4 soldiers, 4 workers (four samples); Mbonge; 30 Nov. 2016; ULB.
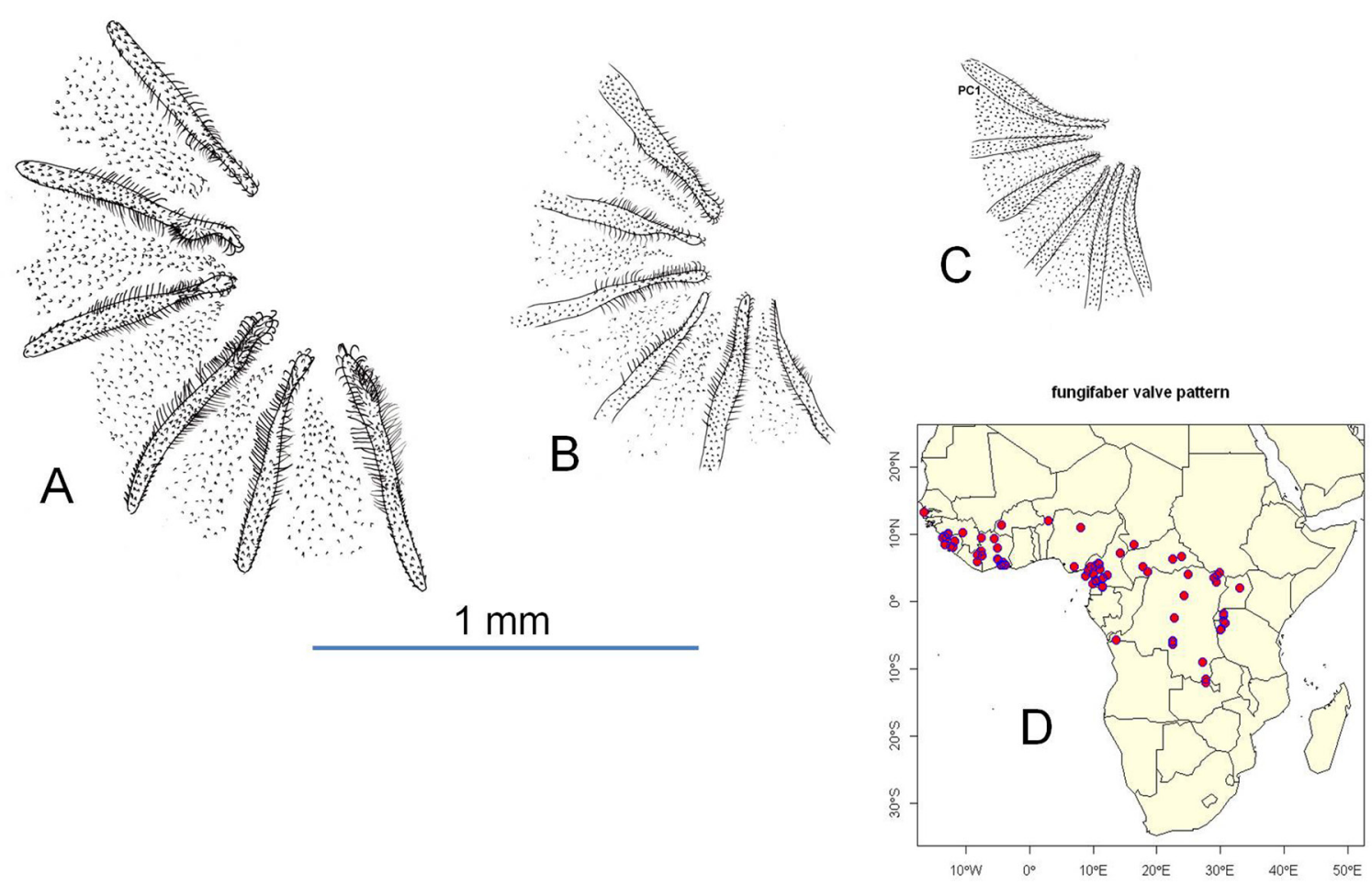

Fig. 15. A. Enteric valve of the "fungifaber valve pattern", from a worker of Cubitermes fungifaber (Sjöstedt, 1896): note the crest on PC5 which is twisted; B. Idem from a soldier of C. fungifaber without any crest on the odd PCs; C. Idem from an imago of C. fungifaber without any crest on the odd PCs; A, $\mathrm{B}$ and $\mathrm{C}$ at the same scale; D. Geographical distribution of the species with the fungifaber valve pattern. 
BIOKO • 1 q (alate), 1 soldier, 1 worker; Punta Frailes; Oct. 1901; MCGD.

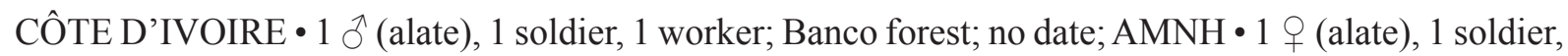
1 worker; Yapo forest; 22 Aug. 1953; AMNH 1 soldier, 1 worker; Banco forest; 17 Feb. 2015; ULB.

GABON • 4 soldiers, 3 workers (four samples); Bitam-Nkobissimo; 15 Apr. 2017; ULB.

GUINEA • 1 q (alate), 1 $\widehat{o}$ (alate); La Mé forest; 31 Jan. 1934; MNHM.

Cubitermes minitabundus (Sjöstedt, 1913)

DEMOCRATIC REPUBLIC OF THE CONGO • 1 soldier, syntype; Katanga, Lumata; 6 Jun. 1912;

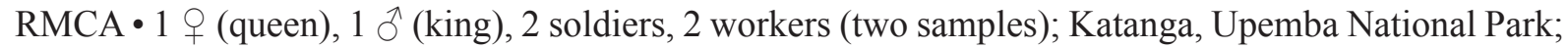
17 Jul. 1947; RMCA - 2 soldiers, 2 workers (two samples); Kasaï, Bunkonde; 26 Jan. 1912; RMCA • 1 q (queen), 1 soldier, 1 worker; Kasaï, Kananga; 21 Jan. 1912; RMCA 15 우 (queens), 4 + $q$ (alates), 3 ठึ (alates), 6 soldiers, 6 workers (six samples); Kasaï, Kananga; 26-27 Oct. 1921; RMCA.

Cubitermes modestior Silvestri, 1914

CÔTE D’IVOIRE • 1 soldier, 1 worker; Banco forest; 21 Aug. 1968; RMCA.

GUINEA • 1 q (queen), 1 soldier, 1 worker, syntypes; Kindia; 20 Aug. 1912; IEAP • 1 § (king), 1 soldier, 1 worker, syntypes; Kindia; 20 Aug. 1912; AMNH.

Cubitermes schmidti (Emerson, 1928)

CAMEROON $\bullet 1$ soldier, 1 worker, paratypes; Bipindi; 1920; RMCA 11 soldier, 1 worker, paratypes; Bipindi; 1920; AMNH.

Cubitermes severus Silvestri, 1914

BENIN • 1 q (queen), 5 soldiers, 5 workers (five samples); Birni forest; Nov. 2016; ULB.

BURKINA FASO • 1 soldier, 1 worker; Bama; 2012; ULB.

CAMEROON • 1 q (alate), $1 \hat{\jmath}$ (alate), 1 soldier, 1 worker; Batié; ULB $\bullet 1 \uparrow$ (alate), $1 \hat{\jmath}$ (alate), 1 soldier, 1 worker; Boulourou; ULB $\bullet 1$ ( (alate), 1 § (alate), 1 soldier, 1 worker; Ekoua; ULB 1 ㅇ (alate), 1 ठ (alate), 2 soldiers, 2 workers (two samples); Koutaba; ULB.

CÔTE D'IVOIRE • 1 soldier, 1 worker; Youhouli; 7 Sep. 1953; AMNH $\bullet 2$ soldiers, 2 workers (two samples); Dabou; 18 Feb. 2015; ULB $\bullet 1$ ㅇ (alate), 1 đ (alate), 2 soldiers, 1 worker (two samples); Korhogo; 2011-2013; ULB • 1 soldier, 1 worker; Katiola; Feb. 2015 • 1 q (queen), 3 soldiers, 3 workers (three samples); Man; Feb. 2015; ULB • 1 q (queen), 1 § (king), 2 soldiers, 2 workers (two samples); Zéalé; 18 Feb. 2015; ULB • 1 (alate), 3 soldiers, 3 workers (three samples); Lamto; 2010; ULB • 1 soldier, 1 worker; Lamto; 21 Feb. 2015; ULB • 1 soldier, 1 worker; Taabo; 21 Feb. 2015; ULB.

GAMBIA 1 soldier, 1 worker; Brikama; 7 Sep. 1953; ULB.

GUINEA • 2 soldiers, 2 workers, syntypes (two samples); Camayenne and Kakoulima; Aug.-Oct. 1912; AMNH $\bullet 1$ q (queen), 2 soldiers, 1 worker (two samples); Camayenne; 1934; MNHN • 1 soldier; Forecariah; 21 Jun. 1996; RMCA• 1 soldier, 1 worker; Haut-Niger National Park; 22 Dec. 1996; MURS.

Cubitermes silvestrii Sjöstedt, 1925

CAMEROON • 1 § (alate), 1 soldier, 1 worker; Genderu mounts; no date; AMNH.

CÔTE D’IVOIRE • 1 soldier, 1 worker; Ahoutoue; 9 Aug. 1969; RMCA. 
GUINEA • 1 soldier, 1 worker, syntypes; Kakoulima; 1912; AMNH.

SIERRA LEONE • 1 q (alate), 1 worker; 14 Jun. 1917; AMNH. • 1 soldier, 1 worker; Njala; 24 Aug. 1930; AMNH 1 \& (queen), 1 § (alate), 1 soldier, 1 worker; Njala; 29 May 1947; AMNH.

Cubitermes ugandensis Fuller, 1923

BURUNDI • 1 soldier, 1 worker; Moso; 4 Jul. 1989; RMCA • 1 soldier, 1 worker; Mahanga; 26 Nov. 2013; ULB • 1 soldier, 1 worker; Gisagara; 30 Nov. 2013; ULB • 1 q (alate), 1 ○ (alate), 3 soldiers, 3 workers (three samples); Ruvubu National Parc; 2014; ULB.

CENTRAL AFRICAN REPUBLIC • 1 soldier, 1 worker; Bangui; 30 Oct. 2010; ULB • 2 soldiers, 2 workers (two samples); Bondoé; Apr.-May 2007; ULB.

DEMOCRATIC REPUBLIC OF THE CONGO • 1 soldier, 1 worker; Kinshasa, Luki; 20 Sep. 1965; RMCA -2 soldiers, 1 worker (two samples); Uélé, Manda; Feb.-Mar. 1925; RMCA 3 q $q$ (queens),

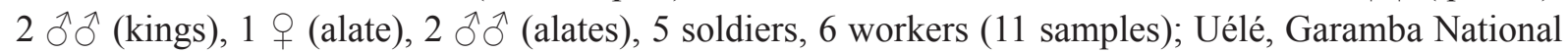
Park; 1951; RMCA • 2 soldiers, 2 workers (2 samples); Katanga, Mikembo; Feb. 2011-Jun. 2016; ULB.

RWANDA • 2 soldiers, 2 workers (two samples); Rukara; Jan.-Feb. 1953; RMCA.

UGANDA • 1 soldier, 1 worker, syntypes; 1921, AMNH.

Cubitermes zenkeri (Desneux, 1904)

CAMEROON $\bullet 1$ q (alate), 1 soldier, 1 worker, syntypes; 1904?; NHMM $\bullet 1$ q (queen), 1 q (alate), 1 soldier, 1 worker; Bipindi?; 1904?; AMNH.

The above were collected in West, Central and East Africa (Fig. 15D).

\section{Intermediate valve pattern group}

The crests on the odd PCs of the fungifaber valve pattern are sometimes weakly developed, especially in the soldiers' valves; their valves are then sometimes difficult to distinguish from the basic bilobatodes or muneris valve patterns.

\section{The finitimus valve pattern group}

In the worker's enteric valve, the primary cushions are of two types: the even PCs are similar to the PCs of the basic enteric valves but the odd PCs, in their downstream part, are wide and bear at that place a higher density of rather short bristles (Fig. 16A). The primary cushions, particularly the odd PCs, are roughly rectangular and rather wide, thus giving an impression of massiveness (in comparison with the other patterns): their lateral margins are almost parallel until the bristly part, where they are more or less narrowed (Fig. 11F). The bristly parts of the odd PCs are wider than they are high or globular (as high as they are wide) with a density of short bristles becoming abruptly high; as a consequence, on a microscope slide, these bulges are almost never twisted and can hardly be seen in profile (Fig. 11F'). The enteric valve thus shows triradial symmetry.

An odd PC is made of (a) an upstream spiny part (12-30\% of total length) with relatively strong spines, (b) a middle spiny part (39-62\% of total length) with somewhat weaker spines and with 17-37 lateral supporting bristles on each side, and (c) a bristly part (22-34\% of total length) with $75-125$ straight and rather short bristles on a bulge as wide as or wider than high; behind this area, the bristly part bears 20-30 large, curved or hooked bristles (Fig. 16A). 
The secondary cushions are wide at the upstream end, narrowing noticeably downstream with a homogeneous spine scattering (Fig. 16A).

In the soldier's enteric valve, the PCs are also relatively wide, and the bristly parts, although weakly developed, are always present and recognisable by the density of bristles becoming abruptly higher (Fig. 16B). The secondary cushions are like those of workers but bear less developed spines.

This basic valve pattern is therefore characterised by low and wide crests which are densely hairy on the downstream end of the odd PCs; most species are large.

\section{Material examined}

Twelve known and one unknown species, and a variety have such enteric valves:

Cubitermes bulbifrons Sjöstedt, 1924

DEMOCRATIC REPUBLIC OF THE CONGO • 1 soldier, 1 worker, syntypes; Bas-Congo, Mukimbungu; 1904?; AMNH.

Cubitermes congoensis (Emerson, 1928)

DEMOCRATIC REPUBLIC OF THE CONGO • 1 soldier, 1 worker, paratypes; Bas-Congo, Banana; Aug. 1915; AMNH.
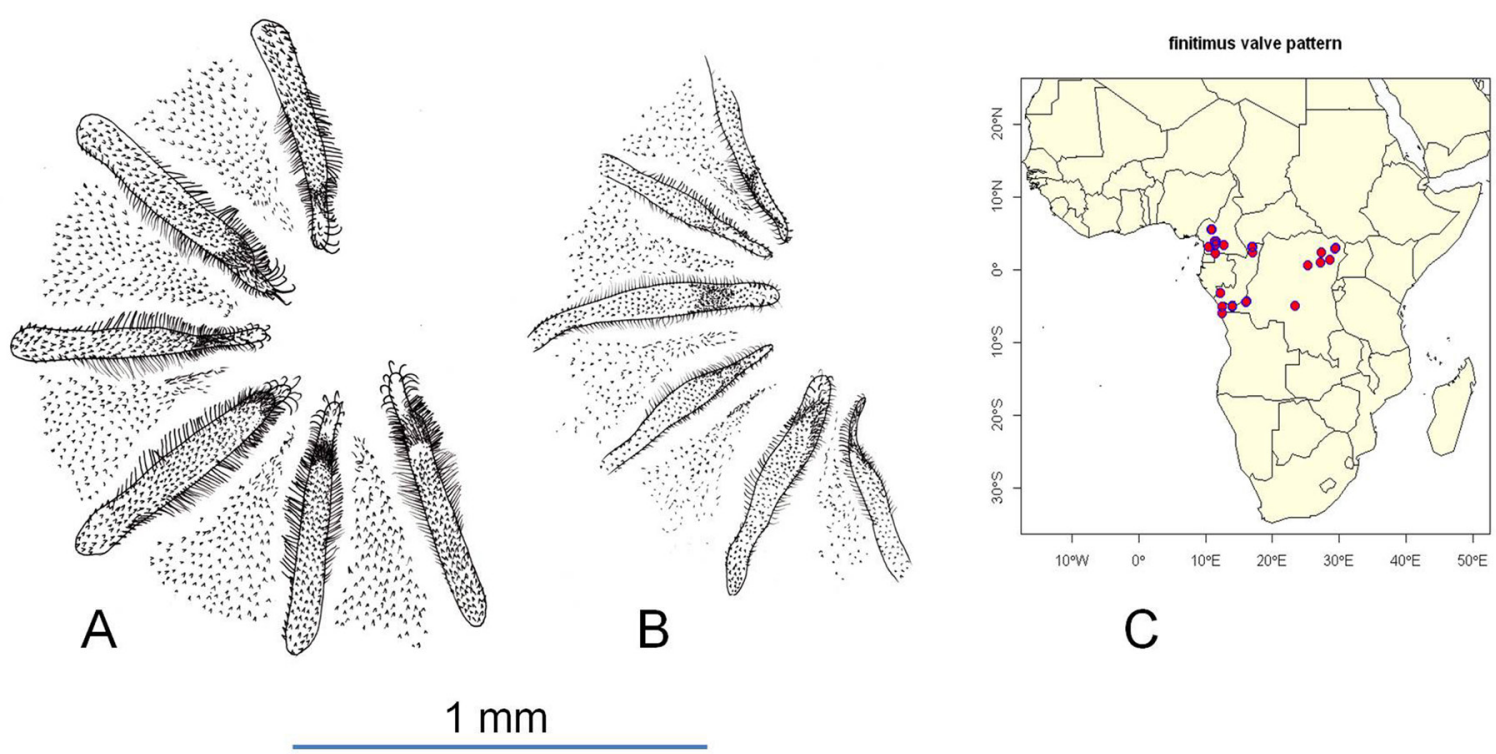

Fig. 16. A. Enteric valve of the "finitimus valve pattern", from a worker of Cubitermes finitimus Schmitz, 1915: note the high density of short setae on the bulges; B. Idem from a soldier of $C$. finitimus without any bulge but with a high density of short setae on the downstream part on the odd PCs; $\mathbf{C}$. Geographical distribution of the species with the finitimus valve pattern. 
Cubitermes finitimus Schmitz, 1915

DEMOCRATIC REPUBLIC OF THE CONGO • 1 q (queen), syntype; Tshopo, Kisangani; no date; $\mathrm{AMNH} \bullet 1$ q (queen), 1 soldier, 1 worker; Tshopo, Epulu; 15 May 1948; AMNH 11 q (queen), 1 q (alate), 1 đ (alate); Haut-Uélé, Moto; 1923; RMCA.

GABON • 1 soldier, 1 worker; Nkobissimo; 15 Apr. 2017; ULB.

Cubitermes fungifaber var. elongata Sjöstedt, 1924 (invalid name)

DEMOCRATIC REPUBLIC OF THE CONGO • 1 soldier, 1 worker, syntypes; Bas-Congo, Mukimbungu;

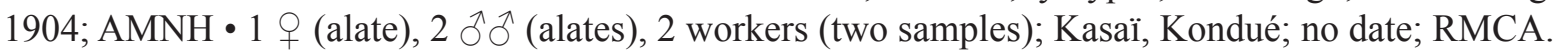

Cubitermes gaigei (Emerson, 1928)

CAMEROON • 1 soldier, 1 worker, paratypes; Bipindi; 1920; AMNH.

Cubitermes gibbifrons Sjöstedt, 1924

DEMOCRATIC REPUBLIC OF THE CONGO $\bullet 1$ soldier, 1 worker, syntypes; Bas-Congo, Mukimbungu;

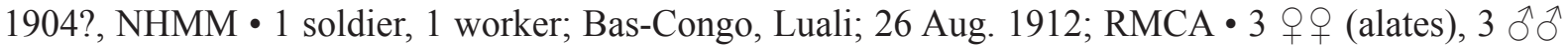
(alates), 3 soldiers, 4 workers (four samples); Kasaï, Kondué; 1924; RMCA.

Cubitermes heghi Sjöstedt, 1924

CAMEROON $\bullet 1$ soldier, 1 worker; Bipindi; 1920; RMCA 11 soldier, 1 worker; Mbalmayo; 17 Apr. 2015; ULB.

DEMOCRATIC REPUBLIC OF THE CONGO • 1 soldier, 1 worker, syntypes; Bas-Congo, Mukimbungu; 1904?; AMNH.

Cubitermes kemneri (Emerson, 1928)

CAMEROON • 1 soldier, 1 worker, paratypes; Bipindi; 1920; AMNH.

Cubitermes loubetsiensis Sjöstedt, 1924

CONGO • 1 soldier, syntype; Loubetsi; no date; NHMM • 1 soldier, 1 worker; Medje; Jun. 1914; RMCA.

Cubitermes planifrons Sjöstedt, 1924

CAMEROON • 1 q (queen), 1 soldier, 1 worker; Bipindi; 1920; AMNH • 1 soldier, 1 worker; Somalomo; 3 Mar. 2015; ULB.

DEMOCRATIC REPUBLIC OF THE CONGO • 1 soldier, 1 worker, syntypes; Bas-Congo, Mukimbungu; 1904?; AMNH.

Cubitermes speciosus Sjöstedt, 1924

DEMOCRATIC REPUBLIC OF THE CONGO • 1 q (queen), 1 soldier, 1 worker, syntypes; Haut-Uélé,

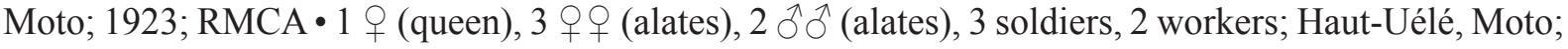
1920-1922; RMCA • 1 q (queen), 1 soldier, 1 worker; Kisangani, Masako reserve; 1990?; ULB.

Cubitermes subarquatus Sjöstedt, 1926

CAMEROON • 1 soldier, 1 worker; Kala; Apr. 1992; RMCA • 1 soldier, 1 worker; Nkolbison; Jun. 1992; RMCA.

DEMOCRATIC REPUBLIC OF THE CONGO 1 1 (queen), 1 soldier, 1 worker, syntypes; Lubila; 20 Sep. 1919; AMNH 1 soldier, 1 worker, syntypes; Lubila; 20 Sep. 1919; RMCA.

Unknown, new species

DEMOCRATIC REPUBLIC OF THE CONGO • 1 q (queen), 1 soldier, 1 worker; Kasaï, Kondué; 1905; RMCA 1 soldier, 1 worker; Kinshasa, Bateke Plateau, Duale; Jan. 2011; ULB • 1 soldier, 1 worker; Kinshasa, Bateke Plateau, Bombo-Lumene reserve; 22 Apr. 2017; ULB.

The above were all collected only in Central Africa (Fig. 16C). 
Table 5. Ranges of measurements taken of the enteric valves of 427 soldiers and 410 workers in 73 taxa, including some possible synonyms and some possible new species (in alphabetical order of the "Code" column); comparison between patterns.

\begin{tabular}{|c|c|c|c|c|c|c|c|c|c|c|}
\hline & $\begin{array}{l}\text { Valve } \\
\text { pattern }\end{array}$ & $\begin{array}{l}\text { biloba- } \\
\text { tus }\end{array}$ & $\begin{array}{l}\text { biloba- } \\
\text { todes }\end{array}$ & $\begin{array}{c}\text { mune- } \\
\text { ris }\end{array}$ & $\begin{array}{l}\text { fungi- } \\
\text { faber }\end{array}$ & $\begin{array}{c}\text { finiti- } \\
\text { mus }\end{array}$ & $\begin{array}{c}\text { ocula- } \\
\text { tus }\end{array}$ & $\begin{array}{l}\text { sanku- } \\
\text { rensis }\end{array}$ & $\begin{array}{c}\text { oblec- } \\
\text { tatus }\end{array}$ & $\begin{array}{l}\text { sulci- } \\
\text { frons }\end{array}$ \\
\hline Soldiers & Sample size & 28 & 31 & 25 & 107 & 34 & 22 & 147 & 10 & 23 \\
\hline Soldiers: indices \& averages & Code & Ratio & Ratio & Ratio & Ratio & Ratio & Ratio & Ratio & Ratio & Ratio \\
\hline $\begin{array}{l}\text { Valve: bilateral symmetry } \\
\text { index }\end{array}$ & SVP1-Bil & $\begin{array}{c}0.96- \\
1.61\end{array}$ & $\begin{array}{l}0.93- \\
1.35\end{array}$ & $\begin{array}{c}0.96- \\
1.40\end{array}$ & $\begin{array}{c}0.95- \\
1.41\end{array}$ & $\begin{array}{c}0.96- \\
1.33\end{array}$ & $\begin{array}{c}1.33- \\
1.88\end{array}$ & $\begin{array}{c}0.80- \\
1.72\end{array}$ & $\begin{array}{c}0.80- \\
1.23\end{array}$ & $\begin{array}{c}0.96- \\
1.21\end{array}$ \\
\hline $\begin{array}{l}\text { Valve: PC1 pre-eminence } \\
\text { index }\end{array}$ & SVP1-Pre & $\begin{array}{c}1.03- \\
1.58\end{array}$ & $\begin{array}{c}1.07- \\
1.41\end{array}$ & $\begin{array}{c}1.14- \\
1.54\end{array}$ & $\begin{array}{c}0.98- \\
1.70\end{array}$ & $\begin{array}{l}1.00- \\
1.46\end{array}$ & $\begin{array}{c}1.26- \\
1.95\end{array}$ & $\begin{array}{c}0.81- \\
1.69\end{array}$ & $\begin{array}{c}0.83- \\
1.25\end{array}$ & $\begin{array}{c}0.97- \\
1.28\end{array}$ \\
\hline Valve: alternation index & SVP-Alt & $\begin{array}{c}0.82- \\
1.44\end{array}$ & $\begin{array}{c}1.06- \\
1.51\end{array}$ & $\begin{array}{c}1.09- \\
1.75\end{array}$ & $\begin{array}{c}0.89- \\
1.70\end{array}$ & $\begin{array}{l}1.00- \\
1.39\end{array}$ & $\begin{array}{l}1.00- \\
1.42\end{array}$ & $\begin{array}{c}0.86- \\
1.42\end{array}$ & $\begin{array}{l}0.86- \\
1.23\end{array}$ & $\begin{array}{c}0.93- \\
1.22\end{array}$ \\
\hline Valve: average cushion length & SVP-AvL & $\begin{array}{c}0.31- \\
0.49\end{array}$ & $\begin{array}{c}0.48- \\
0.68\end{array}$ & $\begin{array}{c}0.41- \\
0.70\end{array}$ & $\begin{array}{c}0.32- \\
0.74\end{array}$ & $\begin{array}{c}0.37- \\
0.69\end{array}$ & $\begin{array}{c}0.35- \\
0.45\end{array}$ & $\begin{array}{c}0.41- \\
0.72\end{array}$ & $\begin{array}{c}0.62- \\
0.82\end{array}$ & $\begin{array}{c}0.57- \\
0.79\end{array}$ \\
\hline $\begin{array}{l}\text { Valve: odd PC elongation } \\
\text { index }\end{array}$ & $\begin{array}{l}\text { SVPOdd- } \\
\text { Elg }\end{array}$ & $\begin{array}{c}5.39- \\
10.1 \\
\end{array}$ & $\begin{array}{c}7.36- \\
13.5 \\
\end{array}$ & $\begin{array}{c}8.89- \\
15.8\end{array}$ & $\begin{array}{c}5.52- \\
13.6 \\
\end{array}$ & $\begin{array}{c}5.10- \\
9.19\end{array}$ & $\begin{array}{l}4.97- \\
8.47\end{array}$ & $\begin{array}{c}5.20- \\
12.3 \\
\end{array}$ & $\begin{array}{c}8.55- \\
11.9\end{array}$ & $\begin{array}{c}6.02- \\
14.4\end{array}$ \\
\hline Workers & Sample size & 24 & 29 & 22 & 103 & 34 & 21 & 144 & 10 & 23 \\
\hline Workers: counts & Code & Number & Number & Number & Number & Number & Number & Number & Number & Number \\
\hline $\begin{array}{l}\text { Valve: number of bristles on } \\
\text { PC1downstream part }\end{array}$ & WVP1NDB & $15-60$ & $35-75$ & $50-75$ & $35-85$ & $75-125$ & $30-50$ & $40-110$ & $70-160$ & $45-110$ \\
\hline $\begin{array}{l}\text { Valve: number of lateral } \\
\text { supporting bristles on PC1 } \\
\text { (one side) }\end{array}$ & WVP1NLB & $3-6$ & $10-30$ & $10-19$ & $13-30$ & $17-37$ & $3-15$ & $8-24$ & $16-23$ & $14-23$ \\
\hline $\begin{array}{c}\text { Workers: linear } \\
\text { measurements }\end{array}$ & Code & mm & $\mathbf{m m}$ & mm & mm & mm & mm & mm & mm & mm \\
\hline $\begin{array}{l}\text { Valve: length of downstream } \\
\text { bristly part of PC1 }\end{array}$ & WVP1DL & $\begin{array}{c}0.16- \\
0.31\end{array}$ & $\begin{array}{c}0.15- \\
0.25\end{array}$ & $\begin{array}{c}0.14- \\
0.26\end{array}$ & $\begin{array}{c}0.13- \\
0.29\end{array}$ & $\begin{array}{c}0.14- \\
0.22\end{array}$ & $\begin{array}{c}0.09- \\
0.28\end{array}$ & $\begin{array}{c}0.13- \\
0.39\end{array}$ & $\begin{array}{c}0.21- \\
0.32\end{array}$ & $\begin{array}{c}0.09- \\
0.19\end{array}$ \\
\hline Valve: length of PC1 & WVP1L & $\begin{array}{c}0.50- \\
0.73\end{array}$ & $\begin{array}{c}0.53- \\
0.95\end{array}$ & $\begin{array}{c}0.55- \\
1.04\end{array}$ & $\begin{array}{c}0.45- \\
0.97\end{array}$ & $\begin{array}{c}0.54- \\
0.88\end{array}$ & $\begin{array}{c}0.65- \\
0.82\end{array}$ & $\begin{array}{c}0.56- \\
1.01\end{array}$ & $\begin{array}{c}0.70- \\
0.94\end{array}$ & $\begin{array}{c}0.61- \\
0.86\end{array}$ \\
\hline $\begin{array}{l}\text { Valve: length of middle spiny } \\
\text { part of PC1 }\end{array}$ & WVP1ML & $\begin{array}{c}0.05- \\
0.16\end{array}$ & $\begin{array}{c}0.12- \\
0.40\end{array}$ & $\begin{array}{c}0.12- \\
0.29\end{array}$ & $\begin{array}{c}0.17- \\
0.44\end{array}$ & $\begin{array}{c}0.21- \\
0.53\end{array}$ & $\begin{array}{c}0.04- \\
0.20\end{array}$ & $\begin{array}{c}0.10- \\
0.44\end{array}$ & $\begin{array}{c}0.28- \\
0.38\end{array}$ & $\begin{array}{c}0.18- \\
0.35\end{array}$ \\
\hline $\begin{array}{l}\text { Valve: length of upstream } \\
\text { spiny part of PC1 }\end{array}$ & WVP1UL & $\begin{array}{c}0.18- \\
0.40\end{array}$ & $\begin{array}{c}0.18- \\
0.37\end{array}$ & $\begin{array}{c}0.32- \\
0.57\end{array}$ & $\begin{array}{c}0.10- \\
0.37\end{array}$ & $\begin{array}{c}0.07- \\
0.21\end{array}$ & $\begin{array}{c}0.28- \\
0.54\end{array}$ & $\begin{array}{c}0.08- \\
0.41\end{array}$ & $\begin{array}{c}0.12- \\
0.28\end{array}$ & $\begin{array}{c}0.11- \\
0.32\end{array}$ \\
\hline Valve: width of PC1 & WVP1W & $\begin{array}{c}0.05- \\
0.12 \\
\end{array}$ & $\begin{array}{c}0.04 \\
0.11\end{array}$ & $\begin{array}{c}0.04- \\
0.08\end{array}$ & $\begin{array}{c}0.04- \\
0.11 \\
\end{array}$ & $\begin{array}{c}0.06- \\
0.12\end{array}$ & $\begin{array}{c}0.05- \\
0.12\end{array}$ & $\begin{array}{c}0.05- \\
0.15 \\
\end{array}$ & $\begin{array}{c}0.08- \\
0.13\end{array}$ & $\begin{array}{c}0.07- \\
0.12\end{array}$ \\
\hline Workers: indices \& averages & Code & Ratio & Ratio & Ratio & Ratio & Ratio & Ratio & Ratio & Ratio & Ratio \\
\hline $\begin{array}{l}\text { Valve: bilateral symmetry } \\
\text { index }\end{array}$ & WVP1-Bil & $\begin{array}{c}0.95- \\
1.46\end{array}$ & $\begin{array}{c}0.94 \\
1.24\end{array}$ & $\begin{array}{c}0.96- \\
1.28\end{array}$ & $\begin{array}{c}0.94 \\
1.33\end{array}$ & $\begin{array}{c}0.96- \\
1.34\end{array}$ & $\begin{array}{c}1.36- \\
1.74\end{array}$ & $\begin{array}{c}0.95- \\
1.56\end{array}$ & $\begin{array}{c}0.94- \\
1.17\end{array}$ & $\begin{array}{c}0.95- \\
1.25\end{array}$ \\
\hline $\begin{array}{l}\text { Valve: PC1 pre-eminence } \\
\text { index }\end{array}$ & WVP1-Pre & $\begin{array}{c}0.98- \\
1.46\end{array}$ & $\begin{array}{c}1.06- \\
1.40\end{array}$ & $\begin{array}{c}1.12- \\
1.48\end{array}$ & $\begin{array}{c}0.96- \\
1.37\end{array}$ & $\begin{array}{c}0.97- \\
1.38\end{array}$ & $\begin{array}{c}1.31- \\
1.74\end{array}$ & $\begin{array}{c}0.94- \\
1.52\end{array}$ & $\begin{array}{c}0.96- \\
1.18\end{array}$ & $\begin{array}{l}0.98- \\
1.25\end{array}$ \\
\hline Valve: alternation index & WVP-Alt & $\begin{array}{c}0.94 \\
1.43\end{array}$ & $\begin{array}{c}1.13- \\
1.47\end{array}$ & $\begin{array}{c}1.24- \\
1.63\end{array}$ & $\begin{array}{c}0.91- \\
1.31\end{array}$ & $\begin{array}{c}0.96- \\
1.29\end{array}$ & $\begin{array}{c}0.97- \\
1.37\end{array}$ & $\begin{array}{c}0.83- \\
1.28\end{array}$ & $\begin{array}{c}0.94- \\
1.17\end{array}$ & $\begin{array}{c}0.93- \\
1.14\end{array}$ \\
\hline Valve: average length of PCs & WVP-AvL & $\begin{array}{c}0.43- \\
0.63\end{array}$ & $\begin{array}{c}0.47- \\
0.78\end{array}$ & $\begin{array}{c}0.44- \\
0.82\end{array}$ & $\begin{array}{c}0.42- \\
0.87\end{array}$ & $\begin{array}{c}0.46- \\
0.79\end{array}$ & $\begin{array}{c}0.44- \\
0.59\end{array}$ & $\begin{array}{c}0.49- \\
0.84\end{array}$ & $\begin{array}{c}0.67- \\
0.88\end{array}$ & $\begin{array}{c}0.54- \\
0.82\end{array}$ \\
\hline Valve: average width of PCs & WVP-AvW & $\begin{array}{c}0.06- \\
0.09\end{array}$ & $\begin{array}{c}0.05- \\
0.10\end{array}$ & $\begin{array}{c}0.04- \\
0.08\end{array}$ & $\begin{array}{c}0.04 \\
0.10\end{array}$ & $\begin{array}{c}0.06- \\
0.10\end{array}$ & $\begin{array}{c}0.05- \\
0.08\end{array}$ & $\begin{array}{c}0.05- \\
0.12\end{array}$ & $\begin{array}{c}0.07- \\
0.12\end{array}$ & $\begin{array}{c}0.07- \\
0.12\end{array}$ \\
\hline $\begin{array}{l}\text { Valve: odd PC elongation } \\
\text { index }\end{array}$ & $\begin{array}{l}\text { WVPOdd- } \\
\text { Elg }\end{array}$ & $\begin{array}{c}5.07- \\
10.0\end{array}$ & $\begin{array}{c}6.94 \\
13.1\end{array}$ & $\begin{array}{c}9.99- \\
16.4\end{array}$ & $\begin{array}{c}6.83- \\
12.7\end{array}$ & $\begin{array}{c}5.47- \\
10.2\end{array}$ & $\begin{array}{c}6.01- \\
10.4\end{array}$ & $\begin{array}{c}5.21- \\
11.3\end{array}$ & $\begin{array}{c}6.61- \\
9.89\end{array}$ & $\begin{array}{c}5.84- \\
10.9\end{array}$ \\
\hline Valve: average length of SCs & WVS-AvL & $\begin{array}{c}0.31- \\
0.50\end{array}$ & $\begin{array}{c}0.31- \\
0.73\end{array}$ & $\begin{array}{c}0.42- \\
0.74\end{array}$ & $\begin{array}{c}0.38- \\
0.71\end{array}$ & $\begin{array}{c}0.37- \\
0.64\end{array}$ & $\begin{array}{c}0.17- \\
0.39\end{array}$ & $\begin{array}{c}0.32- \\
0.62\end{array}$ & $\begin{array}{c}0.51- \\
0.70\end{array}$ & $\begin{array}{c}0.42- \\
0.58\end{array}$ \\
\hline Valve: average width of SCs & WVS-AvW & $\begin{array}{c}0.10- \\
0.24\end{array}$ & $\begin{array}{c}0.13- \\
0.38\end{array}$ & $\begin{array}{c}0.17- \\
0.34\end{array}$ & $\begin{array}{c}0.18- \\
0.50\end{array}$ & $\begin{array}{c}0.19- \\
0.32\end{array}$ & $\begin{array}{c}0.03- \\
0.10\end{array}$ & $\begin{array}{c}0.05- \\
0.11\end{array}$ & $\begin{array}{c}0.17- \\
0.21\end{array}$ & $\begin{array}{c}0.10- \\
0.18\end{array}$ \\
\hline Valve: SC elongation index & WVS-Elg & $\begin{array}{c}1.72- \\
3.91\end{array}$ & $\begin{array}{c}1.40- \\
3.48\end{array}$ & $\begin{array}{c}1.62- \\
3.00\end{array}$ & $\begin{array}{c}1.22- \\
2.60\end{array}$ & $\begin{array}{c}1.43- \\
2.27\end{array}$ & $\begin{array}{c}5.34- \\
11.1\end{array}$ & $\begin{array}{c}4.29- \\
8.75\end{array}$ & $\begin{array}{c}2.56- \\
3.62\end{array}$ & $\begin{array}{c}2.65- \\
5.02\end{array}$ \\
\hline Valve: SC to PC width index & WVS/WVP & $\begin{array}{c}1.28- \\
3.55\end{array}$ & $\begin{array}{c}1.58- \\
5.18\end{array}$ & $\begin{array}{c}2.95- \\
5.80\end{array}$ & $\begin{array}{c}2.77- \\
6.20\end{array}$ & $\begin{array}{c}2.55- \\
4.79\end{array}$ & $\begin{array}{c}0.33- \\
1.72\end{array}$ & $\begin{array}{c}0.62- \\
1.49\end{array}$ & $\begin{array}{c}1.53- \\
2.85\end{array}$ & $\begin{array}{c}0.97- \\
2.29\end{array}$ \\
\hline
\end{tabular}




\section{Intermediate valve pattern group}

Some samples show an intermediate pattern between the fungifaber and the finitimus valve patterns (within the species C. severus, C. silvestrii and C. ugandensis).

\section{The oculatus valve pattern group}

The workers within this pattern have basic enteric valves (Fig. 17A): all six primary cushions are similar in their arrangement but not in their sizes.

The primary cushions are roughly triangular: their largest width is generally located near their upstream end and their lateral margins converge gradually downstream until the bristly part, where they remain parallel (Fig. 11B). The enteric valve shows bilateral symmetry, PC1 being much longer and often wider than the other PCs (WVP1-Pre > 1.30) (Fig. 17A).

PC1 is made of (a) an upstream spiny part (40-66\% of total length) with relatively strong spines, (b) a middle spiny part (10-27\% of total length) with somewhat weaker spines and generally with 5-8 lateral supporting bristles on each side, and (c) a bristly part (22-38\% of total length) with 30-50 straight, curved and eventually hooked bristles (Fig. 11B).

The secondary cushions, near their upstream end, are never wider than the primary cushions; however, in some cases, they widen in their downstream, bristly, fuzzy parts (Figs 4G, 17A). The secondary cushions SC12 and SC61 (on both sides of PC1) are often faint or may be totally lacking (Fig. 17A).

In the soldier's enteric valve, the primary cushions are well outlined except at their upstream end; PC1 is much longer than the other primary cushions (SVP1-Pre $>1.25$ ) and often substantially widened
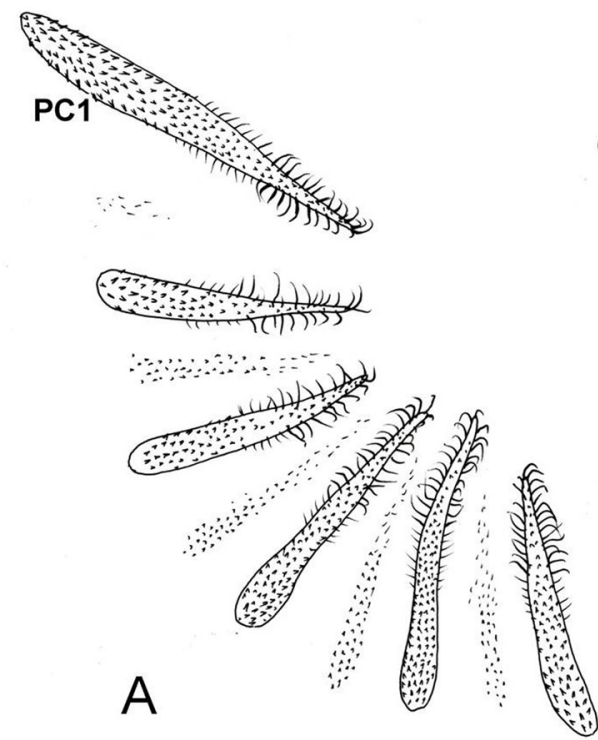
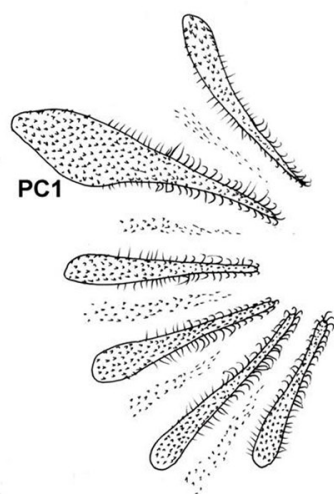

B

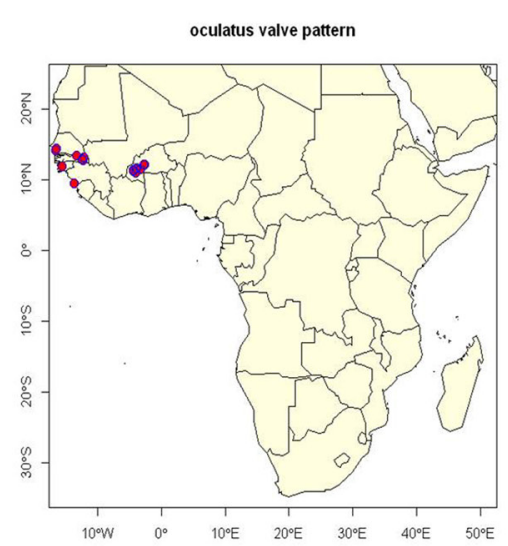

C

Fig. 17. A. Enteric valve of the "oculatus valve pattern" from a worker of Cubitermes sp.: note the narrowness of the secondary cushion, almost faint in the case of SC61 (SC12 is not figured); B. Idem from a soldier of the same sample of $C$. sp., note the widening of PC1; C. Geographical distribution of the species with the oculatus valve pattern. 
between the first upstream quarter and the middle (Fig. 17B). The secondary cushions are like those of workers but bear less developed spines.

This basic valve pattern is characterised by a long PC1 and therefore by high bilateral symmetry and $\mathrm{PC} 1$ pre-eminence indices in both soldiers and workers, and by the high elongation index of the workers' SCs (Table 5); most species are small.

\section{Material examined}

Two species have such enteric valves:

Cubitermes niokoloensis Roy-Noël, 1969

SENEGAL • 1 \& (alate), 1 soldier, paratypes; Bangare-Niokolo-Koba road; Jan. 1965; AMNH.

Cubitermes oculatus Silvestri, 1914

GUINEA • 1 q (queen), 1 soldier, 1 worker, syntypes; Camayenne; 12 Oct. 1912; IEAP.

The so-called 'miles minor' (minor soldier) of C. bilobatodes Silvestri, 1912 also has this form of enteric valve (mixed type series) (MCGD, AMNH).

Undetermined samples in C. oculatus valve pattern group

BURKINA FASO • 1 soldier, 1 worker; Pâ; 16 Jul. 2014; ULB • 3 soldiers, 3 workers (three samples); Tiogo; Aug. 2016; ULB • 2 soldiers, 2 workers (two samples); Bana; Aug. 2016; ULB • 2 soldiers, 2 workers (two samples); Bama; Aug. 2016; ULB • 1 soldier, 1 worker; Bala; 18 Jul. 2014; ULB • 1 soldier, 1 worker; Bekuy; Aug. 2016; ULB.

SENEGAL • 1 soldier, 1 worker; Kedougou; 23 May 2014; ULB $・ 1$ soldier, 1 worker; Sabodala; 17 Aug. 2009; ULB • 1 q (alate), 1 soldier, 1 worker; Fimela; 24 Apr. 2010; ULB • 1 soldier, 1 worker; Diouroup; 19 Nov. 2016; ULB • 2 soldiers, 2 workers; Wassadou (two samples); 22 Nov. 2016; ULB • 1 soldier, 1 worker; Casamance, Bougnery; 11 Jul. 2017; ULB.

The above were only collected in West African rather dry savannas (Fig. 18C).

\section{The sankurensis valve pattern group}

The worker within this pattern has an enteric valve with two primary cushions, normally PC3 and PC4, ending downstream in two yellow to brown sclerotised spatulae which look like two jaws ("valvule à mâchoires" in Bouillon \& Vincke 1971; fig. 11G) sticking out of the valve (Fig. 18E-F); the jawlike spatulae may as an exception be borne either by PC4 and PC5 (two occurrences on 148 workers examined) or by PC5 and PC6 (one occurrence). The other primary cushions are roughly triangular: their largest width is generally located near the upstream fourth, and their lateral margins converge gradually downstream. PC1 is often clearly longer than PC2, PC5 and PC6 (and may be longer or shorter than PC3 and PC4 depending on the species), not resulting in any kind of symmetry. Unopened, the valve seen in profile is more or less strongly concave on the side (Fig. 18E); on a microscope slide, it is sometimes difficult to flatten this kind of valve.

A PC1 is made of (a) an upstream spiny part of variable length (13-49\% of total length) with relatively strong spines, (b) a middle spiny part (18-48\% of total length) with somewhat weaker spines and with 9-24 lateral supporting bristles on each side, and (c) a bristly part (24-43\% of total length) with 40-110 straight, curved and hooked bristles (Fig. 18A).

A PC ending in a spatula (PC3 or PC4) is made of (a) an upstream spiny part (12-37\% of total length) with relatively strong spines, (b) a middle spiny part (18-49\% of total length) with somewhat weaker 
spines and with 10-23 lateral supporting bristles on each side, (c) a bristly part (12-36\% of total length) with 35-80 straight bristles on a low bulge, and (d) an asymmetric, sclerotised spatula (15-33\% of total length) with a rounded side bearing a few short curved bristles and an almost straight side with numerous short tooth-like spines; in situ, the two spatulae are close together and their denticulate sides face each other (Fig. 18F). The other PCs are similar to the PCs of a basic enteric valve.

The secondary cushions, in their upstream, spiny parts are generally not wider than the primary cushions; if they are somewhat wider, they do not exceed the PC width by more than $20 \%$. Their largest width is sometimes located near the upstream fourth or third and they narrow gradually downstream; however, in many cases they widen in their downstream, bristly, fuzzy parts (Fig. 18A). In some species SC12
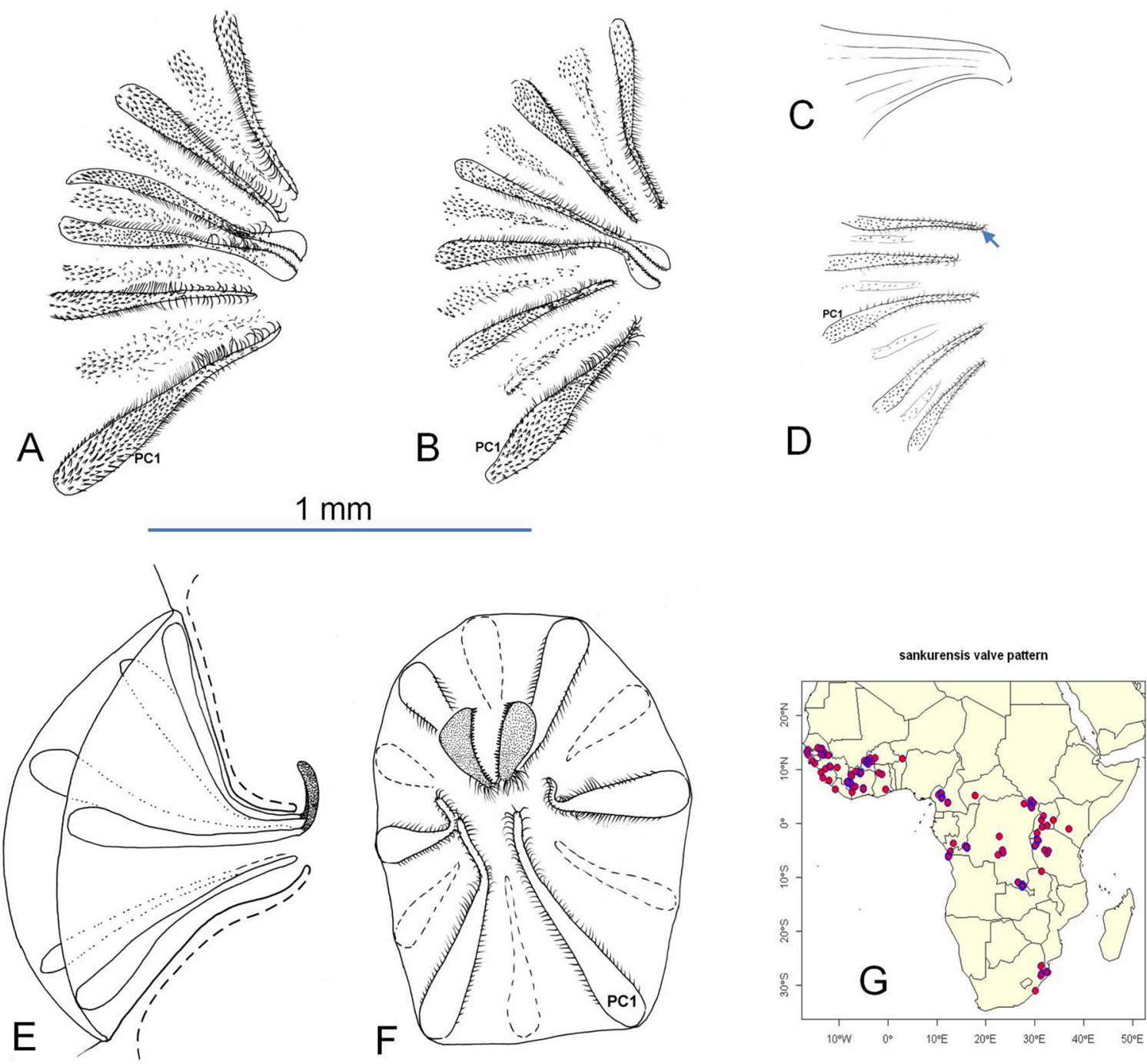

Fig. 18. A. Enteric valve of the "sankurensis valve pattern", from a worker of Cubitermes sankurensis Wasmann, 1911: note the narrowness of the secondary cushions in their upstream thirds; B. Idem from a soldier of C. sankurensis; C. Idem from an imago, unopened and seen in profile, of C. orthognathus (Emerson, 1928); D. The same as C, opened: the spatula on PC3 is only sketched (arrow), PC4 is lacking (damaged); E. Idem from a worker of C. proximatus Silvestri, 1914, unopened and seen in profile, the spatulae stick out of the valve into the second paunch, the contour of which is marked as a dotted line; F. The same as E unopened and seen from behind; A to F at the same scale; G. Geographical distribution of species with the sankurensis valve pattern. 
and/or SC61 are weakly developed (Fig. 18A) and fuzzy: they can be wider than PC1 but bear very few scattered spines and/or bristles.

In the soldier's enteric valve, the two spatulae on PC3 and PC4 are always present, but sometimes weakly developed; the primary cushions are more slender than in the worker, but PC1 is frequently widened between the first third and the middle (Fig. 18B). The secondary cushions are like those of workers but bear less developed spines.

In the imago's enteric valve, the two spatulae on PC3 and PC4 are either absent or simply indicated; unopened, the valve is slightly curved at its downstream end (Fig. 18C-D).

This valve pattern is therefore characterised by two spatulae in the workers' and soldiers' valves and by the high elongation index of the workers' SCs (Table 5); most species are small.

\section{Material examined}

Seventeen known species and varieties and probably two unknown species have such enteric valves:

Cubitermes aemulus Silvestri, 1914

GUINEA $\bullet 1$ q (queen), 1 ○ (king), 1 soldier, 1 worker, syntypes; Camayenne; 1912; IEAP $\bullet 1$ + (queen), 1 q (alate), $1 \widehat{\partial}$ (alate), $1 \widehat{\partial}$ (king), 2 soldiers, 2 workers (two samples); Camayenne; 1934; MNHN.

Cubitermes anatruncatus (Fuller, 1925)

REPUBLIC OF SOUTH AFRICA • 1 soldier, lectotype (designated by Ruelle 1971); Kwazulu-Natal, Conjeni; 29 Jul. 1921; PPRI, registration number: TYPH 02119 • 1 क (alate), 1 ô (alate), 1 soldier, 1 worker, paralectotypes; Kwazulu-Natal, Conjeni; 29 Jul. 1921; PPRI.

Cubitermes cubicephalus (Sjöstedt, 1913)

DEMOCRATIC REPUBLIC OF THE CONGO • 1 q (queen), 1 soldier, 1 worker, syntypes; Kasaï, Kananga; 1912; RMCA 1 soldier, 1 worker; Bas-Congo, near Banana; RMCA 11 soldier, 1 worker; Kasaï, Bunkonde; 1912; RMCA • 1 ㅇ (queen), 1 soldier, 1 worker; Haut-Uele, Manda; 27 Feb. 1925; RMCA.

Cubitermes curtatus Silvestri, 1914:

BURKINA FASO • 1 soldier, 1 worker; Pâ; 16 Jul. 2014; ULB • 1 soldier, 1 worker; Bala; 18 Jul. 2014; ULB.

GUINEA 1 1 (queen), 1 (king), 1 soldier, 1 worker, syntypes (two samples); Kindia and Mamou; 22-26 Aug. 1912; IEAP.

SENEGAL • 1 soldier, 1 worker; Tambacounda; 24 May 2014; ULB • 1 soldier, 1 worker; Kedougou; 23 May 2014; ULB.

Cubitermes duplex forma nduma Fuller, 1925

REPUBLIC OF SOUTH AFRICA • 1 \& (alate), lectotype (designated by Ruelle 1971); Eastern Cape, Nduma; 20 Sep. 1922; PPRI, registration number: TYPH $02127 \cdot 1$ ^ (alate), paralectotype; Eastern Cape, Nduma; 20 Sep. 1922; PPRI.

Cubitermes fulvus Williams, 1966

BURUNDI • 1 soldier, 1 worker; Buga; 26 Nov. 2013; ULB • 1 soldier, 1 worker; Ruvubu National Park; 29 Nov. 2013; ULB. 
TANZANIA $• 1$ đ (alate), 1 soldier, 1 worker, paratypes; Kakoma; 19 Sep. 1948; NHMUK 1 q (queen), $1 \widehat{\jmath}$ (king), 1 soldier, 1 worker, paratypes; near Igalulu; 21 Dec. 1934; NHMUK.

Cubitermes orthognathus (Emerson, 1928)

BURUNDI • 1 q (queen), 1 (king), 2 soldiers, 2 workers (two samples); Gihofi-Giharo road; 27 Nov. 2013; ULB • 1 soldier, 1 worker; Gisagara; 30 Nov. 2013; ULB • 1 क (queen), 1 ठ (king), 3 soldiers, 3 workers (three samples); Ruvubu National Park; 29 Nov. 2013; ULB • 4 soldiers, 4 workers (four samples); Ruvubu National Park; 2014; ULB.

DEMOCRATIC REPUBLIC OF THE CONGO • 1 soldier, 1 worker, paratypes; Haut-Uélé, Faradje; 1912; RMCA • 1 worker, paratype; Haut-Uélé, Faradje; 1912; PPRI • 2 soldiers, 2 workers (two

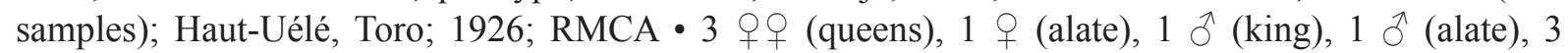
soldiers, 3 workers (six samples); Haut-Uélé, Garamba National Park; 1950-1951; RMCA 1 soldier, 1 worker; Mikembo; 21 Dec. 2011; ULB.

KENYA • 1 (alate), 1 soldier, 1 worker; 7 Aug. 2015; ULB.

RWANDA 1 1 (queen), 1 soldier, 1 worker; Kinazi; 8 Jan. 1953; RMCA.

UGANDA • 1 (queen), 1 soldier, 1 worker; Bugiri; 8 Aug. 1957; RMCA.

Cubitermes proximatus Silvestri, 1914

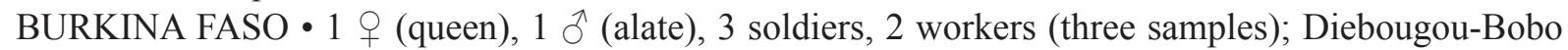
road; 1934; MNHN • 1 q (queen), 3 soldiers, 3 workers (three samples); Bobo-Dioulasso; 1934; Aug. 2016; ULB • 1 soldier, 1 worker; Banfora; 17 Jul. 2014; ULB.

CÔTE D'IVOIRE • 1 soldier, 1 worker; Sipilou; 17 Apr. 1968; RMCA $\bullet 7$ soldiers, 5 workers (seven samples); region of Korhogo; 2013; ULB • 1 + (alate), 1 đ (alate), 1 soldier, 1 worker; Sangouiné; Feb. 2015; ULB • 2 우우 (alates), 2 § $\widehat{\jmath}$ (alates), 2 soldiers, 2 workers (two samples); Korhogo; Feb. 2015; ULB 1 1 (alate), 1 đ̂ (alate), 1 soldier, 1 worker; Boundiali-Odienné road; Feb. 2015; ULB.

GAMBIA 1 1 soldier, 1 worker; Brikama; 1 Nov. 2013; ULB.

GUINEA 1 1 (queen), $1 \widehat{\jmath}$ (king), 1 ( alate), 1 soldier, 1 worker, syntypes; Kindia and Mamou; Aug. 1912; IEAP 1 1 (king), 1 soldier, 1 worker; Camayenne; 1934; MNHN.

GUINEA BISSAU • 1 soldier, 1 worker (two samples); Bolama; 6 Dec. 1899; MCGD.

SENEGAL • 1 soldier, 1 worker; Dienoudiala; 22 Nov. 2016; ULB • 1 soldier, 1 worker; Malem Niani; 20 Nov. 2016; ULB • 1 soldier, 1 worker; Samékouta; 22 Nov. 2016; ULB • 1 soldier, 1 worker; Botou; 21 Nov. 2016; ULB • 1 soldier, 1 worker; Ngari; 22 Nov. 2016; ULB • 1 soldier, 1 worker; Kedougou; 16 Jul. 2007; ULB • 1 ㅇ (alate), 1 ô (alate), 1 soldier, 1 worker; Karang; 22 May 2014; ULB.

Cubitermes sankurensis Wasmann, 1911

ANGOLA • 1 q (alate), 1 soldier, 1 worker; Sant Antonio; Aug. 1915; RMCA.

BURUNDI • 1 soldier, 1 worker; Gisagara; 30 Nov. 2013; ULB • 1 q (queen), 1 soldier, 1 worker; Mahanga; 26 Nov. 2013; ULB.

CAMEROON • 1 soldier, 1 worker; Boulourou; 9 Apr. 1915; ULB.

DEMOCRATIC REPUBLIC OF THE CONGO • 1 soldier, 1 worker, syntypes; Kasaï, Kondué; 1905; RMCA $\bullet 1$ q (queen), $1 \hat{\jmath}$ (king), 1 q (alate), $1 \hat{\jmath}$ (alate), 3 soldiers, 3 workers (three samples); Haut- 
Uélé, Garamba National Park; 1950-1952; RMCA • 1 q (alate), 1 soldier, 1 worker; Haut-Uélé, Niangara; Mar. 1948; RMCA • 1 q (queen), 1 soldier, 1 worker; Haut-Uélé, Manda; 27 Feb. 1925;

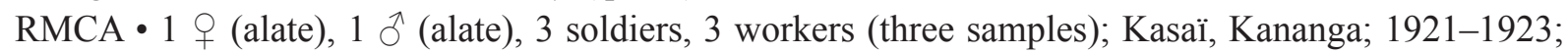
RMCA 11 soldier, 1 worker; Bas-Congo, near Boma; 30 Mar. 1971; RMCA 11 soldier, 1 worker; BasCongo, Mbata-Mbenge; 7 Aug. 1962; RMCA 11 त (alate), 2 soldiers, 2 workers (two samples); BasCongo, Banana; Jul.-Aug. 1920; RMCA 1 क (queen), 1 ô (king), 2 soldiers, 2 workers (two samples); Kinshasa, Bateke Plateau; Aug. 1959; RMCA $\bullet 2$ q (queens), 1 ô (king), 2 soldiers, 2 workers (two samples); Kinshasa, Bateke Plateau, Bombo-Lumene reserve; 22 Apr. 2017; ULB • 2 soldiers, 2 workers (two samples); Kinshasa, Bateke Plateau; 2011-2014; ULB.

REPUBLIC OF CENTRAL AFRICA • 2 ổ (alates), 2 soldiers, 2 workers (two samples); Bondoé; Apr. 2006-Mar. 2009; ULB.

Cubitermes sankurensis var. elongata Sjöstedt, 1926

DEMOCRATIC REPUBLIC OF THE CONGO • 1 soldier, syntype; no date; AMNH.

Cubitermes schereri (von Rosen, 1912)

CÔTE D’IVOIRE • 1 q (queen), 1 § (king), 4 soldiers, 4 workers (four samples); Yalé; Apr.-Dec. 1968;

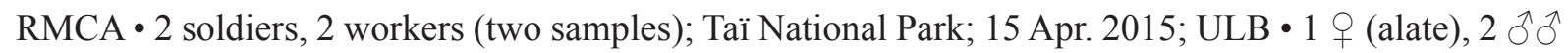
(alates), 2 soldiers, 2 workers (two samples); Daloa; Feb. 2015; ULB.

DEMOCRATIC REPUBLIC OF THE CONGO • 1 soldier, 1 worker; Katanga, Lubumbashi; 24 Apr. 1912; RMCA.

GAMBIA • 1 soldier, 1 worker; Brikama; 2 Nov. 2013; ULB.

GUINEA • 2 우 (queens), 2 soldiers, 2 workers (two samples); Nzo; Mar. 1947; MNHN • 1 soldier, 1 worker; Haut-Niger National Park, Faranah; 11 Jun. 1996; RMCA • 3 workers (three samples); HautNiger National Park, Faranah; Jun.-Dec 1996; MURS.

GUINEA BISSAU • 1 ô (king), 1 soldier, 1 worker; Cacine; Sep. 1996; RMCA.

LIBERIA • 1 q (alate), 1 worker, paratypes; Cape Mesurado; 2 Jul. 1908; AMNH • 1 soldier, 1 worker, paratypes; Cape Mesurado; 2 Jul. 1908; NHMM $\bullet 1$ q (queen), 2 soldiers (two samples); no date; AMNH.

Cubitermes sibitiensis Sjöstedt, 1925

$\mathrm{CONGO} \bullet 1$ \& (alate), 1 soldier, 1 worker, syntypes; Sibiti; no date; AMNH.

Cubitermes sierraleonicus (Sjöstedt, 1911)

SIERRA LEONE $\bullet 1$ soldier, 1 worker, syntypes; no date; AMNH $\bullet 1$ soldier, 1 worker; Freetown; 8 Jan. 1958; NHMUK.

Cubitermes testaceus Williams, 1966

BURUNDI • 1 q (alate), 1 § (alate), 1 soldier, 1 worker; Mahanga; 26 Nov. 2013; ULB.

RWANDA 1 1 (queen), 2 soldiers, 2 workers (two samples); Rukara; 5 Feb. 1953; RMCA.

UGANDA • 1 q (queen), 1 soldier, 1 worker, paratypes; Hoima-Fort Portal road; 17 Feb. 1955; NHMUK

- 1 soldier, 1 worker, paratypes; Kawanda; 28 Dec. 1949; PPRI. 
Cubitermes truncatoides (Fuller, 1925)

REPUBLIC OF SOUTH AFRICA • 1 soldier, lectotype (designated by Ruelle 1971); Mbazwane swamp; 4 Oct. 1923; PPRI, registration number: TYPH $02125 \cdot 1$ \& (alate), 1 soldier, 1 worker, paralectotypes; same data as preceding; PPRI.

SWAZILAND • 1 soldier; Mbabane-Bremersdorp road; 21 Apr. 1935; AMNH.

Cubitermes truncatoides var. sordwana (Fuller, 1925)

REPUBLIC OF SOUTH AFRICA • 1 soldier, lectotype (designated by Ruelle 1971); Kwazulu-Natal, near Sordwana Bay; 5 Oct. 1923; PPRI, registration number: TYPH $02126 \bullet 1$ (alate), paralectotype; Kwazulu-Natal, near Sordwana Bay; 5 Oct. 1923; PPRI • 1 q (alate), 1 soldier, 1 worker, paralectotypes; same data as preceding; AMNH.

Cubitermes truncatus (Holmgren, 1913)

REPUBLIC OF SOUTH AFRICA - 1 soldier, lectotype (designated by Ruelle 1971); KwazuluNatal, Ubombo near Sordwana; 5 Oct. 1923; PPRI, registration number: TYPH $02126 \bullet 1$ q (alate), paralectotype; same data as preceding; PPRI.

Unknown, new species 1

BURKINA FASO • 1 soldier, 1 worker; Bala; Aug. 2016; ULB • 2 soldiers, 2 workers (two samples);

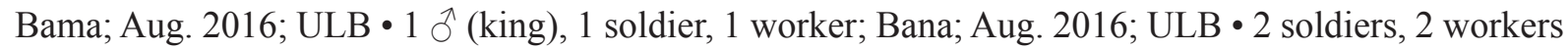
(two samples:); Bekuy; Aug. 2016; ULB - 1 soldier, 1 worker; Bobo Dioulasso; Aug. 2016; ULB • 1 soldier, 1 worker; Poundoun; Aug. 2016; ULB • 1 q (queen), 4 soldiers, 4 workers (four samples); Tiogo; Aug. 2016; ULB.

CÔTE D’IVOIRE • 1 soldier, 1 worker; Lamto; no date; ULB • 3 $q$ q (alates), $3 \hat{\jmath} \hat{o}$ (alates), 4 soldiers, 4 workers (four samples); Toumodi; Feb.-Apr. 2015; ULB.

GUINEA • 1 soldier; Kindia; Nov. 1995; RMCA.

SENEGAL • 1 soldier, 1 worker; Casamance, Balingore; 13 Sept. 2011; ULB 11 soldier, 1 worker; Indiga; 22 Nov. 2016; ULB • 1 soldier, 1 worker; Tambacounda; 22 Nov. 2016; ULB.

Unknown, new species 2

CAMEROON • 1 soldier, 1 worker; Ekoua; 28 Mar. 2015; ULB • 1 + (alate), 1 soldier, 1 worker; Akolo; 1 Apr. 2015; ULB • 1 soldier, 1 worker; Boulourou; 1 Apr. 2015; ULB 11 soldier, 1 worker; Foumban; 5 Apr. 2015; ULB • 1 soldier, 1 worker; Batié; 7 Apr. 2015; ULB • 1 soldier, 1 worker; Koutaba; 8 Apr. 2015; ULB • 1 soldier, 1 worker; Néfanté; 9 Apr. 2015; ULB.

The above were collected in West, Central, East and Southern Africa (Fig. 17G).

\section{The oblectatus valve pattern group}

The worker within this group has an enteric valve with three primary cushions, PC3, PC4 and PC5, ending downstream in three yellow-to-brown sclerotised spatulae that stick out of the valve $($ Fig. $11 \mathrm{H}$, H'). The spatula of PC4 ends symmetrically with two right angles, whereas the spatulae of PC3 and PC5 end in acute angles pointing towards the spatula of PC4; PC3 and PC5 bear crests that are higher than they are wide; PC4 bears a less high crest. The other primary cushions (PC1-PC2 \& PC6) are roughly rectangular to fusiform. The enteric valve shows bilateral symmetry due to the three spatulae and to PC1, which is generally longer than PC2 and PC6 (Fig. 19A). 
PC1 is made of (a) an upstream spiny part (25-31\% of total length) with relatively strong spines, (b) a middle spiny part (37-39\% of total length) with somewhat weaker spines and with 18-23 lateral supporting bristles on each side, and (c) a bristly part (32-36\% of total length) with very numerous (estimated at 140-160) curved and apparently soft bristles (Fig. 19A).

PC4 is made of (a) an upstream spiny part (20-22\% of total length) with relatively strong spines, (b) a middle spiny part (37-41\% of total length) with somewhat weaker spines and with 17-20 lateral supporting bristles on each side, (c) a bristly part (21-24\% of total length) with 120-150 curved and apparently soft bristles on a low crest, and (d) a symmetric sclerotised spatula (15-21\% of total length) bearing some short spines and 15-20 very short tooth-like spines on each side (Fig. 11H).

The secondary cushions are generally two to three times wider than the primary cushions and are more or less outlined; their largest widths are located in the upstream fourth or third and they narrow noticeably downstream with a homogeneous spine (upstream) and bristle (downstream) scattering (Fig. 19A).

In the soldier's enteric valve, the three spatulae on PC3, PC4 and PC5 are present but weakly developed, with blunt downstream ends (Fig. 19B). The secondary cushions are wider than the PCs (their largest widths located in the upstream fourth or third) and they narrow noticeably downstream.

This valve pattern is therefore characterised by three spatulae in the workers' and soldiers' valves; the unique species is large.
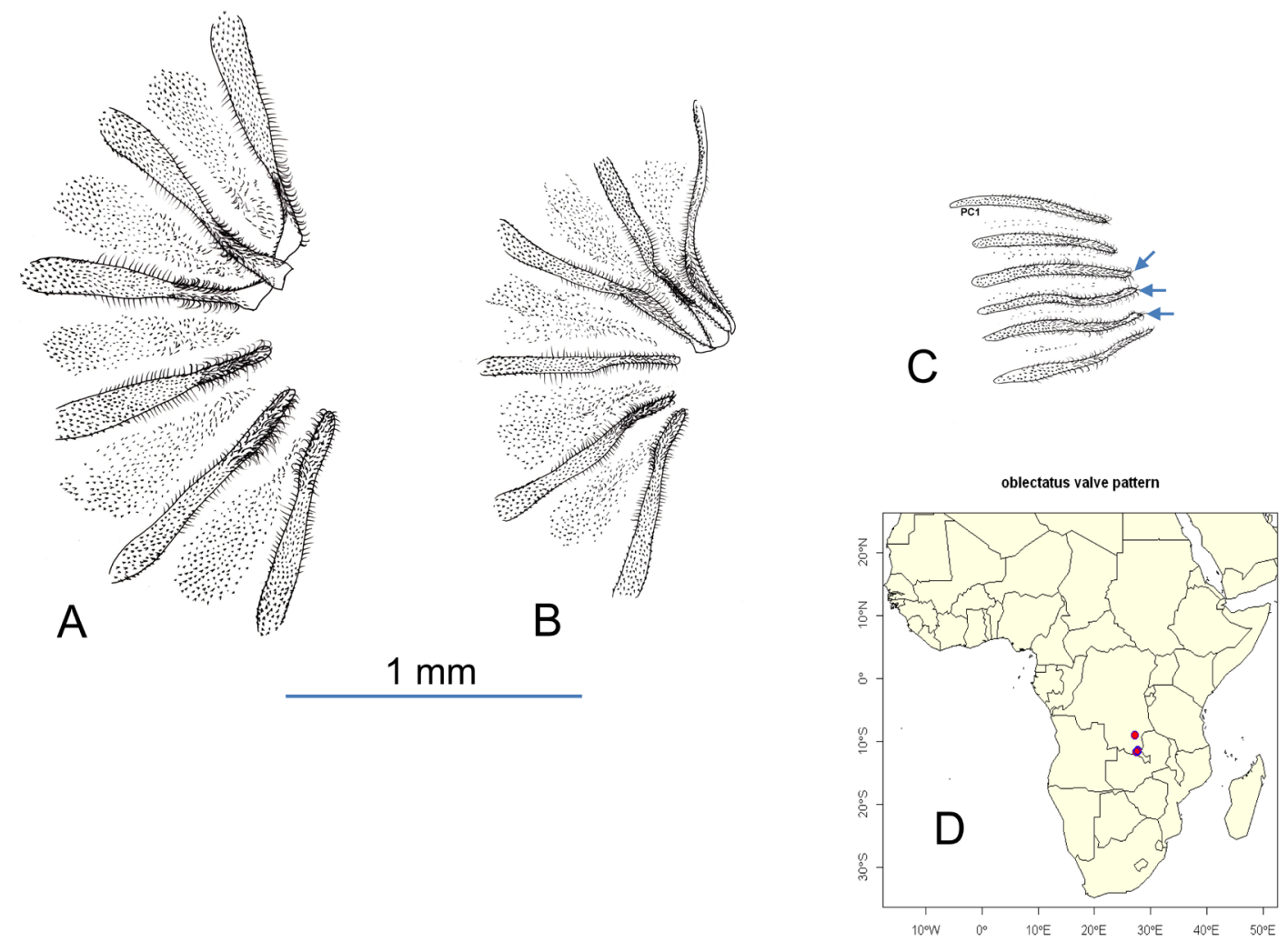

Fig. 19. A. Enteric valve of the "oblectatus valve pattern", from a worker of Cubitermes oblectatus Harris, 1958; B. idem from a soldier of $C$. oblectatus; C. Idem from an imago of $C$. sp., spatulae on PC3, PC4 and PC5 are sketched (arrows); A, B and C at the same scale; D. Geographical distribution of species with the oblectatus valve pattern. 


\section{Material examined}

One species has such enteric valves:

Cubitermes oblectatus Harris, 1958

DEMOCRATIC REPUBLIC OF THE CONGO $\bullet 1$ (queen), 1 soldier, 1 worker, paratypes (two samples); Katanga, Upemba National Park; 14 Jul. 1947; RMCA • 1 q (queen), 1 soldier, 1 worker (two samples); same data as preceding; RMCA.

This species has only been collected in East Africa (Fig. 19D).

\section{The sulcifrons valve pattern group}

The worker within this group has an enteric valve with all the six primary cushions ending downstream in yellow to brown sclerotised spatulae that stick out of the valve (Fig. 20A). The spiny parts of the primary cushions are more or less fusiform: the largest widths are located in the first upstream third and their lateral margins converge gradually towards both ends (Fig. 11I). All of the spatulae end symmetrically with two right or acute angles and all the six primary cushions are more or less protruding into the lumen of the valve. All of the six primary cushions are of the same size, forming hexaradial symmetry (Fig. 20A).

A PC is made of (a) an upstream spiny part (16-36\% of total length) with relatively strong spines, (b) a middle spiny part (26-43\% of total length) with somewhat weaker spines and with 14-23 lateral supporting bristles on each side, (c) a bristly part (13-27\% of total length) with 45-65 straight or curved and apparently soft bristles on a low crest, and (d) a symmetric sclerotised spatula with two right or acute
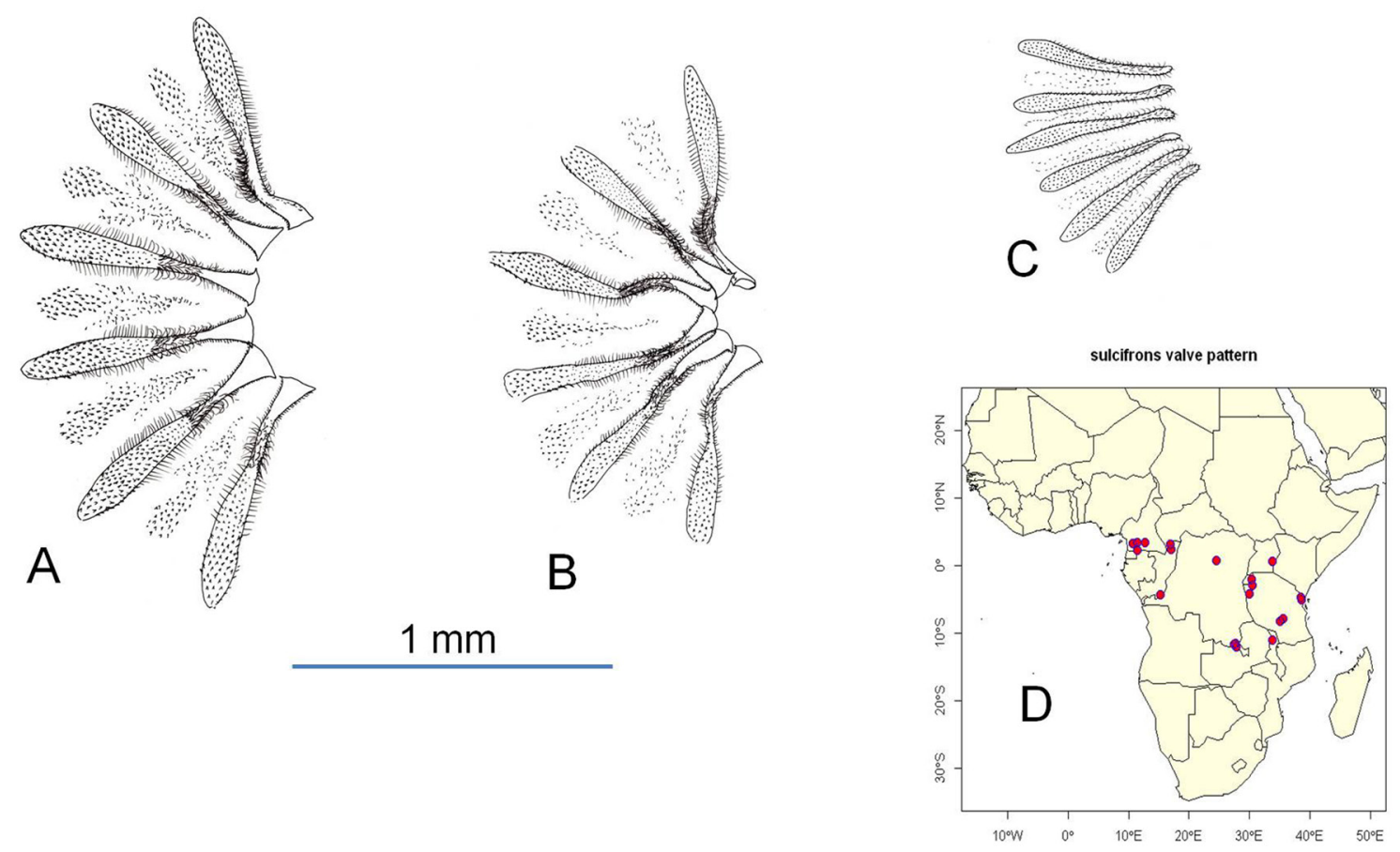

Fig. 20. A. Enteric valve of the "sulcifrons valve pattern", from a worker of Cubitermes sulcifrons Wasmann, 1911: note the spearhead-shape of the secondary cushions; B. Idem from a soldier of C. sulcifrons; C. Idem from an imago of C. umbratus Williams, 1954, spatulae are sketched on each PC; $\mathrm{A}, \mathrm{B}$ and $\mathrm{C}$ at the same scale; D. Geographical distribution of species with the sulcifrons valve pattern. 
angles (13-27\% of total length) bearing some short spines and, on each side, some 10-15 very short tooth-like setae (Fig. 11I, 11I').

The secondary cushions are either narrow in their upstream end, widen downstream and sketch spearheads (Fig. 20A), or are about twice as wide as the primary cushions, with their largest widths located in the upstream fourth or third, narrowing noticeably downstream with a homogeneous spine scattering.

This valve pattern is therefore characterised by six spatulae in the workers' and soldiers' valves and by the workers' SCs which are either rather narrow or with a spearhead shape; most species are large.

\section{Material examined}

Eight species have such enteric valves:

Cubitermes bugeserae Bouillon \& Vincke, 1971

BURUNDI • 1 soldier, 1 worker; Mahanga; 26 Nov. 2013; ULB • 1 q (alate), 1 o (alate), 4 soldiers, 4 workers (four samples); Ruvubu National Park; 2014; ULB.

RWANDA 1 1 (queen), holotype; Bugesera; 16 Nov. 1963; RMCA $\bullet 1$ soldier, paratype; same data as preceding; RMCA.

Cubitermes domifaber (Sjöstedt, 1913)

DEMOCRATIC REPUBLIC OF THE CONGO • 1 soldier, 1 worker, syntypes; Katanga, Lubumbashi; 6 May 1912; AMNH.

Cubitermes hamatus Sjöstedt, 1926

CONGO • 1 soldier, 1 worker, syntypes; Brazzaville; 1907; AMNH.

Cubitermes inclitus Silvestri, 1912

DEMOCRATIC REPUBLIC OF THE CONGO • 1 soldier, 1 worker, syntypes; Katanga, Kasumbalesa; 6 May 1912; RMCA. 4 soldiers, 4 workers (four samples); Katanga, Mikembo; 2012-2016; ULB.

ZAMBIA • 1 soldier, 1 worker, syntypes; Bangwelo; no date; IEAP.

Cubitermes intercalatus Silvestri, 1914

CAMEROON • 3 soldiers, 3 workers (three samples); Somalomo; 29-30 Mar. 2015; ULB • 1 soldier, 1 worker; Ebogo; 15 Apr. 2015; ULB.

CONGO 1 1 (alate), 1 soldier, 1 worker, syntypes; Brazzaville; no date; IEAP.

DEMOCRATIC REPUBLIC OF THE CONGO • 1 soldier, 1 worker; Kinshasa; 5 Apr. 1948; RMCA.

Cubitermes montanus Williams, 1966

MALAWI • 1 soldier, 1 worker; Rumpi; 29 Sep. 1953; PPRI.

TANZANIA • 1 q (alate), 1 soldier, paratypes; Iringa; 1937; NHMUK.

Cubitermes sulcifrons Wasmann, 1911

CAMEROON • 1 q (queen), 1 soldier, 1 worker, paratypes; Lolodorf; Nov. 1895; NHMM.

DEMOCRATIC REPUBLIC OF THE CONGO • 1 soldier, 1 worker; Yangambi; 15 Jul. 2013; ULB.

GABON • 1 soldier, 1 worker; Nkobissimo; 15 Apr. 2017; ULB.

Cubitermes umbratus Williams, 1954

TANZANIA $• 1$ (alate), 1 soldier, 1 worker, paratypes; Usambara; 1 Apr. 1951; NHMUK 1 q (queen), 1 soldier, 1 worker, paratypes; Amani; 3 Jan. 1952; NHMUK.

The above were collected in Central and East Africa (Fig. 20D). 


\section{Discussion}

\section{External morphology versus enteric valves}

Principal component analyses (PCAs) were first applied to all three castes and to all of the morphological variables except those concerning the enteric valves; the individuals were then marked and connected according to their valve patterns (Figs 21A-B, 22A).

These three PCAs show consistent results, at least for the first axis, which is clearly linked to the individual sizes. In the soldiers ( $\mathrm{n}=425$; Fig. 21B), a group of five valve patterns (bilobatus, oculatus, sankurensis, bilobatodes and muneris) clusters the smaller species on the left side, and a group of four valve patterns (fungifaber, finitimus, sulcifrons and oblectatus) clusters the larger species on the right side. Furthermore, in the first group, two subgroups may be distinguished: the first one brings together three patterns of small species (bilobatus, oculatus and sankurensis), while the second subgroup comprises the two other patterns of small- to medium-sized species (bilobatodes and muneris). In the imagines ( $\mathrm{n}=243$; Fig. 21A), the disposition of valve patterns along the first axis is almost similar but the two groups of smaller and larger species are less well separated. In the workers $(n=414 ;$ Fig. 22A), the two groups of smaller and larger species are still less well separated, and the nine patterns are more regularly spread along a gradient.

The second PCA axis is linked to different variables depending on the caste. In the soldiers (Fig. 21B), the second axis is linked mainly to the curvature of the mandibles; the individuals with rather straight mandibles are at the top of the graph and the individuals with more curved mandibles are at the bottom. In the imagines (Fig. 21A), the second axis is linked to the size of the eyes and ocelli (and related variables); the individuals with large and more or less protruding eyes are at the top of the graph, and the individuals with relatively small eyes are at the bottom. In the workers (Fig. 22A), the second axis, of little interest, is linked to several indices concerning the mandibles, such as the left and right apicomarginal indices.

In all three castes, several patterns overlap to a large extent, illustrating the difficulty of separating the Cubitermes patterns on the basis of their external morphology and the necessity in using the enteric valves of mainly the worker caste. The geographical origin of the individuals, not used in the analyses, can also help to identify them.

A PCA has also been applied to the variables concerning the workers' enteric valves (Fig. 22B). Only 347 individuals could be used: some workers were discarded due to poor preservation, and a few of them due to the fact that their valves showed obvious abnormalities. In this case as well, the first axis is linked to the individual sizes (lengths and widths, mainly of the secondary cushions) but they do not follow precisely the same order as in the PCA on the external morphology: a pattern (oculatus) with the smallest valves is rather well isolated on the left side, two patterns (bilobatus and sankurensis) cluster the small to medium-sized valves in the middle, and a group of six patterns (bilobatodes, finitimus, sulcifrons, fungifaber, muneris and oblectatus) clusters the medium- to larger-sized valves on the right side. The second axis is linked to the spatulae and clearly separates the three patterns with spatulae at the top of the graph (sankurensis, oblectatus and sulcifrons) from the other patterns at the bottom.

\section{Meaning of the patterns}

This work is a first step towards a complete revision of the genus Cubitermes. The patterns that have been recognised are for the moment an effective means of distinguishing nine groups of species that sometimes look very similar on external morphology. Could each of them acquire a taxonomic status? Probably not, but as mentioned previously, an ongoing molecular study on some species of Cubitermes 
will try to disentangle their phylogeny and show whether the species groups are monophyletic. Some relationships may, however, already be suggested.

The fungifaber and finitimus valve patterns seem closely related for several reasons: some worker samples show intermediate valve morphologies; in the PCAs, both patterns are close to each other in all three castes (Figs 21, 22A) and they live mainly in forests of West and Central Africa (Figs 15D, 16C).

The bilobatodes and muneris valve patterns also seem closely related: in the PCAs, both patterns are close to each other in all three castes (Figs 21, 22A) and some worker samples show intermediate valve morphologies. However, the similarity between the valves of the bilobatodes and muneris patterns might be of little significance because they are close to the basic kind of valves that can also be found in several other Cubitermitinae. The muneris pattern is present mainly in East Africa and marginally in Southern Africa (Fig. 14); in contrast, the geographical range of the bilobatodes pattern seems somewhat fragmented (Fig. 13C), and as mentioned previously, the secondary cushions differ somewhat between the western and central African species on the one hand, and the eastern and southern species on the other hand.

The sankurensis and oculatus valve patterns are close to each other in the PCAs on soldiers and workers (external morphology); they share characteristic narrow secondary cushions in their valves. Nevertheless, both patterns are rather separated in the PCA on the workers' valves: this can be explained by the obvious presence / absence of spatulae. The sankurensis pattern is spread over a large area from West to Southern Africa (actually the entire geographical range of the genus Cubitermes, Fig. 17G), whereas the oculatus pattern is limited to the savannas of West Africa (Fig. 18C); it can be hypothesized that this pattern has recently evolved in West Africa.

\section{Synonymies}

Although this revision does not address the specific level yet, some already published synonymies can be discussed, and some of them can be rejected on the grounds of different enteric valves. Table 6 summarizes the status (valve pattern and synonymy) of every Cubitermes taxon.

Among the species with the bilobatus valve pattern, only one synonymy has been proposed: $C$. zulucola has been used as a senior synonym of C. pseudoduplex (Ruelle 1975: 8; Krishna et al. 2013: 1946): this is compatible with their enteric valves. Cubitermes pseudoduplex may therefore for now be considered to be an invalid name. All of the nine other species' names may be considered as valid for the time being (Table 6).

Among the species with the bilobatodes valve pattern, no synonymy has been proposed, and all five species may therefore be considered as valid for the time being.

Among the species with the muneris valve pattern, only one synonymy has been proposed: C. muneris (Sjöstedt, 1913) has been given as a senior synonym of C. bisulcatus Sjöstedt, 1914 (Williams 1966: 93; Krishna et al: 2013); this is compatible with their enteric valves, and C. bisulcatus may therefore be considered for now to be an invalid name. All of the eight other species may be considered as valid for the time being.

Among the species with the fungifaber valve pattern, seven synonymies have been proposed; four of them are compatible with the enteric valve patterns:

- Cubitermes fungifaber has been considered as a possible senior synonym (a) of C. banksi, (b) of C. comstocki and (c) of C. schmidti (Ruelle 1992: 501; Krishna et al. 2013: 1913, 1918, 1935). 

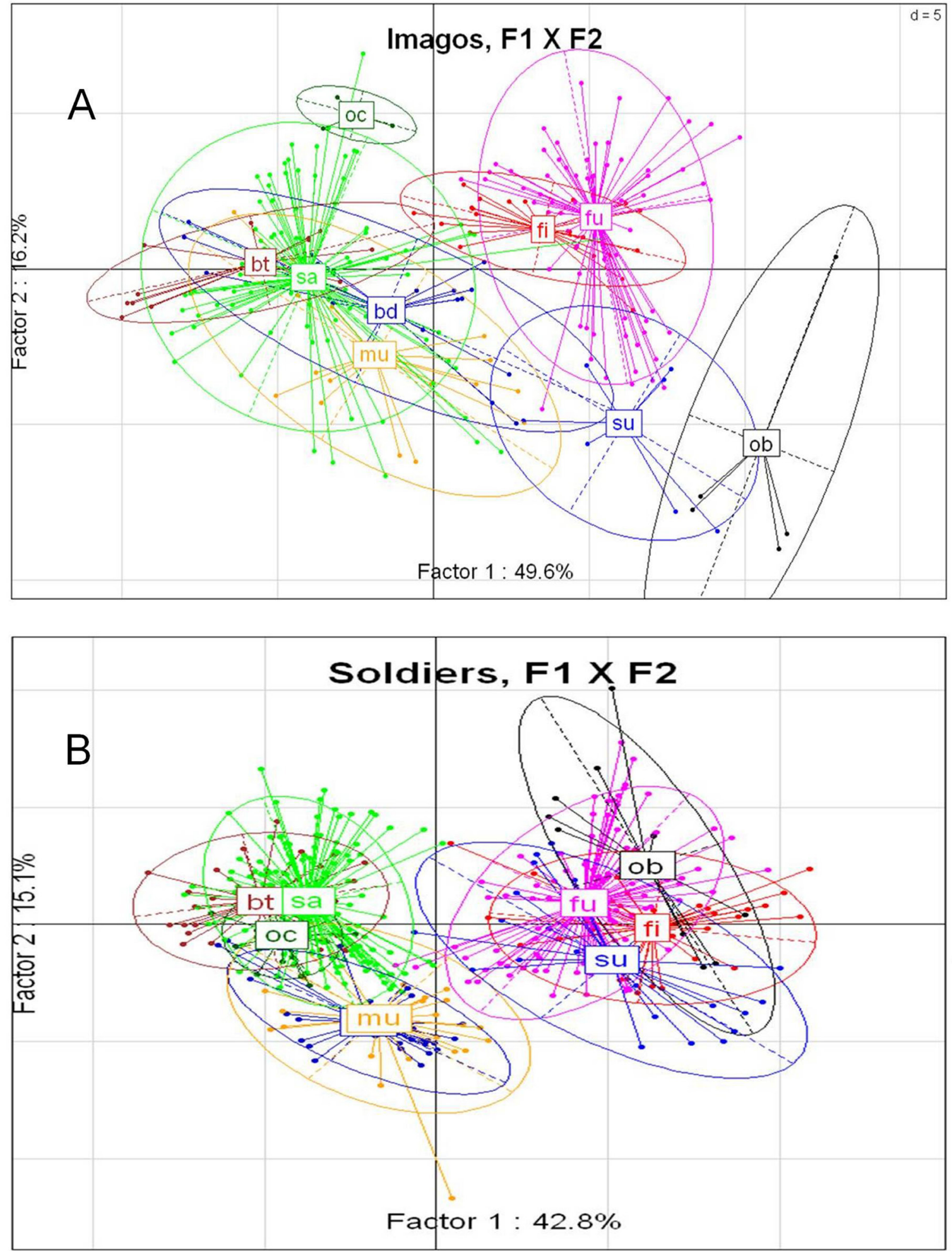

Fig. 21. Result of principal component analyses; each ellipse joins the samples from the same valve pattern: $\mathrm{bd}=$ bilobatodes, $\mathrm{bt}=$ bilobatus, $\mathrm{fi}=$ finitimus, $\mathrm{fu}=$ fungifaber, $\mathrm{mu}=$ muneris, $\mathrm{ob}=$ oblectatus, $\mathrm{oc}=$ oculatus, $\mathrm{sa}=$ sankurensis and $\mathrm{su}=$ sulcifrons. A. For the imagines, based on all variables and indices of their morphology (excluding those concerning their wings, $n=257$ ); B. For the soldiers, based on all variables and indices of their morphology (excluding those concerning their valves, $n=427$ ); the "bd" label is hidden behind the "mu" label. 

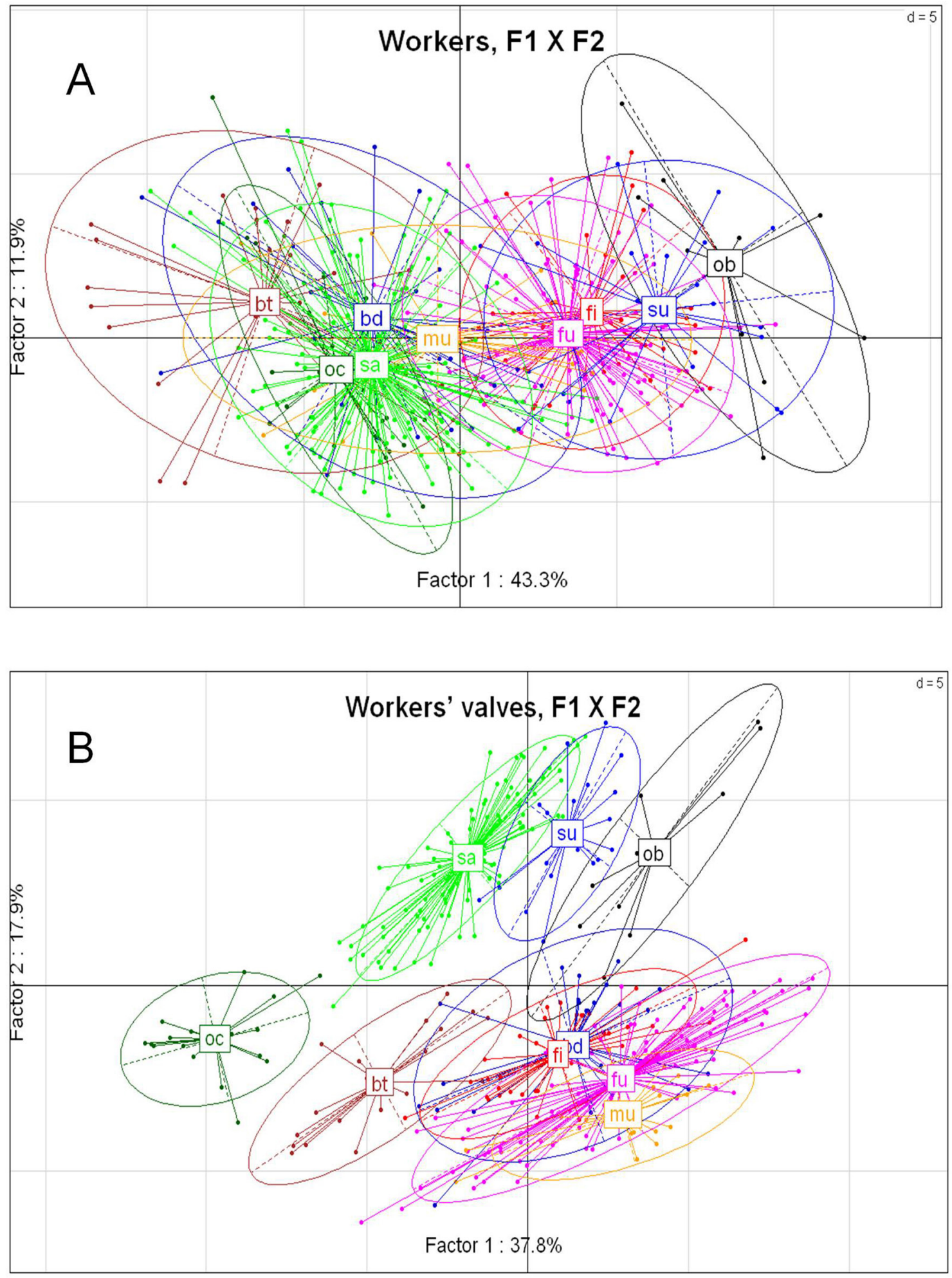

Fig. 22. Result of principal component analyses; each ellipse joins the samples from the same valve pattern: $\mathrm{bd}=$ bilobatodes, $\mathrm{bt}=$ bilobatus, $\mathrm{fi}=$ finitimus, $\mathrm{fu}=$ fungifaber, $\mathrm{mu}=$ muneris, $\mathrm{ob}=$ oblectatus, $\mathrm{oc}=$ oculatus, $\mathrm{sa}=$ sankurensis and $\mathrm{su}=$ sulcifrons. A. For the workers, based on all variables and indices of their morphology (excluding those concerning their valves) $(\mathrm{n}=421)$; B. For the workers, based only on the variables and indices concerning their valves $(n=347)$, the "bd" label is partly hidden behind the "fi" label. 
Table 6. (continued on next page) Cubitermes:Wasmann,1906 pattern and synonymy status of all current taxa.

\begin{tabular}{|c|c|c|c|c|}
\hline Name & Mat. $^{1}$ & Pattern $^{2}$ & $\begin{array}{l}\text { Present (2018) status } \\
\text { and comments }\end{array}$ & $\begin{array}{c}\text { Senior synonym } \\
\text { (with literature quotation) }\end{array}$ \\
\hline C. aemulus Silvestri, 1914 & $\mathrm{~T}$ & sank & valid & \\
\hline C. anatruncatus (Fuller, 1925) & $\mathrm{T}$ & sank & valid & \\
\hline C. antennalis Sjöstedt, 1924 & $\mathrm{~T}$ & fung & invalid, junior synonym of & C. ugandensis (Williams 1966) \\
\hline C. atrox (Smeathman, 1781) & NA & - & material lost & \\
\hline C. banksi (Emerson, 1928) & $\mathrm{T}$ & fung & invalid, junior synonym of & C. fungifaber (Ruelle 1992) \\
\hline C. bilobatodes Silvestri, 1912 miles major & $\mathrm{T}$ & bild & valid & \\
\hline C. bilobatodes Silvestri, 1912 miles minor & $\mathrm{T}$ & ocul & $\begin{array}{l}\text { invalid, oculatus pattern, not } \\
\text { bilobatodes pattern }\end{array}$ & \\
\hline C. bilobatus (Haviland, 1898) & $\mathrm{T}$ & bilt & valid & \\
\hline C. bilobatus forma curta Sjöstedt, 1926 & NS & - & invalid, junior synonym of & C. bilobatus (Krishna et al. 2013) \\
\hline C. bisulcatus (Sjöstedt, 1914) & $\mathrm{T}$ & mune & invalid, junior synonym of & C. muneris (Williams 1966) \\
\hline C. breviceps (Sjöstedt, 1913) & $\mathrm{T}$ & mune & valid, pattern based on soldier & \\
\hline C. bugeserae Bouillon \& Vincke, 1971 & $\mathrm{~T}$ & sulc & valid & \\
\hline C. bulbifrons Sjöstedt, 1924 & $\mathrm{~T}$ & fini & valid & \\
\hline C. caesareus (Sjöstedt, 1911) & NS & - & misidentification & $\begin{aligned}= & \text { Trichotermes caesareus } \\
& (\text { Krishna et al. } 2013)\end{aligned}$ \\
\hline C. comstocki (Emerson, 1928) & $\mathrm{T}$ & fung & invalid, junior synonym of & C. fungifaber (Ruelle 1992) \\
\hline C. congoensis (Emerson, 1928) & $\mathrm{T}$ & fini & valid & \\
\hline C. conjenii (Fuller, 1925) & $\mathrm{T}$ & bilt & valid & \\
\hline C. cubicephalus (Sjöstedt, 1913) & $\mathrm{T}$ & sank & invalid, junior synonym of & C. sankurensis (Williams 1966) \\
\hline C. curtatus Silvestri, 1914 & $\mathrm{~T}$ & sank & valid & \\
\hline C. domifaber (Sjöstedt, 1913) & $\mathrm{T}$ & sulc & invalid, junior synonym of & C. inclitus (Williams 1966) \\
\hline C. duplex (Holmgren, 1913) & $\mathrm{T}$ & bild & valid & \\
\hline C. duplex forma nduma Fuller, 1925 & $\mathrm{~T}$ & sank & invalid, junior synonym of & C. truncatus (Ruelle 1975) \\
\hline C. exiguus Mathot, 1964 & NT & bilt & valid, holotype lost & \\
\hline C. falcifer Williams, 1966 & $\mathrm{~T}$ & mune & valid & \\
\hline C. finitimus Schmitz, 1915 & $\mathrm{~T}$ & fini & valid & \\
\hline C. fulvus Williams, 1966 & $\mathrm{~T}$ & sank & valid & \\
\hline C. fungifaber (Sjöstedt, 1896) & $\mathrm{T}$ & fung & valid & \\
\hline C. fungifaber var. elongata Sjöstedt, 1924 & $\mathrm{~T}$ & fini & $\begin{array}{l}\text { invalid, fini vs fung patterns, } \\
\text { incorrectly considered as } \\
\text { synonym of }\end{array}$ & C. fungifaber (Krishna et al. 2013) \\
\hline C. gaigei (Emerson, 1928) & $\mathrm{T}$ & fini & valid & \\
\hline C. gibbifrons Sjöstedt, 1924 & $\mathrm{~T}$ & fini & valid & \\
\hline C. glebae (Sjöstedt, 1913) & NT & mune & valid & \\
\hline C. hamatus Sjöstedt, 1926 & $\mathrm{~T}$ & sulc & invalid, junior synonym of & C. intercalatus (Krishna et al. 2013) \\
\hline C. heghi Sjöstedt, 1924 & $\mathrm{~T}$ & fini & invalid, junior synonym of & C. bulbifrons (Ruelle 1975) \\
\hline C. inclitus Silvestri, 1912 & NT & sulc & valid & \\
\hline C. intercalatus Silvestri, 1914 & $\mathrm{~T}$ & sulc & valid & \\
\hline C. kemneri (Emerson, 1928) & $\mathrm{T}$ & fini & $\begin{array}{c}\text { valid, fini vs fung patterns, } \\
\text { incorrectly considered as } \\
\text { synonym of }\end{array}$ & C. zenkeri (Ruelle 1975) \\
\hline C. latens Williams, 1966 & $\mathrm{~T}$ & mune & valid & \\
\hline C. loubetsiensis Sjöstedt, 1924 & $\mathrm{~T}$ & fini & invalid, junior synonym of & C. finitimus (Krishna et al. 2013) \\
\hline C. microduplex (Fuller, 1925) & $\mathrm{T}$ & bild & valid & \\
\hline C. minitabundus (Sjöstedt, 1913) & $\mathrm{T}$ & fung & valid & \\
\hline C. modestior Silvestri, 1914 & $\mathrm{~T}$ & fung & valid & \\
\hline C. montanus Williams, 1966 & $\mathrm{~T}$ & sulc & valid & \\
\hline C. mordax (Smeathman, 1781) & NA & - & Material lost & \\
\hline
\end{tabular}


Table 6. (continued) Cubitermes Wasmann, 1906: pattern and synonymy status of all current taxa.

\begin{tabular}{|c|c|c|c|c|}
\hline Name & Mat. $^{1}$ & Pattern $^{2}$ & $\begin{array}{l}\text { Present (2018) status } \\
\text { and comments }\end{array}$ & $\begin{array}{c}\text { Senior synonym } \\
\text { (with literature quotation) }\end{array}$ \\
\hline C. muneris (Sjöstedt, 1913) & $\mathrm{T}$ & mune & valid & \\
\hline C. niokoloensis Roy-Noël, 1969 & $\mathrm{~T}$ & ocul & valid & \\
\hline C. oblectatus Harris, 1958 & $\mathrm{~T}$ & oble & valid & \\
\hline C. oculatus Silvestri, 1914 & $\mathrm{~T}$ & ocul & valid & \\
\hline C. orthognathus (Emerson, 1928) & $\mathrm{T}$ & sank & valid & \\
\hline C. pallidiceps (Sjöstedt, 1913) & $\mathrm{T}$ & mune & valid & \\
\hline C. planifrons Sjöstedt, 1924 & $\mathrm{~T}$ & fini & $\begin{array}{l}\text { valid, fini vs fung patterns, } \\
\text { incorrectly considered as } \\
\text { synonym of }\end{array}$ & C. fungifaber (Krishna et al. 2013) \\
\hline C. pretorianus Silvestri, 1914 & $\mathrm{~T}$ & bilt & valid & \\
\hline C. pretorianus var. heidelbergi Fuller, 1925 & $\mathrm{~T}$ & bilt & valid & \\
\hline C. proximatus Silvestri, 1914 & $\mathrm{~T}$ & sank & valid & \\
\hline C. pseudoduplex (Fuller, 1925) & $\mathrm{T}$ & bilt & invalid, junior synonym of & C. zulucola (Ruelle 1975) \\
\hline C. sanctaeluciae (Fuller, 1925) & $\mathrm{T}$ & bilt & valid & \\
\hline C. sankurensis Wasmann, 1911 & $\mathrm{~T}$ & sank & valid & \\
\hline C. sankurensis var. elongata Sjöstedt, 1926 & $\mathrm{~T}$ & sank & invalid, junior synonym of & C. sankurensis (Krishna et al. 2013) \\
\hline C. schereri (von Rosen, 1912) & $\mathrm{T}$ & sank & valid & \\
\hline C. schmidti (Emerson, 1928) & $\mathrm{T}$ & fung & invalid, junior synonym of & C. fungifaber (Krishna et al. 2013) \\
\hline C. severus Silvestri, 1914 & $\mathrm{~T}$ & fung & valid & \\
\hline C. sibitiensis Sjöstedt, 1925 & $\mathrm{~T}$ & sank & invalid, junior synonym of & C. sankurensis (Emerson 1928) \\
\hline C. sierraleonicus (Sjöstedt, 1911) & $\mathrm{T}$ & sank & valid & \\
\hline C. silvestrii Sjöstedt, 1925 & $\mathrm{~T}$ & fung & valid & \\
\hline C. speciosus Sjöstedt, 1924 & $\mathrm{~T}$ & fini & valid & \\
\hline C. subarquatus Sjöstedt, 1926 & $\mathrm{~T}$ & fini & invalid, junior synonym of & C. finitimus (Krishna et al. 2013) \\
\hline C. subcrenulatus Silvestri, 1914 & $\mathrm{~T}$ & bild & valid & \\
\hline C. sulcifrons Wasmann, 1911 & $\mathrm{~T}$ & sulc & valid & \\
\hline C. tenuiceps (Sjöstedt, 1913) & $\mathrm{T}$ & bilt & valid & \\
\hline C. testaceus Williams, 1966 & $\mathrm{~T}$ & sank & valid & \\
\hline C. transvaalensis (Fuller, 1925) & $\mathrm{T}$ & bilt & valid & \\
\hline C. truncatoides (Fuller, 1925) & $\mathrm{T}$ & sank & valid & \\
\hline C. truncatoides var. sordwana (Fuller, 1925) & $\mathrm{T}$ & sank & invalid, junior synonym of & C. truncatoides (Ruelle 1975) \\
\hline C. truncatus (Holmgren, 1913) & $\mathrm{T}$ & sank & valid & \\
\hline C. ugandensis Fuller, 1923 & $\mathrm{~T}$ & fung & valid & \\
\hline C. umbratus Williams, 1954 & $\mathrm{~T}$ & sulc & valid & \\
\hline C. undulatus (Fuller, 1925) & $\mathrm{T}$ & mune & valid & \\
\hline C. weissi Silvestri, 1912 & $\mathrm{~T}$ & bild & valid & \\
\hline C. zavattarii Ghidini, 1937 & $\mathrm{~T}$ & mune & valid & \\
\hline C. zenkeri (Desneux, 1904) & $\mathrm{T}$ & fung & valid & \\
\hline C. zulucola Sjöstedt, 1924 & NT & bilt & valid & \\
\hline C. zuluensis (Holmgren, 1913) & NS & - & valid & \\
\hline
\end{tabular}

${ }^{1}:$ Mat. $=$ Material, NA = not available, NS = not studied yet, NT = non type material examined, $\mathrm{T}=$ type material examined.

2: pattern really observed, bild $=$ bilobatodes, bilt $=$ bilobatus, fini $=$ finitimus, fung $=$ fungifaber, mune $=$ muneris, oble $=$ oblectatus, ocul $=$ oculatus, sank = sankurensis, sulc $=$ sulcifrons 
- Cubitermes ugandensis has been used as a senior synonym of C. antennalis (Williams 1966: 107; Krishna et al. 2013: 1943).

On the contrary, three other synonymy proposals cannot be accepted:

- Cubitermes fungifaber has been considered as a senior synonym of the subspecies C. fungifaber var. elongata (Krishna et al. 2013: 1923, after Emerson's unpublished manuscript notes), but the types of both taxa have different enteric valves (fungifaber and finitimus valve patterns, respectively). Cubitermes fungifaber var. elongata is therefore an invalid name.

- Cubitermes fungifaber has also been considered as a possible senior synonym of C. planifrons (Krishna et al. 2013: 1931, after Emerson's unpublished manuscript notes), but the types of both taxa have different enteric valves (fungifaber and finitimus valve patterns, respectively). Cubitermes planifrons therefore becomes valid again.

- Cubitermes zenkeri has been applied as a senior synonym of C. kemneri (Ruelle 1975: 8; Krishna et al. 2013: 1945) but the types of both taxa have different enteric valves (fungifaber and finitimus valve patterns, respectively). Cubitermes kemneri therefore becomes valid again.

Inside the fungifaber valve pattern, the following species may therefore be considered for now as junior synonyms of other species, and therefore invalid: C. antennalis, C. banksi, C. comstocki, and C. schmidti. All of the eight other species of this valve pattern may therefore be considered as valid (Table 6).

Among the species with the finitimus valve pattern, three synonymies have been proposed and are all compatible with their valve patterns:

- Cubitermes bulbifrons has been used as a senior synonym of C. heghi (Ruelle 1975: 7) and later rectified as a junior synonym of $C$. heghi (Ruelle 1992: 500); however, Krishna et al. (2013: 1916), restored C. bulbifrons as a senior synonym of C. heghi.

- Cubitermes finitimus has been considered as a possible senior synonym (a) of C. loubetsiensis and (b) of C. subarquatus (Krishna et al. 2013: 1926 \& 1938, after Emerson's unpublished manuscript notes).

Inside the finitimus valve pattern, the following species may therefore be considered for now as invalid: C. heghi, C. loubetsiensis and C. subarquatus.

On the contrary, as mentioned above, the following species are to be considered as valid because they have been erroneously synonymized with species belonging to the fungifaber valve pattern: $C$. kemneri (not a junior synonym of $C$. zenkeri), as well as $C$. fungifaber var. elongata and C. planifrons (not junior synonyms of $C$. fungifaber). Apart from C. heghi, C. loubetsiensis and C. subarquatus, all of the other nine species of the valve pattern may therefore be considered for now as valid. Concerning the taxon C. fungifaber var. elongata, which is an invalid name, it should not stay within the species $C$. fungifaber and ought to be renamed (Table 6).

Among the species with the sankurensis valve pattern, five synonymies have been proposed and are all compatible with their valve patterns:

- Cubitermes sankurensis has been given as a senior synonym (a) of C. sibitiensis (Snyder 1949: 163; Krishna et al. 2013: 1934), (b) of C. cubicephalus (Williams 1966: 101; Krishna et al. 2013: 1934) and (c) of C. sankurensis var. elongata (Krishna et al. 2013: 1934).

- Cubitermes truncatoides has been used as a senior synonym of C. truncatoides var. sordwana (Ruelle 1975: 8; Krishna et al. 2013: 1941). 
- Cubitermes truncatus has been given as a senior synonym of C. duplex forma nduma (Ruelle 1975: 8; Krishna et al. 2013: 1942). The type material of $C$. duplex forma $n d u m a$ contains only alates; a valve has nevertheless been extracted and it bears an indication of two spatulae, characteristic of the sankurensis valve pattern.

Inside this valve pattern, the following taxa may be considered for now as junior synonyms of another taxon and therefore invalid: C. sibitiensis, C. cubicephalus, C. sankurensis var. elongata, C. truncatoides var. sordwana and $C$. duplex forma nduma. All of the other 12 species may therefore be considered as valid (Table 6).

Among the species with the oculatus valve pattern, no synonymy has been proposed yet.

The two species $C$. oculatus and $C$. niokoloensis may be considered for now as valid. Concerning the third species, C. bilobatodes, Silvestri (1912) described under that name two soldier morphs which actually belong to two different species in a mixed syntype series. The name will be kept for the socalled miles major or major soldier, which has an enteric valve of the bilobatodes valve pattern; as a consequence, the so-called miles minor or minor soldier, with an enteric valve of the oculatus valve pattern, will join the oculatus group (with another name).

Among the species with the oblectatus valve pattern, only one species, C. oblectatus, may be considered as valid for the time being.

Among the species with the sulcifrons valve pattern, two synonymies have been proposed, and both are compatible with their valve patterns:

- Cubitermes inclitus, initially described as C. bilobatus inclitus, was recognized as a species by Sjöstedt (1926: 236) and has been used as a senior synonym of $C$. domifaber (Williams 1966: 86; Krishna et al. 2013: 1925).

- Cubitermes intercalatus is considered as a possible senior synonym of C. hamatus (Krishna et al. 2013: 1924, according to Emerson's unpublished manuscript notes).

In the sulcifrons valve pattern, the following species may be considered for now as a junior synonym for another species and therefore invalid: C. domifaber and C. hamatus. All of the six other species may therefore be considered for now as valid (Table 6).

\section{Key to valve pattern groups: imagines}

The imagines of the genus Cubitermes can be recognized by the presence of two marginal teeth on the right mandible and the presence of three marginal teeth on the left mandible, the second one only suggested by an undulation of the edge between the first and third marginal teeth, and by the fore, mid and hind tibiae bearing 3,2, 2 apical spurs and 0,2,0 subapical spurs, respectively (but the latter sometimes weakly developed). The gut generally contains a little soil and the weakly developed enteric valve bears six tiny primary cushions.

The identification of Cubitermes imagines as belonging to a valve pattern group is not always possible without observing associated workers or soldiers from the same sample. As an aid to identification, Fig. 23 gives a comparison of the ranges of variation of the most discriminatory measures and indices.

1. Fontanelle in a rather deep, large, conspicuous depression, at least $10 \%$ of IHdW; large species: $1.23 \mathrm{~mm} \leq \mathrm{IHdL} \leq 1.54 \mathrm{~mm}, 1.58 \mathrm{~mm} \leq \mathrm{IHdW} \leq 1.87 \mathrm{~mm}$..............sulcifrons valve pattern

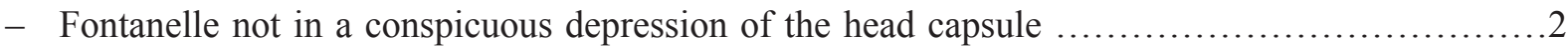

2. Large species: $1.38 \mathrm{~mm} \leq \mathrm{IHdL} \leq 1.58 \mathrm{~mm} ; 1.75 \mathrm{~mm} \leq \mathrm{IHdW} \leq 1.91 \mathrm{~mm}$...oblectatus valve pattern

- Smaller species: $0.82 \mathrm{~mm} \leq \mathrm{IHdL} \leq 1.39 \mathrm{~mm} ; 1.10 \mathrm{~mm} \leq \mathrm{IHdW} \leq 1.82 \mathrm{~mm} \ldots \ldots \ldots . .3$ 
3. Compound eye bulging weakly: $0.08 \mathrm{~mm} \leq \mathrm{IEyW} \leq 0.14 \mathrm{~mm}$; compound eye prominence index

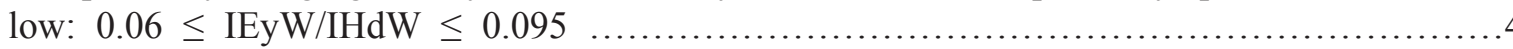

- Compound eye bulging strongly: $0.14 \mathrm{~mm} \leq \mathrm{IEyW} \leq 0.23 \mathrm{~mm}$; compound eye prominence

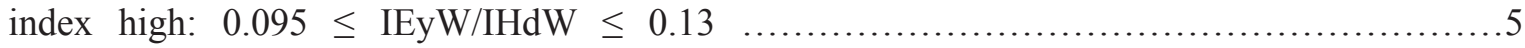

4. Smaller eyes: $0.23 \mathrm{~mm} \leq \mathrm{IEy} D \leq 0.33 \mathrm{~mm}$ and shorter mandibles: $0.44 \mathrm{~mm} \leq \mathrm{IMlL} \leq 0.58 \mathrm{~mm}$ bilobatus valve pattern + bilobatodes valve pattern (part) + muneris valve pattern (part) + sankurensis valve pattern (part)

- Larger eyes: $0.37 \mathrm{~mm} \leq \operatorname{IEy} D \leq 0.56 \mathrm{~mm}$ and longer mandibles: $0.60 \mathrm{~mm} \leq \mathrm{IMIL} \leq 0.72 \mathrm{~mm}$ fungifaber valve pattern (part) + bilobatodes valve pattern (part) + muneris valve pattern (part) + sankurensis valve pattern (part)

5. Eye to ocellus minimal distance index low: $0.24 \leq \mathrm{IEyOcD} / \mathrm{IOc} D \leq 0.35$; left apico-marginal index small: $0.91 \leq \mathrm{IMlAmD} / \mathrm{IMlmmD} \leq 1.01$; small species: $0.97 \leq \mathrm{IHdL} \leq 1.05,1.30 \leq \mathrm{IHdW}$ $\leq 1.48$; from West African savannahs oculatus valve pattern

- Eye to ocellus minimal distance index generally higher: $0.21 \leq \mathrm{IEyOcD/IOc} D \leq 1.37$; left apico-marginal index generally higher: $0.93 \leq \mathrm{IMlAmD} / \mathrm{IMlmmD} \leq 1.87$; generally larger species: $0.82 \leq \mathrm{IHdL} \leq 1.39,1.14 \leq \mathrm{IHdW} \leq 1.82$

finitimus valve pattern + fungifaber valve pattern (part) + sankurensis valve pattern (part)
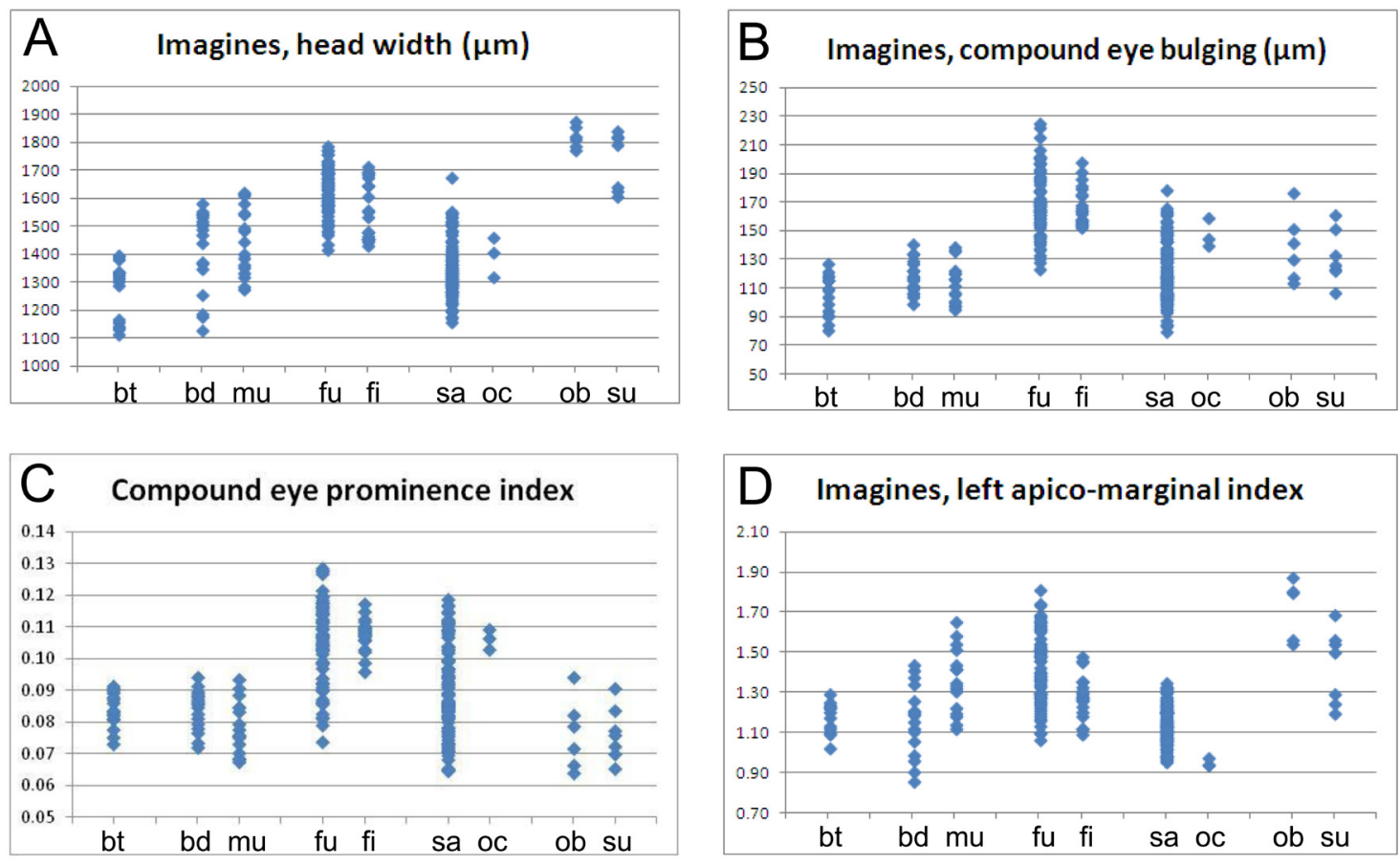

Fig. 23. Comparison of the most discriminating variables and indices between the imagines of the various valve patterns: $\mathrm{bt}=$ bilobatus, $\mathrm{bd}=$ bilobatodes, $\mathrm{mu}=$ muneris, $\mathrm{fu}=$ fungifaber, $\mathrm{fi}=$ finitimus, $\mathrm{sa}=$ sankurensis, $\mathrm{oc}=$ oculatus, $\mathrm{ob}=$ oblectatus and $\mathrm{su}=$ sulcifrons. All the individuals studied are plotted in these graphs. A. The head width across the eyes shows a pattern with relatively low values and four patterns with high values but with high superimpositions. B. The imagines' compound eye bulging shows three patterns with low values in comparison with the other patterns but here also with some superimpositions. C. The imagines' compound eye prominence index shows five patterns with low values, two patterns with high values and two patterns crossing almost the entire range. D. The left apico-marginal index shows one pattern with low values and one pattern with high values. 


\section{Key to valve pattern groups: soldiers}

The soldiers of the genus Cubitermes can be recognized by the presence of a diverticulum on the second paunch, by the presence of soil in their gut (dark abdomen), by the rectangular shape of the head capsule, bearing a dense bunch of bristles around and above the fontanelle, by the bifurcate shape of the labrum, by the fore, mid and hind tibiae bearing 3,2,2 apical spurs and 0,2,0 subapical spurs, respectively, and by their reaping mandibles from almost straight to evenly curved or even more or less hooked, each one bearing a small marginal tooth near the molar tooth. As an aid to identification, Fig. 24 gives a comparison of the ranges of variation of the most discriminatory measures and indices.

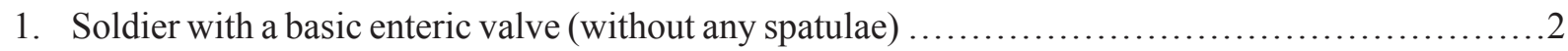

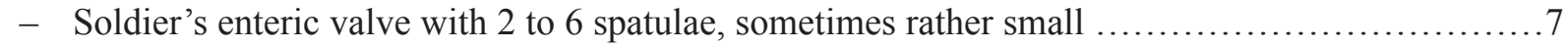

2. Soldier's valve: secondary cushions not wider than the primary cushions; PC1-bilaterality index high: $1.33 \leq \mathrm{SVP} 1-\mathrm{Bil} \leq 1.88$; PC1 often substantially widened between the first quarter and the middle; small species: $1.57 \mathrm{~mm} \leq \mathrm{SHdL} \leq 2.05 \mathrm{~mm}$ with short heads: $1.09 \leq \mathrm{SHdL} / \mathrm{SHdW}$ $\leq 1.28$; from West African savannahs

oculatus valve pattern

- Soldier's valve: secondary cushions clearly wider than the primary cushions; PC1-bilaterality index generally lower: $0.80 \leq \mathrm{SVP} 1$-Bil $\leq 1.40$ with some higher outlying values; PC1 not widened between the first quarter and the middle; species of various sizes: $1.40 \mathrm{~mm} \leq \mathrm{SHdL} \leq 3.83 \mathrm{~mm} \ldots 3$
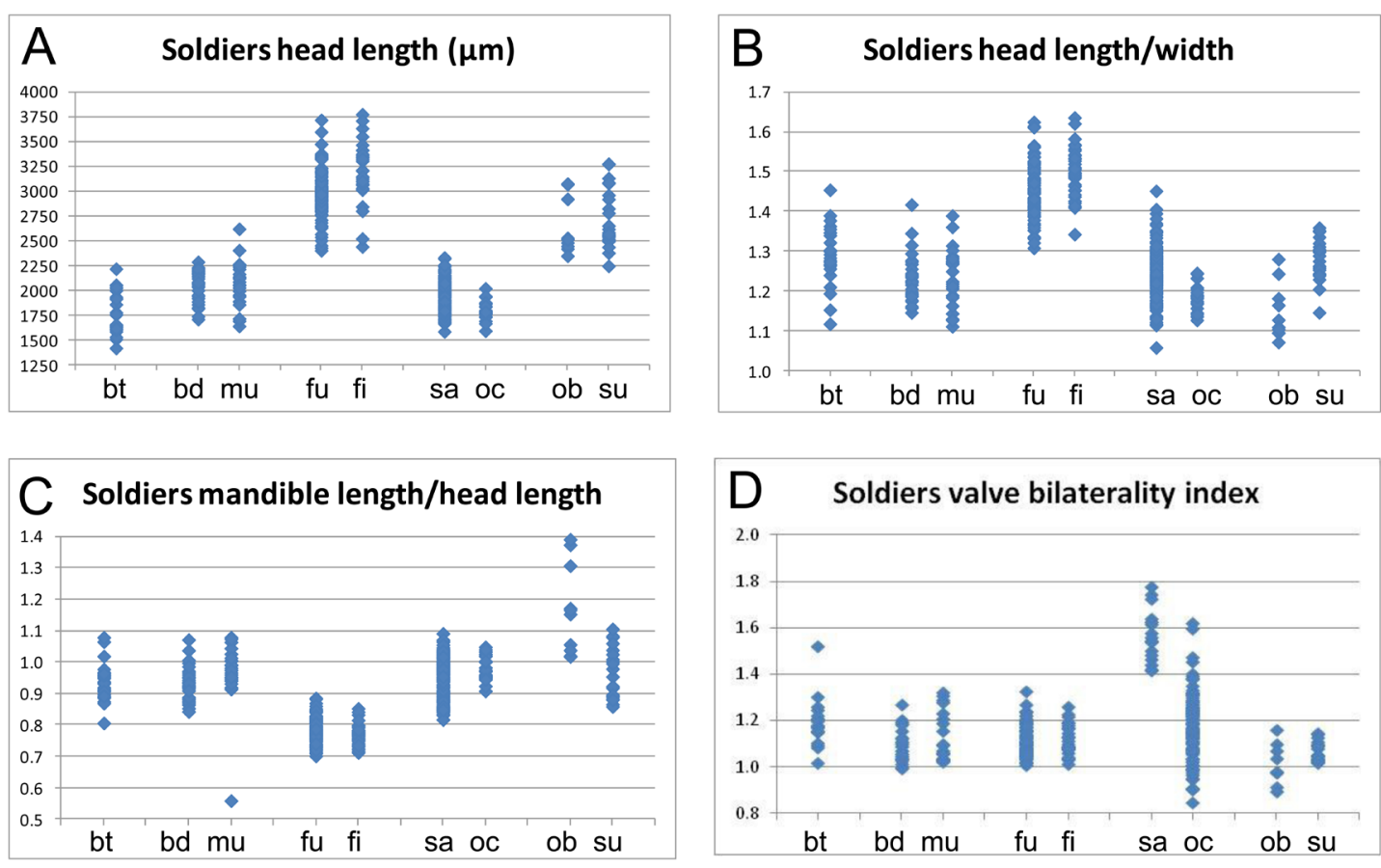

Fig. 24. Comparison of the most discriminating variables and indices between the soldiers of the various valve patterns: $\mathrm{bt}=$ bilobatus, $\mathrm{bd}=$ bilobatodes, $\mathrm{mu}=$ muneris, $\mathrm{fu}=$ fungifaber, $\mathrm{fi}=$ finitimus, $\mathrm{sa}=$ sankurensis, $\mathrm{oc}=$ oculatus, $\mathrm{ob}=$ oblectatus and $\mathrm{su}=$ sulcifrons. All the individuals studied are plotted in these graphs. A. The soldiers head length distinguishes a group (four patterns) of larger species from a group (five patterns) of smaller species. B. The soldier's cephalic elongation index shows two patterns with elongated heads. C. The soldier's gnatho-cephalic index shows two patterns with relatively short mandibles and one with long mandibles (the outlier point in the muneris pattern is due to C. falcifer). D. The soldier's valve bilaterality index distinguishes the oculatus valve pattern from almost all the other patterns. 
3. Small species: $1.40 \mathrm{~mm} \leq \mathrm{SHdL} \leq 2.20$; soldier's valve with the PCs barely or not at all outlined; PCs with very few (0-6), short lateral supporting bristles bilobatus valve pattern

- Small to large species: $1.56 \mathrm{~mm} \leq \mathrm{SHdL} \leq 3.83$; soldier's valve bearing well outlined PCs with more than 6 supporting bristles on each side

4. Lobes of the labrum elongated, finger-like; head weakly elongate: $1.08 \leq \mathrm{SHdL} / \mathrm{SHdW} \leq 1.46$; mandibles from a little shorter to a little longer than head length: $0.84 \leq \mathrm{SMIL} / \mathrm{SHdL} \leq 1.11$, but one species with very short hooked mandibles: $\mathrm{SMIL} / \mathrm{SHdL} \approx 0.55$; small to medium-sized species: $1.62 \mathrm{~mm} \leq \mathrm{SHdL} \leq 2.66 \mathrm{~mm}$

- Lobes of the labrum either triangular or lyre-shaped; head more elongate: $1.27 \leq \mathrm{SHdL} / \mathrm{SHdW}$ $\leq 1.68$; mandibles always shorter than head length: $0.68 \leq \mathrm{SMlL} / \mathrm{SHdL} \leq 0.91$; medium-sized to large species: $2.37 \mathrm{~mm} \leq \mathrm{SHdL} \leq 3.83 \mathrm{~mm}$

5. Soldier's valve: all PCs fusiform, their largest width located near the middle and their lateral margins converge gradually upstream and downstream; SCs wide and sometimes tend to have the shape of spearheads; smaller species: $1.15 \leq \mathrm{SHdW} \leq 1.58$

bilobatodes valve pattern

- Soldier's valve: odd PCs elongated and roughly rectangular: the lateral margins almost parallel; SCs wide with homogeneous scattering of the spines; larger species: $1.30 \leq$ SHdW $\leq 1.87$

muneris valve pattern

6. Soldier's valve: odd PCs generally without crests on their downstream end or with weakly developed crests bearing some long bristles; $1.58 \leq \mathrm{SHdW} \leq 2.43 \ldots$.... fungifaber valve pattern

- Soldier's valve: odd PCs with low bulges on their downstream end, weakly developed, but bearing a high density of short bristles; $1.76 \leq \mathrm{SHdW} \leq 2.49$

finitimus valve pattern

7. Soldier's valve with 6 spatulae, secondary cushions somewhat wider than the primary cushions; medium-sized to large species: $2.21 \mathrm{~mm} \leq \mathrm{SHdL} \leq 3.32 \mathrm{~mm}$ sulcifrons valve pattern

- Soldier's valve with 2 or 3 spatulae .8

8. Soldier's valve with 2 spatulae, secondary cushions not wider than the primary cushions; PC1 sometimes substantially widened between the first quarter and the middle; small to medium-sized species: $1.56 \mathrm{~mm} \leq \mathrm{SHdL} \leq 2.37 \mathrm{~mm}$ sankurensis valve pattern

- Soldier's valve with 3 spatulae, secondary cushions wider than the primary cushions; mediumsized to large species: $2.31 \mathrm{~mm} \leq \mathrm{SHdL} \leq 3.12 \mathrm{~mm}$ oblectatus valve pattern

\section{Key to valve pattern groups: workers}

The workers of the genus Cubitermes can be recognised by the presence of a caecum-like diverticulum on the hind paunch, by the presence of soil in their gut (dark abdomen), by the presence of two marginal teeth on the right mandible and three marginal teeth on the left mandible, with the second one suggested only by an undulation of the edge between the first and third marginal teeth, and by the fore, mid and hind tibiae bearing 3,2,2 apical spurs and 0,2,0 subapical spurs, respectively. As an aid to identification, Fig. 25 gives a comparison of the ranges of variation of the most discriminatory measures and indices.

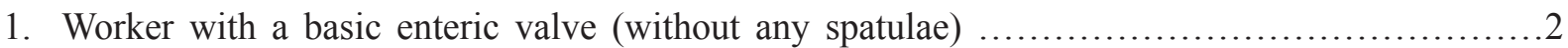

- Worker's enteric valve with 2 to 6 spatulae that stick out of the valve ........................ 7

2. Worker's valve: secondary cushions not wider than the primary cushions; small species $(0.93 \mathrm{~mm} \leq$ WHdW $\leq 1.17 \mathrm{~mm} ; 0.93 \mathrm{~mm} \leq$ WT3L $\leq 1.16 \mathrm{~mm})$ from West African savannahs oculatus valve pattern

- Worker's valve: secondary cushions clearly wider than the primary cushions; species of various sizes: $0.84 \mathrm{~mm} \leq \mathrm{WHdW} \leq 1.44 \mathrm{~mm} ; 0.84 \mathrm{~mm} \leq \mathrm{WT} 3 \mathrm{~L} \leq 1.55 \mathrm{~mm}$ .3 
3. Worker's valve without any crests or bulges on the odd PCs; smaller species: $0.84 \mathrm{~mm} \leq$ WHdW

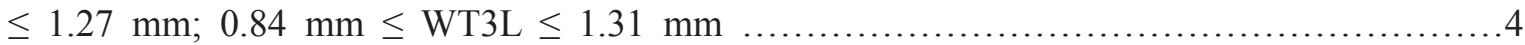

- Worker's valves with crests or bulges near the downstream end of the odd PCs; larger species: $0.94 \mathrm{~mm} \leq \mathrm{WHdW} \leq 1.44 \mathrm{~mm} ; 1.06 \mathrm{~mm} \leq \mathrm{WT} 3 \mathrm{~L} \leq 1.55 \mathrm{~mm} \ldots \ldots \ldots \ldots \ldots \ldots \ldots \ldots \ldots .6$

4. $\mathrm{PC} 1$ of the worker's valve bearing no more than 3-6 supporting bristles on each side; alternation index generally low: $0.94 \leq \mathrm{WVP}-\mathrm{Alt} \leq 1.43$; small species: $0.84 \leq \mathrm{WHdW} \leq 1.14 ; 0.84 \mathrm{~mm} \leq$ $\mathrm{WT} 3 \mathrm{~L} \leq 1.12 \mathrm{~mm}$ bilobatus valve pattern

- PC1 of the worker's valve bearing 10-30 supporting bristles on each side .5

5. Odd PCs of the worker's valve fusiform, their largest width located near the middle and their lateral margins converging gradually upstream and downstream; alternation index high: 1.13 $\leq$ WVP-Alt $\leq 1.47$; small to medium-sized species: $0.8 \mathrm{~mm} \leq$ WHdW $\leq 1.21 \mathrm{~mm} ; 0.93 \mathrm{~mm} \leq$ $\mathrm{WT} 3 \mathrm{~L} \leq 1.30 \mathrm{~mm}$ bilobatodes valve pattern

- Odd PCs of the worker's valve elongate and roughly rectangular, their lateral margins almost parallel; alternation index even higher: $1.24 \leq$ WVP-Alt $\leq 1.63$; small to medium-sized species: $0.91 \mathrm{~mm} \leq \mathrm{WHdW} \leq 1.27 \mathrm{~mm} ; 0.95 \mathrm{~mm} \leq \mathrm{WT} 3 \mathrm{~L} \leq 1.27 \mathrm{~mm}$ muneris valve pattern
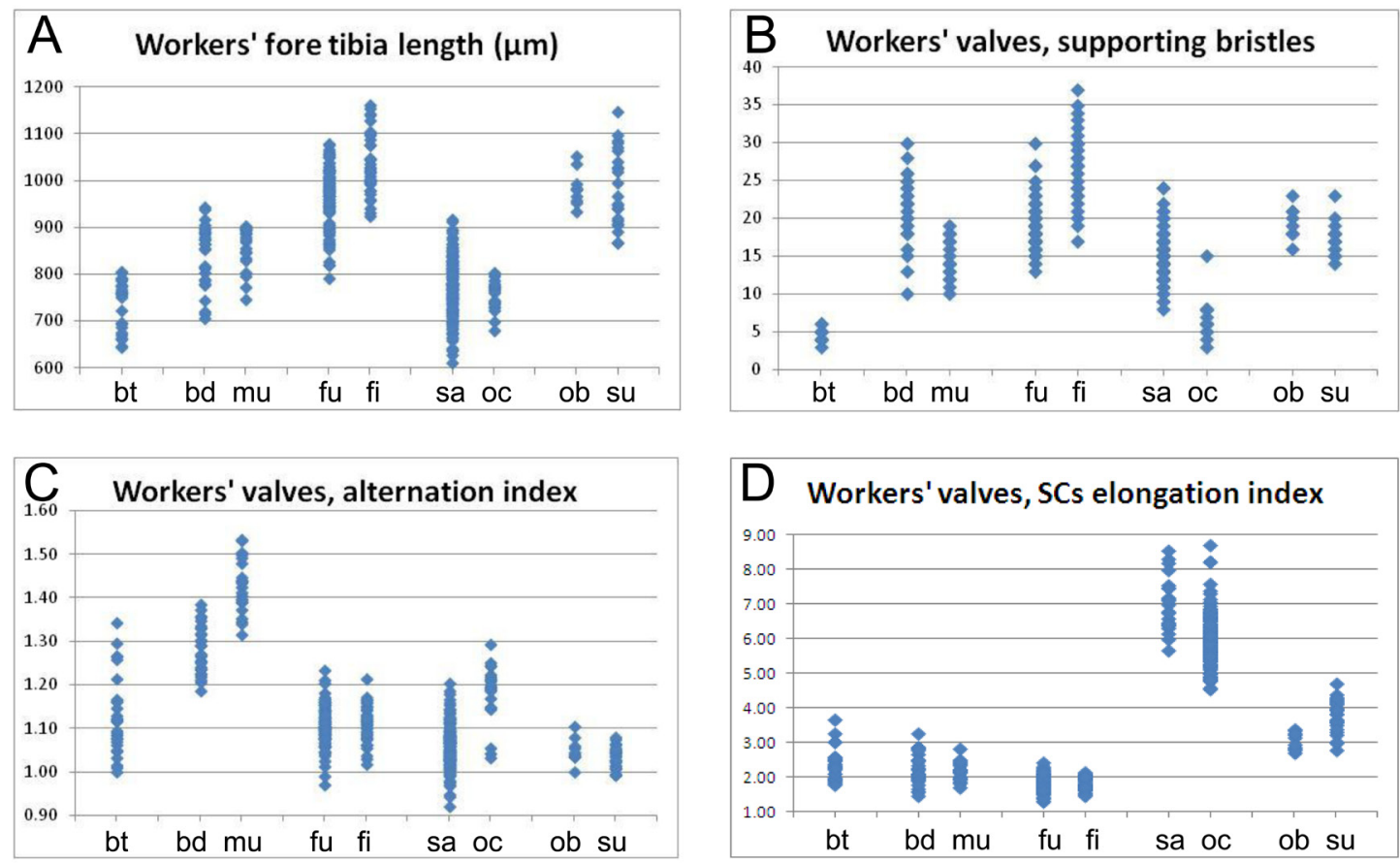

Fig. 25. Comparison of the most discriminating variables and indices between the workers of the various valve patterns: $\mathrm{bt}=$ bilobatus, $\mathrm{bd}=$ bilobatodes, $\mathrm{mu}=$ muneris, $\mathrm{fu}=$ fungifaber, $\mathrm{fi}=$ finitimus, $\mathrm{sa}=$ sankurensis, $\mathrm{oc}=$ oculatus, $\mathrm{ob}=$ oblectatus and $\mathrm{su}=$ sulcifrons. All the individuals studied are plotted in these graphs. A. The length of the fore tibia is used as representative of most length measurements: it distinguishes small, medium-sized and large species. B. The number of lateral supporting bristles on one side of $\mathrm{PC} 1$ distinguishes two patterns with very few bristles (the outlier point in the oculatus valve pattern is due to an undetermined worker). C. The workers' valve alternation index shows two patterns with high values. D. The workers' valve SC elongation index distinguishes the oculatus and sankurensis valve patterns from the others. 
6. Odd PCs of the worker's valve bearing crests at least as high as they are wide, with long bristles; medium-sized to large species: $0.94 \mathrm{~mm} \leq \mathrm{WHdW} \leq 1.44 \mathrm{~mm}, 1.06 \mathrm{~mm} \leq \mathrm{WT} 3 \mathrm{~L} \leq 1.51 \mathrm{~mm}$

fungifaber valve pattern

- Odd PCs of the worker's valve bearing bulges wider than they are high, with a high density of short bristles; medium-sized to large species: $1.06 \leq$ WHdW $\leq 1.37 \mathrm{~mm} ; 1.20 \mathrm{~mm} \leq$ WT3L $\leq 1.55$ $\mathrm{mm}$

finitimus valve pattern

7. Worker's valve with 6 spatulae, secondary cushions somewhat wider than the primary cushions and either fusiform or spearhead-shaped; medium-sized to large species: $1.10 \mathrm{~mm} \leq \mathrm{WHdW} \leq$ $1.45 \mathrm{~mm}$ sulcifrons valve pattern

- Worker's valve with 2 or 3 spatulae ................................................... 8

8. Worker's valve with 2 jaw-like spatulae, secondary cushions almost as wide as the primary cushions; small to medium-sized species: $0.85 \mathrm{~mm} \leq$ WHdW $\leq 1.29 \mathrm{~mm} ; 0.86 \mathrm{~mm} \leq$ WT3L $\leq$ $1.29 \mathrm{~mm}$ sankurensis valve pattern

- Worker's valve with 3 spatulae, secondary cushions either wider than the primary cushions, more or less outlined and fusiform, or as wide as the PCs and suggesting spearheads; large species: $1.25 \mathrm{~mm} \leq \mathrm{WHdW} \leq 1.55 \mathrm{~mm} ; 1.21 \mathrm{~mm} \leq \mathrm{WT} 3 \mathrm{~L} \leq 1.48 \mathrm{~mm}$ oblectatus valve pattern

\section{Acknowledgements}

We would like to thank the museums that lent the material used in this work: the American Museum of Natural History, New York, the United States; the Royal Museum for Central Africa, Tervuren, Belgium; the Instituto di Entomologia Agraria, Portici (Napoli), Italy; the Museo Civico di Storia Naturale "Giacomo Doria", Genoa, Italy; the Natuurhistorisch Museum of Maastricht, the Netherlands; the Plant Protection Research Institute, Biosystematics Division, Queenswood, Pretoria, South Africa; the Natural History Museum, London, the United Kingdom; the Muséum national d'Histoire naturelle, Paris, France; the Museo Università di Roma "Sapienza", Roma, Italy.

We are most grateful to our colleagues who provided Cubitermes samples from various countries: Dr Pierre Akama (from Cameroon), Dr Tenon Coulibaly (from Côte d'Ivoire and Burkina Faso), Dr Kanvaly Dosso (from Côte d'Ivoire), M Benoît Host (from Burundi), Patrick Kasangij (from DRC, Haut-Katanga province), Dr Carmel Kifukieto (from DRC, Kinshasa province), Dr Laura Estelle Loko (from Benin), Prof. Pierre Meerts (from DRC, Haut-Katanga province), Prof. Basile Mujinya Bazirake (from DRC, Haut-Katanga province), Dr Abdoulaye Baila Ndiaye (from Senegal, Gambia and Burkina Faso), Prof. Yves Roisin (from Cameroon, Côte d'Ivoire, DRC, Tshopo province, and Burundi), Dr Jan Šobotnik (from Cameroon and Kenya), Dr Saran Traoré (from Burkina Faso) and Mrs Geo Trembleau (from Gabon).

We would like to thank Dr Tenon Coulibaly and Dr Kanvaly Dosso for their assistance in collecting material in Côte d'Ivoire and Dr Carmel Kifukieto for his assistance in DRC.

\section{References}

Bignell D.E. 2000. Introduction to symbiosis. In: Abe T., Bignell D.E. \& Higashi M. (eds) Termites: Evolution, Sociality, Symbioses, Ecology, Chapter 9: 189-208. Kluwer Academic Publishers, Dordrecht.

Bouillon A. \& Vincke P.P. 1971. Valvule entérique et révision du genre Cubitermes Wasmann. Cubitermes bugeserae sp. nov. (Isoptera, Termitidae). Revue de Zoologie et de Botanique Africaines 84 (3-4): 269280. 
Chessel D., Dufour A.B. \& Thioulouse J. 2004. The ade4 package-I: One-table methods. $R$ News 4 : $5-10$.

Child H.J. 1934. The internal anatomy of termites and the histology of the digestive tract. In: C.A. Kofoid (ed.) Termites and Termite Control, $2^{\text {nd }}$ ed.: 58-88. University of California Press, Berkeley.

Deligne J. 1966. Caractères adaptatifs au régime alimentaire dans la mandibule des termites (Insectes, Isoptères). Comptes rendus des Séances de l'Académie des Sciences, Paris, D, Sciences naturelles 263: $1323-1325$.

Deligne J. 1999. Functional morphology and evolution of a carpenter's plane-like tool in the mandibles of termite workers (Insecta Isoptera). Belgian Journal of Zoology 129: 201-218.

Deligne J. \& Pasteels J.M. 1969. Morphologie, développement et affinités de Labidotermes celisi gen. nov., sp. n. (Isoptères, Amitermitinae) du Kivu. Revue de Zoologie et de Botanique Africaines 79 (1-2): $145-164$.

Desneux J. 1904. Notes termitologiques. Annales de la Société entomologique de Belgique 48 (3): 146151.

Donovan S.E. 2002. A morphological study of the enteric valves of the Afrotropical Apicotermitinae (Isoptera: Termitidae). Journal of Natural History 36: 1823-1840.

https://doi.org/10.1080/00222930110062309

Donovan S.E., Eggleton P., Dubbin W.E., Batchelder M. \& Dibog L. 2001. The effect of a soilfeeding termite, Cubitermes fungifaber (Isoptera: Termitidae) on soil properties: termites may be an important source of soil microhabitat heterogeneity in tropical forests. Pedobiologia 45: 1-11. https://doi.org/10.1078/0031-4056-00063

Emerson A.E. 1928. Termites of the Belgian Congo and the Cameroon. Bulletin of the American Museum of Natural History 57 (7): 401-574.

Emerson A.E. 1933. A revision of the genera of fossil and recent Termopsinae (Isoptera). University of California Publications in Entomology 6 (6): 165-195.

Emerson A.E. 1960. Six new genera of Termitinae from the Belgian Congo (Isoptera, Termitidae). American Museum Novitates 1988: 1-49.

Engel M.S. \& Krishna K. 2004. Family-group names for termites (Isoptera). American Museum Novitates 3432: 1-9.

Engel M.S., Grimaldi D.A. \& Krishna K. 2009. Termites (Isoptera): their phylogeny, classification and rise to ecological dominance. American Museum Novitates 3650: 1-27.

Fuller C. 1923. Two new termites from Uganda. Annals and Magazine of Natural History (9) 11: 191192.

Fuller C. 1925. The termites of South Africa. South African Journal of Natural History 5: 167-246.

Ghidini G.M. 1937. Missione del Prof. Edoardo Zavattari nel paese del Borana. Nuove specie di termitidi (diagnosi preventive). Bollettino della Società Entomologica Italiana 69 (9-10): 141-143.

Grassé P.-P. \& Noirot C. 1955. Apicotermes arquieri (Isoptère): ses constructions, sa biologie. Considérations générales sur la sous-famille des Apicotermitinae nov. Annales des Sciences naturelles, Zoologie (11) 16: 345-388.

Harris W.V. 1958. Isoptera. In: De Witte G.F. (ed.) Exploration du Parc National de l'Upemba, I. Mission G.F. De Witte 52: 3-26. Institut des Parcs nationaux du Congo belge, Bruxelles. 
Haviland G.D. 1898. Observations on termites with descriptions of new species. Journal of the Linnean Society of London 26 (169): 358-442.

Holmgren N. 1909. Termitenstudien. I. Anatomische Untersuchungen. Kungliga Svenska Vetenskapsakademiens Handlingar 44 (3): 1-215.

Holmgren N. 1910. Das System der Termiten. Zoologischer Anzeiger 35 (9-10): 284-286.

Holmgren N. 1912. Termitenstudien. 3. Systematik der Termiten. Die Familie Metatermitidae. Kungliga Svenska Vetenskapsakademiens Handlingar 48 (4): 1-166.

Holmgren N. 1913. Termiten aus Natal und dem Zululande. Gesammelt von Dr Ivar Trägårdh. Entomologisk Tidskrift 34: 321-366.

Imms A.D. 1919. On the structure and biology of Archotermopsis, together with descriptions of new species of intestinal Protozoa and general observations on the Isoptera. Philosophical Transactions of the Royal Society of London B 209: 75-180.

Johnson R.A. 1979. Configuration of the digestive tube as an aid to identification of worker Termitidae (Isoptera). Systematic Entomology 4: 31-38. https://doi.org/10.1111/j.1365-3113.1979.tb00609.x

Krishna K., Grimaldi D.A., Krishna V. \& Engel M.S. 2013. Treatise of the Isoptera of the world. Bulletin of the American Museum of Natural History 377: 1-2704.

Mathot G. 1964. Description d'une nouvelle espèce de Cubitermes du Congo (Isoptera, Termitinae). Cubitermes exiguus n. sp. In: Bouillon, A. (ed.) Etudes sur les termites africains, Un Colloque international, Université Lovanium: 15-21. Edition de l'Université Léopoldville [Kinshasa].

Noirot C. 2001. The gut of termites (Isoptera) comparative anatomy, systematics, phylogeny. II.-Higher termites (Termitidae). Annales de la Société Entomologique de France (N.S.) 37 (4): 431-471.

Noirot C. \& Kovoor J. 1958. Anatomie comparée du tube digestif des termites. 1 Sous-famille des "Termitinae". Insectes sociaux 5: 439-471.

Okwakol M.J.N. 1987. Effects of Cubitermes testaceus (Williams) on some physical and chemical properties of soil in a grassland area of Uganda. African Journal of Ecology 25 (3): 147-153. https://doi.org/10.1111/j.1365-2028.1987.tb01101.x

Roy V., Demanche C., Livet A. \& Harry M. 2006. Genetic differentiation in the soil-feeding termite Cubitermes sp. affinis subarquatus: occurrence of cryptic species revealed by nuclear and mitochondrial markers. BMC Evolutionary Biology 6: 102. https://doi.org/10.1186/1471-2148-6-102

Roy-Noël J. 1969. Isoptera. In: Le Parc national du Niokolo-Koba (Sénégal). Mémoires de l'Institut fondamental d'Afrique noire 84: 113-178.

Ruelle J.E. 1975. Type specimens of Isoptera in the national collection of insects, Pretoria. Entomology memoir, Department of Agricultural and Technical Services (South Africa) 45: 1-22.

Ruelle, J.E. 1992. The genus Cubitermes Wasmann (Isoptera: Termitidae: Termitinae): a review of its taxonomy, nomenclature and distribution in Africa. Journal of African Zoology 106: 499-502.

Sands W.A. 1972. The soldierless termites of Africa (Isoptera, Termitidae). Bulletin of the British Museum (Natural History) Entomology, Supplement 18: 1-244.

Sands W.A. 1992. The termite genus Amitermes in Africa and the Middle East. Natural Resources Institute Bulletin 51: 1-140.

Sands W.A. 1998. The Identification of Worker Castes of Termite Genera from Soils of Africa and the Middle East. CAB International, Wallingford in association with Natural Resources International. 
Schmitz H. 1915. Ein neuer Cubitermes vom Belgischen Kongo, Tijdschrift voor Entomologie (suppl.) 58 [1915]: 119-124.

Silvestri F.1912. Termiti raccolte da L. Fea alla Guinea Portoghesa e alla isole S. Thomè, Annobon, Principe e Fernando Poo. Annali del Museo Civico di Storia Naturale (Ser 3) 5: 211-255.

Silvestri F. 1914. Contribuzione alla conoscenza dei Termitidi e Termitofili dell'Africa occidentale. I. Termitidi. Bollettino del Laboratorio di Zoologia Generale e Agraria della Reale Scuola Superiore d'Agricoltura, Portici 9: 1-146.

Sjöstedt Y. 1896. Termiten aus Kamerun. Entomologisk Tidskrift 17 (4): 297-298.

Sjöstedt Y. 1911a. Neue afrikanische Termiten im schwedischen Reichsmuseum. Arkiv för Zoologi 7 (20): $1-18$.

Sjöstedt Y. 1911b. Neue Ost- und Westafrikanische Termiten. Entomologisk Tidskrift 32 (3-4): 173-188.

Sjöstedt Y. 1913. Über Termiten aus dem inneren Kongo, Rhodesia und Deutsch-Ostafrica. Revue de Zoologique Africaine 2 (3): 354-391.

Sjöstedt Y. 1914. Termiten aus Zambesi, Rhodesia, Nyassa und Süd-Nigeria, Arkiv för Zoologi 8 (28): $1-9$.

Sjöstedt Y. 1924a. Neue Arten und Gattungen Afrikanischer Termiten (Vorläufige Mitteilung). Revue de Zoologique Africaine 12 (2): 253-257.

Sjöstedt Y. 1924b. Neue Afrikanische Termiten. Revue de Zoologique Africaine 12 (4): 490-497.

Sjöstedt Y. 1925. Neue Termiten aus Afrika und Madagaskar. Konowia 4 (1-2): 53-55.

Sjöstedt Y. 1926. Revision der Termiten Afrikas. 3. Monographie. Kungliga Svenska Vetenskapsakademiens Handlingar (Ser. 3) 3 (1): 1-419.

Sjöstedt Y. 1927. Eine neue Termite aus Katanga, Belgischen Kongo. Entomologisk Tidskrift 48 (3): 169.

Smeathman H. 1781. Some accounts of the termites which are found in Africa and other hot climates. Philosophical Transactions of the Royal Society of London 71 (1): 139-192. https://doi.org/10.1098/rstl.1781.0033

Snyder T.E. 1949. Catalog of the termites (Isoptera) of the world. Smithsonian Miscellaneous Collections 112: $1-490$.

Uys V.M. 1994. A systematic revision of the genus Lepidotermes Sjöstedt (Isoptera: Termitidae). Entomology Memoir, Department of Agriculture and Technical Services, Republic of South Africa 90: $1-53$.

Uys V.M. 2002. A Guide to the Termite Genera of Southern Africa. Plant Protection Research Institute Handbook $n^{\circ} 15$. Agricultural Research Council, Pretoria.

von Rosen K. 1912. Neue Termiten aus der zoologischen Staatssammlung in München sowie einigen andere Sammlungen. Zoologische Anzeiger 39 (5-6): 221-232.

Wango S.P. \& Josens G. 2011. Comparison of nest shapes and densities of two sympatric species of Cubitermes (Isoptera: Termitidae: Termitinae) as clues for the study of their population dynamics. African Zoology 46 (1): 156-168. https://doi.org/10.3377/004.046.0106

Wasmann E. 1906. Beispiele rezenter Artenbildung bei Ameisengästen und Termitengästen. Biologisches Centralblatt 26 (17-18): 565-580.

Wasmann E. 1911. Zur Kenntnis der Termiten und Termitengäste vom Belgischen Congo. Revue de Zoologique Africaine 1 (1-2): 91-117 \& 145-176. 
Weidner H. 1956. Beiträge zur Kenntnis der Termiten Angolas, hauptsächlich auf Grund der Sammlungen und Beobachtungen von A. de Barros Machado (I. Beitrag). Publicações Culturais da Companhia de Diamantes de Angola 29: 55-106.

Williams R.M.C. 1954. New East African Termitinae (Isoptera: Termitidae). Proceedings of the Royal Entomological Society of London B 23 (11-12): 215-227.

Williams R.M.C. 1966. The East African termites of the genus Cubitermes (Isoptera: Termitidae). Transactions of the Royal Entomological Society of London 118 (4): 73-118. https://doi.org/10.1111/j.1365-2311.1966.tb00835.x

Wood T.G., Johnson R.A. \& Anderson J.M. 1983. Modification of soils in Nigerian savanna by soil-feeding Cubitermes (Isoptera, Termitidae). Soil Biology and Biochemistry 15 (5) 575-579. https://doi.org/10.1016/0038-0717(83)90052-4

Manuscript received: 25 December 2017

Manuscript accepted: 23 October 2018

Published on: 11 April 2019

Topic editor: Gavin Broad

Desk editor: Jeroen Venderickx

Printed versions of all papers are also deposited in the libraries of the institutes that are members of the EJT consortium: Muséum national d'Histoire naturelle, Paris, France; Meise Botanic Garden, Belgium; Royal Museum for Central Africa, Tervuren, Belgium; Royal Belgian Institute of Natural Sciences, Brussels, Belgium; Natural History Museum of Denmark, Copenhagen, Denmark; Naturalis Biodiversity Center, Leiden, the Netherlands; Museo Nacional de Ciencias Naturales-CSIC, Madrid, Spain; Real Jardín Botánico de Madrid CSIC, Spain; Zoological Research Museum Alexander Koenig, Bonn, Germany. 